\title{
Microbial iron(III) reduction during palsa collapse promotes greenhouse gas emissions before complete permafrost thaw
}

\section{Monique Patzner}

University of Tübingen https://orcid.org/0000-0002-0777-3749

Merritt Logan

Colorado State University https://orcid.org/0000-0002-7040-0750

Amy McKenna

National High Magnetic Field Laboratory, Florida State University

Robert Young

Colorado State University https://orcid.org/0000-0001-7485-0604

Zhe Zhou

Alfred-Wegener-Institute https://orcid.org/0000-0001-7732-9582

Hanna Joss

University of Tuebingen

Carsten Mueller

University of Copenhagen https://orcid.org/0000-0003-4119-0544

Carmen Hoschen

TU München https://orcid.org/0000-0001-5774-2062

Thomas Scholten

University of Tuebingen https://orcid.org/0000-0002-4875-2602

Daniel Straub

Tübingen University https://orcid.org/0000-0002-2553-0660

Sara Kleindienst

University of Tübingen https://orcid.org/0000-0001-8304-9149

Thomas Borch

Colorado State University https://orcid.org/0000-0002-4251-1613

Andreas Kappler

University of Tübingen https://orcid.org/0000-0002-3558-9500

Casey Bryce ( $\nabla$ casey.bryce@bristol.ac.uk)

University of Bristol 
Keywords: Soil organic carbon, iron, bioavailability, permafrost collapse, FT-ICR-MS, microbial Fe(III) reduction and $\mathrm{Fe}(\mathrm{II})$ oxidation, methane and carbon dioxide emissions, Abisko, Arctic, peatland

Posted Date: August 10th, 2021

DOI: https://doi.org/10.21203/rs.3.rs-691992/v1

License: (c) (1) This work is licensed under a Creative Commons Attribution 4.0 International License. Read Full License

Version of Record: A version of this preprint was published at Communications Earth \&amp; Environment on April 1st, 2022. See the published version at https://doi.org/10.1038/s43247-022-00407-8. 


\title{
Microbial iron(III) reduction during palsa collapse promotes greenhouse
}

\author{
gas emissions before complete permafrost thaw
}

Monique S. Patzner ${ }^{1}$, Merritt Logan², Amy M. McKenna ${ }^{3}$, Robert B. Young ${ }^{2,4}$, Zhe

Zhou $^{1,5}$, Hanna Joss ${ }^{1}$, Carsten W. Mueller ${ }^{6,7}$, Carmen Hoeschen ${ }^{6}$, Thomas Scholten ${ }^{8}$, Daniel Straub ${ }^{9,10}$, Sara Kleindienst ${ }^{9}$, Thomas Borch ${ }^{2}$, Andreas Kappler ${ }^{1,11}$ \& Casey Bryce $^{1,12 *}$

${ }^{1}$ Geomicrobiology, Center for Applied Geosciences, University of Tuebingen, Schnarrenbergstrasse 94-96, 72076 Tuebingen, Germany.

${ }^{2}$ Department of Soil \& Crop Sciences and Department of Chemistry, Colorado State University, 307 University Ave, Fort Collins, CO, 80523-1170 US.

${ }^{3}$ National High Magnetic Field Laboratory, Florida State University, Tallahassee, FL 323104005, US.

${ }^{4}$ Chemical Analysis and Instrumentation Laboratory, New Mexico State University, P.O. Box 30001, MSC 3RES, Las Cruces, NM, 88003, US.

${ }^{5}$ Alfred-Wegener-Institute, Helmholtz Centre for Polar and Marine Research, Am Handelshafen 12, 27570 Bremerhaven, Germany

${ }^{6}$ Chair of Soil Science, TUM School of Life Sciences, Technical University of Munich, EmilRamann Strasse 2, 85354 Freising, Germany.

${ }^{7}$ Department of Geosciences and Natural Resource Management, University of Copenhagen, Øster Voldgade 10, 1350 Copenhagen, Denmark.

${ }^{8}$ Chair of Soil Science and Geomorphology, Rümelinstraße 19-23, 72070 Tübingen, University of Tuebingen, Germany.

${ }^{9}$ Microbial Ecology, Center for Applied Geosciences, University Tuebingen, Schnarrenbergstrasse 94-96, 72076 Tuebingen, Germany. 
${ }^{10}$ Quantitative Biology Center (QBiC), University Tuebingen, Auf der Morgenstelle 10, 72076 Tuebingen, Germany.

${ }^{11}$ Cluster of Excellence: EXC 2124: Controlling Microbes to Fight Infection, Tübingen, Germany.

${ }^{12}$ School of Earth Sciences, University of Bristol, Wills Memorial Building, Queens Road Bristol BS8 1RJ, UK.

*Corresponding Author: Casey Bryce

Email: casey.bryce@bristol.ac.uk

For submission to Nature Geoscience

KEYWORDS: Soil organic carbon, iron, bioavailability, permafrost collapse, FT-ICR-MS, microbial $\mathrm{Fe}(\mathrm{III})$ reduction and $\mathrm{Fe}(\mathrm{II})$ oxidation, methane and carbon dioxide emissions, Abisko, Arctic, peatland 


\section{ABSTRACT:}

2 Reactive iron (Fe) minerals can preserve organic carbon (OC) in soils overlying intact

3 permafrost. With permafrost thaw, reductive dissolution of iron minerals releases Fe and OC

4 into the porewater, potentially increasing the bioavailability of OC for microbial

5 decomposition. However, the stability of this so-called rusty carbon sink, the microbial

6 community driving mineral dissolution, the identity of the iron-associated carbon and the

7 resulting impact on greenhouse gas emissions are unknown. We examined palsa hillslopes,

8 gradients from intact permafrost-supported palsa to semi-wet partially-thawed bog in a

9 permafrost peatland in Abisko (Sweden). Using high-resolution mass spectrometry, we found that Fe-bound OC in intact palsa is comprised of loosely bound more aliphatic and strongly-

11 bound more aromatic species. Iron mineral dissolution by both fermentative and dissimilatory

$12 \mathrm{Fe}(\mathrm{III})$ reduction releases Fe-bound OC along the palsa hillslopes, before complete permafrost

13 thaw. The increasing bioavailability of dissolved OC (DOC) leads to its further decomposition,

14 demonstrated by an increasing nominal oxidation state of carbon (NOSC) and a peak in 15 bioavailable acetate $(61.7 \pm 42.6 \mathrm{mg} \mathrm{C} / \mathrm{L})$ at the collapsing palsa front. The aqueous $\mathrm{Fe}^{2+}$ released

16 is partially re-oxidized by $\mathrm{Fe}(\mathrm{II})$-oxidizing bacteria but cannot prevent the overall loss of the 17 rusty carbon sink with palsa collapse. The increasing relative abundance and activity of Fe(III)-

18 reducers is accompanied by an increasing abundance of methanogens and a peak in methane

$19\left(\mathrm{CH}_{4}\right)$ emissions at the collapsing front. Our data suggest that the loss of the rusty carbon sink 20 directly contributes to carbon dioxide $\left(\mathrm{CO}_{2}\right)$ production by $\mathrm{Fe}(\mathrm{III})$ reduction coupled to OC 21 oxidation and indirectly to $\mathrm{CH}_{4}$ emission by promoting methanogenesis even before complete 22 permafrost thaw. 
INTRODUCTION:

25 Climate change has enormous consequences for permafrost environments, causing rapid 26 changes in soil conditions (such as thermal and moisture regime, and aeration) with direct consequences for organic (OC) destabilization ${ }^{1}$. Permafrost soils store $\sim 60 \%$ of the world's soil OC in $15 \%$ of the global soil area ${ }^{2,3}$. This preserved OC will become increasingly exposed to microbial decomposition and thus can be released from the active layer to the atmosphere as greenhouse gases (GHGs) such as carbon dioxide $\left(\mathrm{CO}_{2}\right)$ and methane $\left(\mathrm{CH}_{4}\right)^{4}$ or discharged by drainage ${ }^{5}$. However, the magnitude of the release of this OC depends strongly on a large variety of factors ${ }^{6}$, including the hydrology, soil parent material, organic matter content and the ability of soil minerals to protect $\mathrm{OC}$ from degradation, which can regulate long-term preservation of $34 \mathrm{OC}^{7}$.

Iron $(\mathrm{Fe})$ minerals are known to stabilize organic carbon by sorption/co-precipitation and protect it from degradation by generating OC-Fe associations that are more persistent in soils 8,9 , ${ }^{10-13}$. However, by providing a terminal electron acceptor for anaerobic respiration ${ }^{14,15}$, Fe can also enhance decomposition. The fate of $\mathrm{Fe}$ and associated $\mathrm{OC}$ determines Fe-OC aggregate formation and ultimately accessibility for microbial decomposition ${ }^{15,}$ 16,17. Reactive Fe-OC associations (defined as the solid Fe phases that are reductively dissolved by sodium dithionite $^{11,18,19}$ ) have been shown to serve as an effective rusty carbon sink and to preserve OC over geological timescales ${ }^{11}$. Previously, it has been shown that reactive Fe-OC associations can mainly be found in intact permafrost soils ${ }^{20}$, but cannot preserve OC along a permafrost thaw gradient, following complete permafrost thaw from palsa to bog to fen type wetlands ${ }^{19}$. However, the stability of $\mathrm{Fe}-\mathrm{OC}$ associations during transitional processes along permafrost 46 thaw gradients remain unstudied. The need to better understand the climate impact of transitional processes in thawing permafrost was stated previously by Shelef et al. ${ }^{21}$ who 
emphasize large uncertainty in permafrost carbon stocks (>200\%) due to processes at collapsing fronts. Indeed, methane dynamics can also strongly differ between end-members and transitional thaw stages ${ }^{22}$.

With permafrost thaw, soils become water-logged and oxygen $\left(\mathrm{O}_{2}\right)$ limited, favoring reductive dissolution of reactive $\mathrm{Fe}(\mathrm{III})^{19}$. Fe(III)-reducing microorganisms are able to use the reactive $\mathrm{Fe}(\mathrm{III})$ as an electron acceptor for anaerobic respiration and, depending on its composition, the associated $\mathrm{OC}$ as electron source, resulting in $\mathrm{CO}_{2}$ and $\mathrm{Fe}(\mathrm{II})$ formation ${ }^{22}$. Thus, $\mathrm{Fe}(\mathrm{III})$ reduction directly contributes to $\mathrm{CO}_{2}$ emissions ${ }^{23}$. $\mathrm{Fe}$ (III) reduction may also influence $\mathrm{CH}_{4}$ emissions in thawing permafrost peatlands. On the one hand, $\mathrm{Fe}(\mathrm{III})$ reduction is thermodynamically more favorable and thus could outcompete methanogenesis ${ }^{24}$. On the other hand, $\mathrm{Fe}(\mathrm{III})$ reduction leads to proton consumption which results in an increasing $\mathrm{pH}$ that could favor methanogenesis ${ }^{25}$. The complex balance of these processes that either suppress or promote

60 GHG emissions such as $\mathrm{CO}_{2}$ and $\mathrm{CH}_{4}$ highlights the need for a fundamental understanding of microbial Fe metabolisms and their interactions with methanotrophs and methanogens, which is currently lacking.

The release of previously Fe-associated OC into surrounding porewater following reductive dissolution could lead to further microbial decomposition of OC and emission of GHGs such as $\mathrm{CO}_{2}$ and $\mathrm{CH}_{4}$. Mineral-associated $\mathrm{OC}$ (MAOC) has been proposed to be comprised of low molecular weight compounds of microbial (e.g. microbial polysaccharides, amino sugars, muramic acid) and plant origin ${ }^{13,26-30}$ with low activation energies of MAOC for degradation by microbes. Therefore, the release of MAOC with permafrost thaw is considered an important driver of the composition of arctic surface waters and microbial respiration ${ }^{31,32}$. Recent studies described carboxylic-rich ${ }^{33}$ and aliphatic Fe-bound OC in forest soils as more resistant during 71 reductive dissolution ${ }^{34}$. In Siberian permafrost soils, hydrophobic, aromatic DOC was preferentially sorbed by shallower, acidic soil horizons and correlated with an increasing 
73 abundance of $\mathrm{Fe}$ oxides ${ }^{35}$. The identity of Fe-bound $\mathrm{OC}$ in permafrost environments, however, 74 still remains unknown.

75 To understand the direct impact of the loss of this so called rusty carbon $\operatorname{sink}^{36}$ on net GHG 76 emissions in thawing permafrost peatlands, it is essential to further determine (1) the 77 bioavailability of Fe-bound OC and released OC during permafrost thaw and (2) changes in the 78 present and active microbial community, particularly the Fe(III)-reducing bacteria which are 79 key players in reactive Fe mineral dissolution and their interplay with methanotrophs and 80 methanogens.

81 We followed the dynamic biogeochemical interactions of Fe-OC associations in the active layer 82 along collapsing palsa hillslopes, where palsas underlain by intact permafrost are collapsing into partially-thawed, semi-wet bogs. Fe-OC associations were characterized in the solid phase 84 using selective extractions, scanning electron microscopy (SEM), nanoscale secondary ion 85 mass spectrometry (nanoSIMS), and Mössbauer spectroscopy, and the effect of palsa collapse 86 on porewater geochemistry and $\mathrm{CO}_{2}$ and $\mathrm{CH}_{4}$ fluxes was quantified. Reactive Fe-associated OC 87 and DOC in the porewater along the palsa hillslope were investigated at the molecular-level 88 with Fourier transform ion cyclotron resonance mass spectrometry (FT-ICR-MS), and the 89 present and active microbial community was characterized using DNA- and RNA-based 16S 90 rRNA amplicon (gene) sequencing. 
peatlands. In the palsa and at the collapsing front (Figures $\mathrm{S} 1$ and $\mathrm{S} 2$ ), net $\mathrm{CO}_{2}$ emissions measured from static flux chambers were similar on average $\left(1.57 \pm 0.27 \mu \mathrm{mol} / \mathrm{m}^{2} / \mathrm{s}\right)$ and slightly decreased in the bog to $1.12 \pm 0.51 \mu \mathrm{mol} / \mathrm{m}^{2} / \mathrm{s}$ (Figure 1). Replicate analysis of $\mathrm{CO}_{2}$ concentrations in automatic Eosense eosFD gas flux chambers showed similar $\mathrm{CO}_{2}$ emissions

97 along the palsa hillslope (Figure S3). Net $\mathrm{CH}_{4}$ emissions were very low in the palsa $98\left(0.003 \pm 0.001 \mu \mathrm{mol} / \mathrm{m}^{2} / \mathrm{sec}\right)$, significantly increased at the collapsing front to $0.025 \pm 0.001$ $\mu \mathrm{mol} / \mathrm{m}^{2} / \mathrm{s}$ and then slightly decreased in the bog $\left(0.013 \pm 0.001 \mu \mathrm{mol} / \mathrm{m}^{2} / \mathrm{s} ;\right.$ Figure 1$)$. Emission rates of $\mathrm{CO}_{2}$ and $\mathrm{CH}_{4}$ in the palsa and the bog are in line with previous studies at Stordalen mire ${ }^{37-39}$, however, this is the first report of emissions at the collapsing front, where palsa is collapsing into the bog.

Previous work demonstrated that highest reactive Fe and associated OC contents can be found where the organic and mineral horizons meet, which we have termed the "transition zone"19.

105 DOC concentrations in the porewater of the transition zone were low in the intact palsa (Palsa A, $57.97 \pm 16.49 \mathrm{mg} / \mathrm{L})$. Porewater DOC significantly increased towards the collapsing front to 207.65 $\pm 168.16 \mathrm{mg} / \mathrm{L}$ in the more collapsed palsa (Palsa B). Highest DOC concentrations were found directly at the collapsing front $(535.75 \pm 131.45 \mathrm{mg} / \mathrm{L})$ and then significantly decreased in the bog (279.62 \pm 113.14 to $206 \pm 80.28 \mathrm{mg} / \mathrm{L})$ (Figure 1, Figure S1, Figure S4).

The aqueous $\mathrm{Fe}^{2+}$ concentrations show the same trend as the DOC (Figure 1). Aqueous $\mathrm{Fe}^{2+}$

111 concentrations in the palsa were lowest along the palsa hillslope $(4.47 \pm 3.16$ to $22.62 \pm 30.14$

$112 \mathrm{mg} / \mathrm{L}$; Figure 1) and significantly increased at the collapsing front. Highest aqueous $\mathrm{Fe}^{2+}$ 113 concentrations were measured at the collapsing front $(153.24 \pm 40.14 \mathrm{mg} / \mathrm{L})$ and significantly 114 decreased again at the two measured locations in the bog to $48.86 \pm 11.43$ and $82.43 \pm 47.93 \mathrm{mg} / \mathrm{L}$ 
115 (Figure 1). Other elements such as dissolved phosphorous (P) also strongly correlated with the 116 aqueous $\mathrm{Fe}^{2+}$ pulse at the collapsing front, suggestive of mineral dissolution and release of 117 mineral-associated P (Figures S5- S6).

118 The release of $\mathrm{OC}$ and aqueous $\mathrm{Fe}^{2+}$ along the palsa hillslope was accompanied by an increase 119 in the relative 16S rRNA gene sequence abundance (DNA-based) of iron- and methane-cycling 120 microorganisms in the transition zone and mineral horizon from the palsa to the collapsing front 121 (Figure 1; Figure S7). Towards the collapsing front, Fe(III)-reducing bacteria increased from $1220.41 \pm 0.07$ to $2.46 \pm 0.34 \%$ in the transition zone and from $0.21 \pm 0.05$ to $2.42 \pm 0.27 \%$ in the mineral horizon (Figure 1). Fe(II)-oxidizing bacteria also increased from the palsa to the collapsing front from $0.54 \pm 0.26$ to $2.33 \pm 0.33 \%$ in the transition zone and from $0.92 \pm 0.58$ to $1.66 \pm 0.44 \%$ in the mineral horizon. Methanogens increased along the palsa hillslope from $0.42 \pm 0.37$ to $2.83 \pm 0.26 \%$ in the transition zone and from $1.40 \pm 1.40$ to $11.68 \pm 3.12 \%$ in the mineral horizon. Methanotrophs increased from the palsa to the collapsing front from $0.90 \pm 0.30$ to $1.93 \pm 0.09 \%$ in the transition zone and from $0.58 \pm 0.08$ to $1.26 \pm 0.29 \%$ in the mineral horizon (Figure 1). Along the palsa hillslope, the relative 16S rRNA gene sequence abundances of iron-

130 and methane-cycling microorganisms were stable in the organic horizon (Figure 1). The iron131 and methane-cycling microorganisms are described in detail in Figure 2. For estimated absolute 132 abundances of bacteria and archaea as well as the manually-compiled database used to identify 133 iron- and methane-cycling microorganisms and the whole microbial community see Figure 2 134 and SI (Figures S8 and S9 and Tables S1-S4). This data reveals that the so-called rusty carbon sink is already destabilized during palsa collapse, even before complete permafrost thaw. Lateral flow by runoff of rain and/or melt

137 water ${ }^{40,41}$ in the transition zone between organic and mineral horizon, caused by bulk density 138 shifts (organic horizon: $0.03 \pm 0.01 \mathrm{~g} / \mathrm{cm}^{3}$ and mineral horizon: $0.84 \pm 0.26 \mathrm{~g} / \mathrm{cm}^{3}$ ) ${ }^{19}$, favors microoxic conditions, as also described for other permafrost hillslopes ${ }^{42}$. These redox conditions 
140 promote microbial reduction of reactive Fe(III) minerals coupled to carbon oxidation ${ }^{14,43}$. This

141 results in a release of $\mathrm{Fe}$ and $\mathrm{Fe}$-associated $\mathrm{OC}$ into the surrounding porewater and ultimately

142 contributes to a pulse of aqueous $\mathrm{Fe}^{2+}$ and DOC at the collapsing front - where we observed the

143 highest aqueous $\mathrm{Fe}^{2+}$ and DOC concentrations ever measured along the whole thaw gradient ${ }^{19}$.

144 The release of OC along the palsa hillslope results from multiple co-occurring processes. These

145 include the release of $\mathrm{Fe}$-associated $\mathrm{OC}$, changes in $\mathrm{pH}^{44}$, plant community ${ }^{45}$ (Figure $\mathrm{S} 10$ ), and

146 in microbial degradation of organic matter ${ }^{46}$.

147 Although $\mathrm{Fe}(\mathrm{II})$-oxidizers are present and active, they cannot prevent the overall loss of reactive

$148 \mathrm{Fe}$ and $\mathrm{Fe}$-associated $\mathrm{OC}$ along the palsa hillslope. The $\mathrm{CO}_{2}$ produced from degradation of

149 released carbon, including Fe-associated-OC, further stimulated methanogenic microorganisms

150 at the collapsing front. This $\mathrm{CO}_{2}$ production was at least partially driven by $\mathrm{Fe}(\mathrm{III})$ reduction

151 coupled to carbon oxidation based on the increasing abundance of Fe(III)-reducing bacteria

152 along the palsa hillslope as has also been suggested for subalpine wetland soils ${ }^{47}$.

153 Ultimately, the loss of this so called rusty carbon sink contributes to net GHG emissions of $\mathrm{CO}_{2}$

154 and $\mathrm{CH}_{4}$, directly by $\mathrm{Fe}(\mathrm{III})$ reduction coupled to carbon oxidation and indirectly by promoting 155 methanogenesis at the collapsing front. 


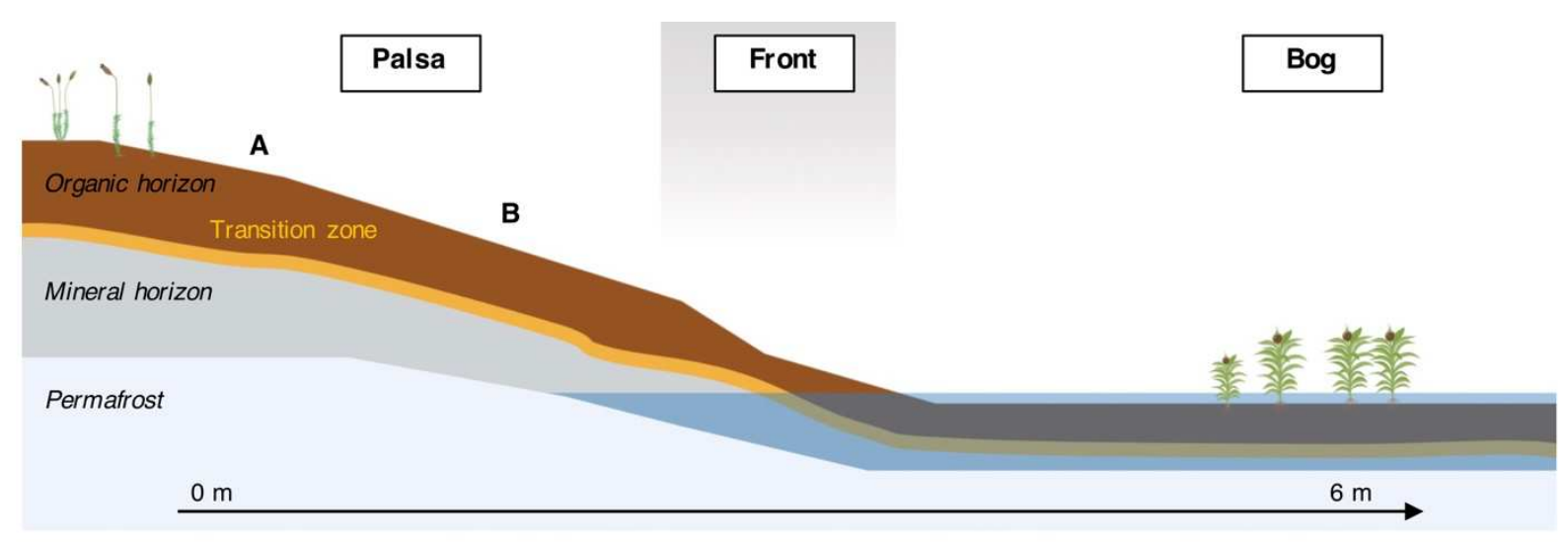

a Carbon dioxide and methane emissions along the palsa hillslope into bog

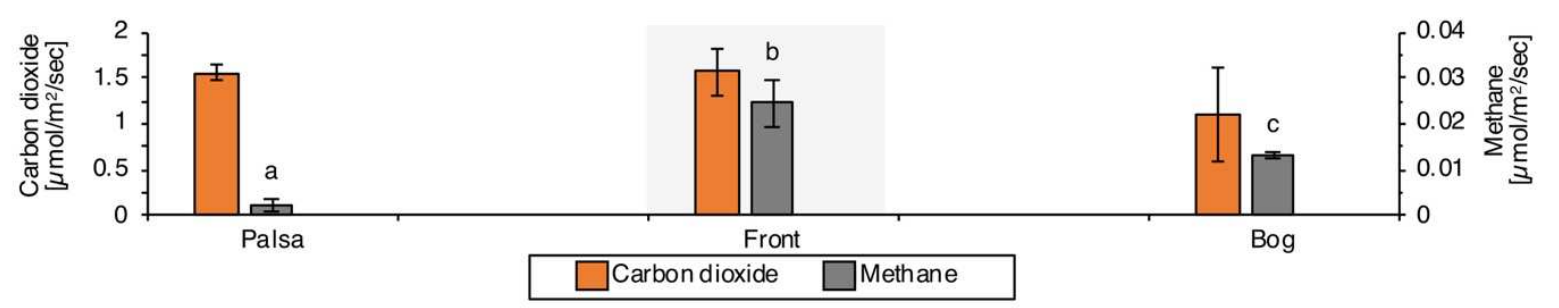

b Aqueous $\mathrm{Fe}^{2+}$ and $\mathrm{DOC}$ pulse along the palsa hillslope into bog

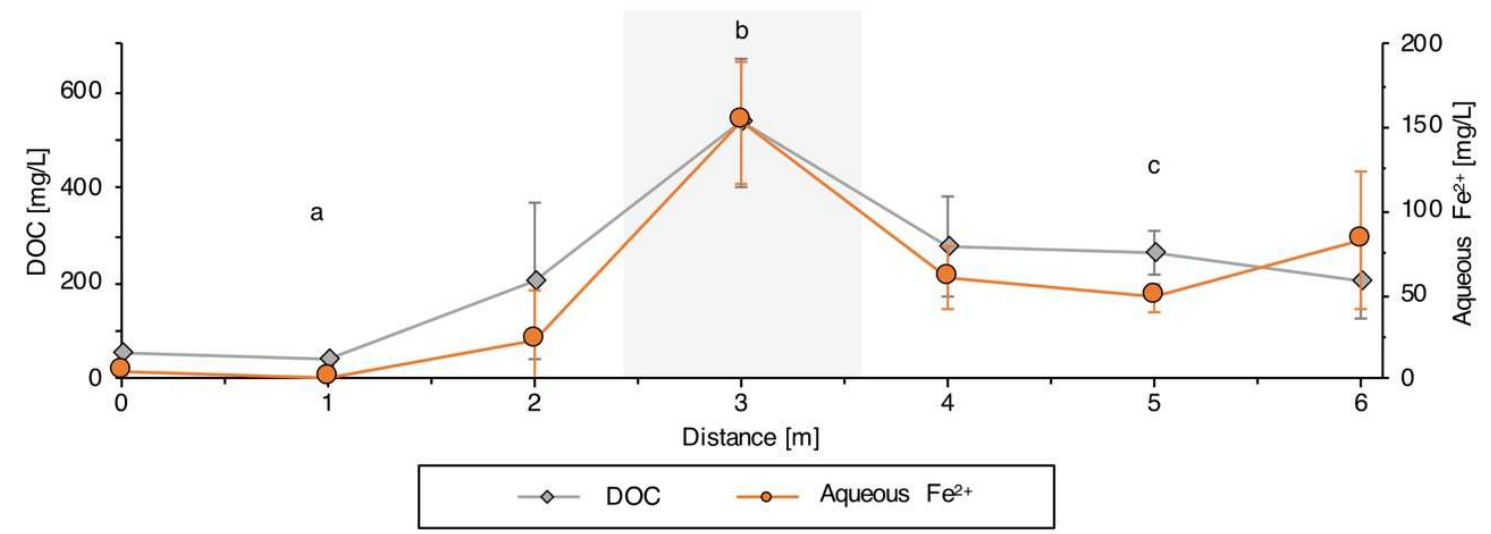

c Relative 16S rRNA gene sequence abundance of iron- and methane-cycling microorganisms from palsa to front

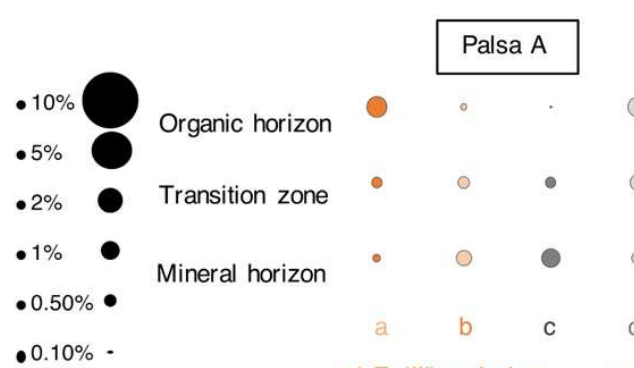

$\bullet 0.10 \% \cdot$

158 Figure 1. Microbial iron cycling and carbon release as dissolved organic carbon (DOC),

159 carbon dioxide and methane emissions along a palsa hillslope. a, Carbon dioxide and

160 methane emissions along the palsa hillslope with highest emissions at the collapsing front. The 
reported values and error bars represent the average and standard deviation of measurements collected on three days at three separate time points. b, Aqueous iron $\left(\mathrm{Fe}^{2+}\right)$ and DOC pulse along the palsa hillslope at $30 \mathrm{~cm}$ depth with highest values at the collapsing front. Reported

164 values and error bars represent the average and standard deviation of eight palsa to bog 165 hillslopes sampled in June/July 2019 c, Relative 16S rRNA gene abundance of iron- and methane-cycling strains along the palsa hillslope with highest abundances at the collapsing front: a) Fe(II)-oxidizing, b) Fe(III)-reducing, c) methanogenic and d) methanotrophic. Small letters above data mean significant differences ( $\mathrm{P}<0.05$, one-way ANOVA: TukeyHSD test).

Microbial iron- and methane-cycling communities during palsa collapse. Along the palsa hillslope, iron- and methane-cycling microorganisms increase in relative abundance, here defined as DNA-based relative $16 \mathrm{~S}$ rRNA gene abundance, and in potential activity, here defined as RNA-based relative 16S rRNA abundance (Figure 2; for total microbial community 174 and replicate analysis see Figure S9 and S11, Table S1-S4).

$175 \mathrm{Fe}(\mathrm{III})$-reducers, driving reactive Fe mineral dissolution and associated OC release, are found 176 in high abundance and potential activity along the palsa hillslope. From Palsa A to the 177 collapsing front, Geobacter spp., a classical Fe(III)-reducer ${ }^{24}$, increased in relative abundance 178 from 0 to $1.55 \pm 0.30 \%$ in the transition zone and to $1.62 \pm 0.18 \%$ in the mineral horizon. The 179 potential activity of Geobacter spp. rose from 0 to $2.50 \pm 0.13 \%$ in the transition zone and to $4.75 \pm 1.07 \%$ in the mineral horizon (Figure 2). Clostridium spp., a fermentative Fe(III)-

181 reducer ${ }^{53}$, increased in relative abundance from 0 to $0.81 \pm 0.02 \%$ in the transition zone and $1820.76 \pm 0.07 \%$ in the mineral horizon (Figure 2). Potential activity of Clostridium spp. increased 183 from 0 to $2.31 \pm 1.15 \%$ in the transition zone and to $1.23 \pm 0.22 \%$ in the mineral horizon (Figure 184 2). Rhodoferax spp., known for dissimilatory Fe(III) reduction ${ }^{52}$, only appeared to be present 
$185(1.98 \pm 1.51 \%)$ and potentially active $(1.62 \pm 0.16 \%)$ in the mineral horizon of the more collapsed 186 palsa (Palsa B), close to the collapsing front (Figure 2). Myxococcales spp. showed highest 187 relative abundance from $1.67 \pm 0.15 \%$ in the intact palsa (Palsa A) to $1.30 \pm 0.23 \%$ at the 188 collapsing front and potential activity from $9.13 \pm 0.08$ in the intact palsa to $7.03 \pm 2.08 \%$ at the 189 collapsing front in the organic horizon (Figure 2).

190 This microbial community analysis further indicates that the rusty carbon sink is lost by 191 dissimilatory and fermentative Fe(III) reduction. Dissimilatory Fe(III) reduction is conducted 192 along the palsa hillslope by abundant and active Fe(III)-reducing microorganisms such as 193 Geobacter spp., Rhodoferax spp. and Myxococcales spp. (Figure 2; see also absolute 194 abundances in Figure S8 and replicate core analysis in Figure S15) ${ }^{48,49}$. Myxococcales spp. are 195 not only capable of $\mathrm{Fe}(\mathrm{III})$ reduction, but also e.g. polysaccharide and protein degradation ${ }^{46}$. 196 Geobacter spp. and Rhodoferax spp. represent classical Fe(III)-reducing microorganisms, that 197 are well studied in different environments ${ }^{23}$ with Rhodoferax spp. also being described at other permafrost sites $^{14}$. Fermentative Fe(III) reduction is probably performed by Clostridium spp. who might use the present DOC as carbon and energy source.

The abundant and active Fe(III)-reducing bacteria are accompanied by less relatively abundant and probably less active $\mathrm{Fe}(\mathrm{II})$-oxidizers. Gallionella spp. had a relative abundance of $0.82 \pm 1.16 \%$ in the present microbial community and $1.42 \pm 1.92 \%$ in the active community of 203 the mineral horizon of the more collapsed palsa (Palsa B). Sideroxydans spp. increased in their relative abundance from below detection to $1.42 \pm 0.21 \%$ in the transition and to $1.08 \pm 0.34 \%$ in the mineral horizon. Other Gallionellaceae, besides Gallionella spp. and Sideroxydans spp., were equally distributed in their relative abundance along the palsa hillslope from $0.54 \pm 0.26 \%$ in the transition zone and $0.86 \pm 0.55 \%$ in the mineral horizon of the intact palsa (Palsa $\mathrm{A}$ ) to $2080.90 \pm 0.12 \%$ in the transition zone and $0.58 \pm 0.09 \%$ in the mineral horizon at the collapsing front. The activity of the other Gallionellaceae was probably highest at the collapsing front 
with $0.53 \pm 0.24 \%$ in the transition zone and $0.35 \pm 0.07 \%$ in the mineral horizon. The classical

211 Fe(II)-oxidizing bacteria ${ }^{48,49}$ such as Gallionella spp. and Sideroxydans spp., observed to be

212 present and potentially active in this system were already described in arctic ponds ${ }^{50}$. In this

213 setting, these cannot sustain or reform the rusty carbon sink during palsa collapse (Figure 2).

214 The increasing relative 16S rRNA (gene) abundance (DNA- and RNA-based) of classical

215 Fe(III)-reducing bacteria is accompanied by an increase in the relative abundance of 216 methanogenic microorganisms, mainly Methanobacterium spp. These significantly increased 217 in their relative abundance in the transition zones from $0.25 \pm 0.24 \%$ in the intact palsa (Palsa 218 A) to $2.05 \pm 0.14 \%$ at the collapsing front. In the mineral horizon, they rose in their relative 219 abundance from $1.15 \pm 1.22 \%$ in the intact palsa (Palsa A) to $10.07 \pm 2.84 \%$ at the collapsing front 220 (Figure 2). Along the palsa hillslope, only a slight increase in potential activity of 221 Methanobacterium spp. was observed in the transition zone from 0 to $0.14 \pm 0.05 \%$ and in the mineral horizon from 0 to $1.91 \pm 0.85 \%$ (Figure 2). Other methanogens belonging to Bathyarchaeia also increased in relative abundance along the palsa hillslope from $0.17 \pm 0.13 \%$ to $0.71 \pm 0.12 \%$ in the transition zone and from $0.25 \pm 0.18 \%$ to $1.45 \pm 0.24 \%$ in the mineral horizon. Methanotrophs, such as Roseiarcus spp. and other Beijerinckiacaeae (i.e. Methylobacterium spp. or Methylocystis spp.) had an equal relative abundance in the community present along the palsa hillslope (i.e. DNA-based) and had its highest potential activity in the palsa closest to the collapsing front (Palsa B; $12.55 \pm 0.30 \%$ ).

Acetate, formed along the palsa hillslope and accounted for up to $61.70 \pm 42.56 \mathrm{mg} \mathrm{C} / \mathrm{L}(10.33 \%$ of the total DOC) at the collapsing front (Figure 4). It is expected that this stimulates Fe(III)

231 reduction coupled to acetate oxidation and leads to $\mathrm{CO}_{2}$ formation by $\mathrm{Fe}(\mathrm{III})$-reducing bacteria 232 such as Geobacter spp., known to metabolize acetate ${ }^{23}$. The potential for reductive acetogenesis 233 from $\mathrm{CO}_{2}$ by Bathyarchaeia was previously suggested ${ }^{51}$. Our MetaCyc ontology predictions 234 showed a high potential for acetoclastic methanogenesis (Figure S12), but contradictory to this, 
235 we only saw a high relative abundance of hydrogenotrophic methanogens such as 236 Methanobacterium spp. This could be explained by the higher thermodynamic favorability of

$237 \mathrm{Fe}(\mathrm{III})$ reduction coupled to acetate oxidation as compared to acetoclastic methanogenesis. $\mathrm{H}_{2}$ 238 and $\mathrm{CO}_{2}$, partially produced by fermentation and $\mathrm{Fe}(\mathrm{III})$ reduction by e.g. Clostridium spp., can 239 be used by hydrogenotrophic methanogens and lead to $\mathrm{CH}_{4}$ emissions at the collapsing front.

240 The $\mathrm{CH}_{4}$ is partially oxidized back to $\mathrm{CO}_{2}$ by methanotrophs as shown by Perryman et al. ${ }^{22}$ who 241 described highest methane oxidation rates for palsa at the transition between palsa and bog (here 242 referred to as the collapsing front).

243 Our data clearly shows a co-existence of microbial iron- and methane-cycling microbial 244 communities during palsa collapse, which ultimately cause GHG emissions and effect the 245 balance between $\mathrm{CO}_{2}$ and $\mathrm{CH}_{4}$ emissions even before complete permafrost thaw. 
a Iron-cycling microorganisms along the palsa hillslope
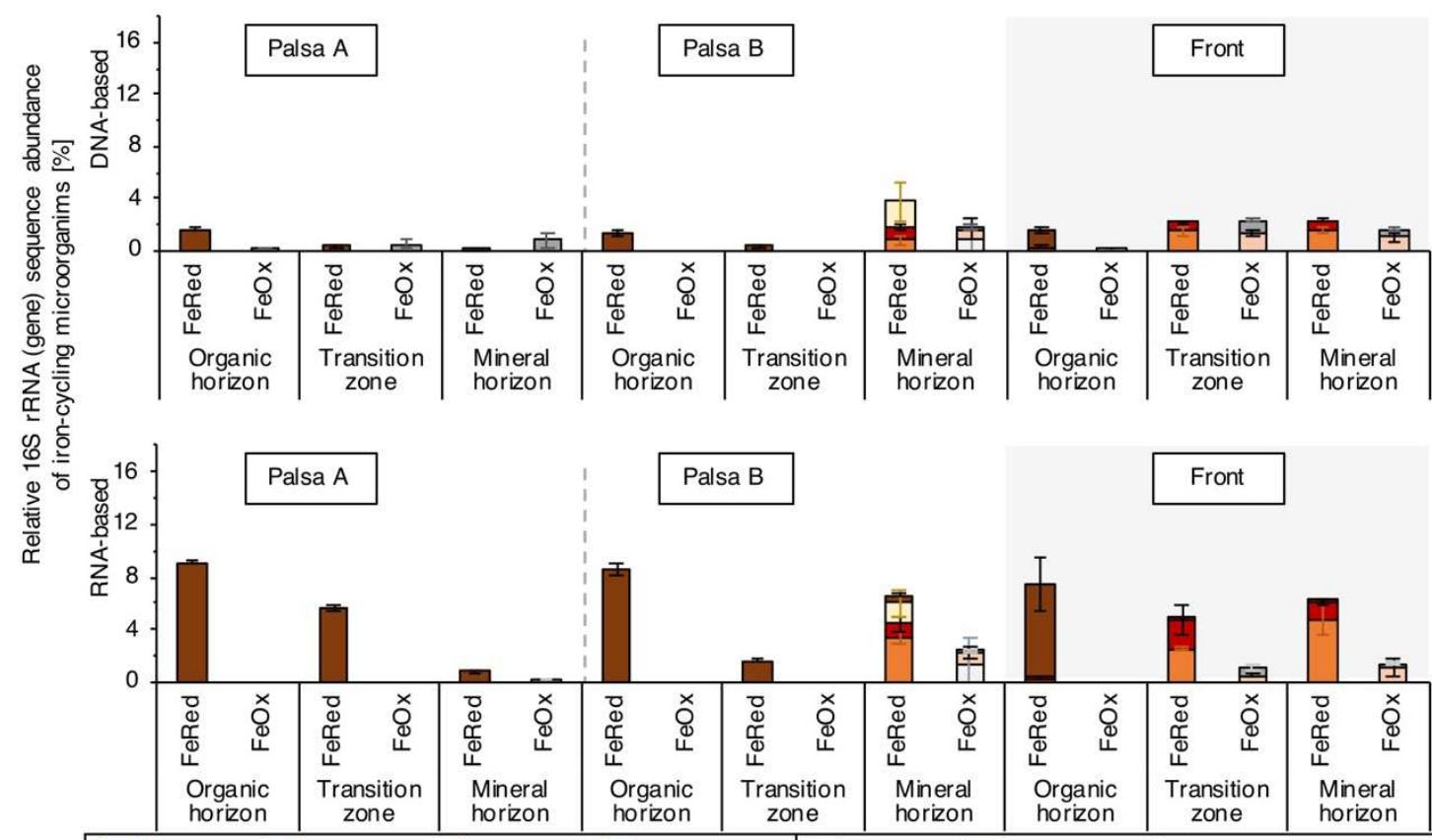

FeRed $\square$ Geobacter $\square$ Clostridium $\square$ Rhodoferax $\square$ Myxococcales $\square$ Gallionella $\square$ Sideroxydans $\square$ Other Gallionellaceae FeOx

b Methane-cycling microorganisms along the palsa hillslope

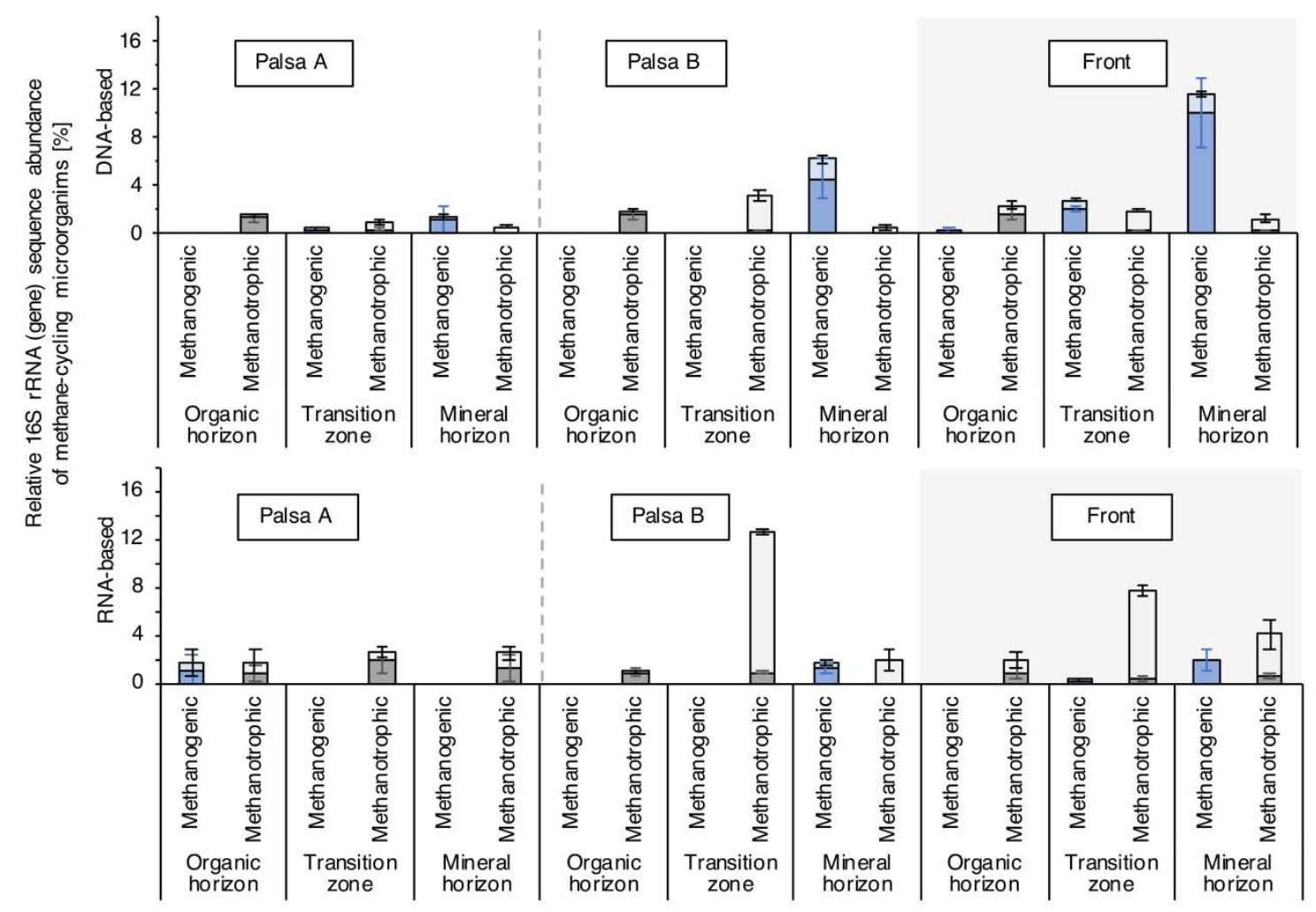

247 Figure 2. Relative 16S rRNA (gene) abundance of abundant (DNA-based) and likely active

248 (RNA-based) iron (Fe)- and methane-cycling microbial communities along the palsa 
hillslope (Palsa A, Palsa B, Front). a, Iron-cycling microorganisms show an increasing relative 16S rRNA (gene) abundance (DNA- and RNA-based) along the palsa hillslope with highest abundances in the transition zone and mineral horizon at the collapsing front. $b$, Methane-cycling microorganisms are increasing in relative 16S rRNA (gene) abundance along the palsa hillslope. Reported values and error bars represent the average and standard deviation of triplicate analysis of each soil horizon along the palsa hillslope. Replicate cores show similar relative 16S rRNA (gene) abundance of abundant (DNA-based) and potentially active (RNAbased) Fe- and methane cycling microbial communities along the palsa hillslope (Figure S11, Table S1-S4).

Release of bioavailable iron-associated organic carbon during palsa collapse. To investigate if the loss of the rusty carbon sink also directly contributes to net GHG emissions by releasing bioavailable, previously $\mathrm{Fe}$-bound organic carbon, into the porewater we determined the quantity and identity of Fe-bound OC in the solid phase (defined as dithionite extractable OC) and of the released OC in the porewater. Dithionite did not affect the identity of extractable OC and did not lead to molecular artifact formation (see SI, Table S5).

Highest reactive Fe concentrations (defined as Fe reductively dissolved by sodium dithionite and control corrected by leachable Fe, see Methods) were found in the transition zone of the most intact palsa (10.04 $\pm 0.07 \mathrm{mg}$ reactive Fe per g soil; Figure 3). Towards the collapsing front, reactive $\mathrm{Fe}$ in the transition zone between the organic and mineral horizons significantly

269 decreased to $3.22 \pm 0.06 \mathrm{mg}$ per g soil at the front (Figure 3). Absolute values are listed in Table

270 S6 and replicate core analysis can be seen in Figure S13. The amount of reactive Fe-associated

271 OC (OC dissolved after reductive dissolution of reactive Fe minerals by sodium dithionite and control corrected by leachable OC, see Methods) also decreased from the palsa to the bog in 
the transition zone $(83.69 \pm 10.04$ and $76.60 \pm 16.89 \mathrm{mg}$ Fe-associated OC per $\mathrm{g}$ soil in the palsa to $40.88 \pm 10.76 \mathrm{mg}$ per $\mathrm{g}$ soil in the bog) (Figure 2). In the organic horizons along the palsa

275 hillslope, reactive Fe and Fe-associated OC abundance was the lowest in the soil profile with 276 average values of $0.49 \pm 0.25 \mathrm{mg}$ reactive Fe per g soil and $2.08 \pm 2.47 \mathrm{mg}$ Fe-associated OC per $277 \mathrm{~g}$ soil (Figure 3). In the mineral horizons from the palsa to the collapsing front, reactive Fe was 278 very stable (average $3.81 \pm 0.38$ reactive Fe per g soil), whereas Fe-associated OC slightly 279 decreased from 47.21 $\pm 14.30 \mathrm{mg}$ Fe-associated OC per g soil in the palsa to the collapsing front 280 which had only $11.60 \pm 8.54 \mathrm{mg}$ Fe-associated OC per g soil (Figure 3 ). The highest content of 281 Fe-associated OC was found in the most intact palsa along the palsa hillslope. This is supported 282 by the strong spatial associations of OC with Fe minerals in the fine fraction observed by nanoSIMS analysis in the transition zone in this core (Figure 3; see replicate analysis of intact

284 palsa core "Palsa A" in Figures S1, S14-S15). The transition zone and mineral horizons at the 285 collapsing front showed organic-free, co-existing $\mathrm{Fe}$ and aluminum (Al), suggestive of $\mathrm{Fe}-$ 286 bearing clays (Figure 3). This is also supported by Mössbauer spectroscopy (Figure S16, Table 287 S7) and by previous observations with extended X-ray adsorption fine structure (EXAFS) ${ }^{19}$.

a Solid phase extraction
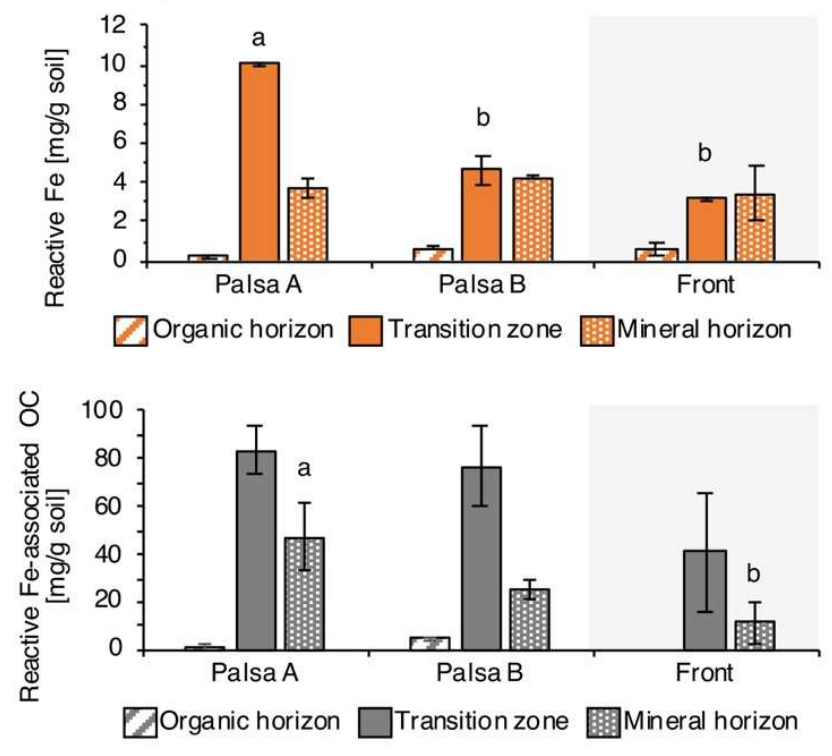

b Fine particle fraction analysis

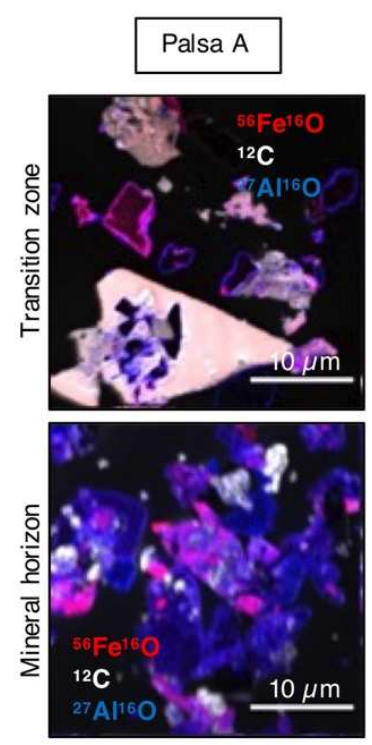

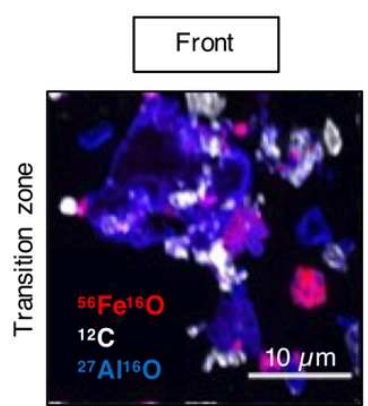

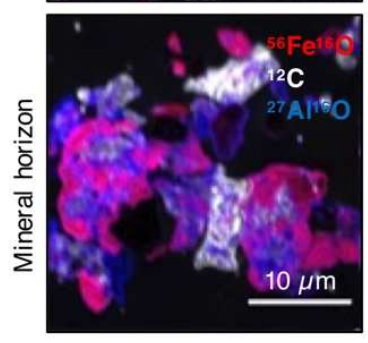



collapsing front in a, the bulk soil and $\mathbf{b}$, in the fine particle fraction. a, Reactive $\mathrm{Fe}$ and $\mathrm{Fe}$ associated organic carbon in the solid phase decrease from the intact palsa (Palsa A) towards the collapsing front. Reactive Fe values are the average of sodium dithionite citrate duplicate extractions, control corrected by sodium chloride bicarbonate extractable Fe (leachable $\mathrm{Fe}$ ). $\mathrm{Fe}$ associated OC values are the average of sodium dithionite citrate extractions, control corrected by subtraction of the citrate background and the sodium chloride bicarbonate extractable OC (leachable OC) (see Methods). Error bars of reactive Fe represent a combined standard deviation of sodium chloride bicarbonate extractable $\mathrm{Fe}$ and sodium dithionite citrate extractable Fe. Errors of the Fe-associated carbon represent a combined standard deviation of the citrate blank, sodium chloride bicarbonate extractable OC and sodium dithionite citrate extractable OC. Different small letters above bars mean significant differences $(\mathrm{P}<0.05$, oneway ANOVA: TukeyHSD test). b, High spatial resolution analysis of $\mathrm{Fe}-\mathrm{OC}$ associations by nanoSIMS in the fine fraction of the soil, displayed as ${ }^{12} \mathrm{C}^{-}$(white), ${ }^{56} \mathrm{Fe}^{16} \mathrm{O}^{-}$(red) and ${ }^{27} \mathrm{Al}^{16} \mathrm{O}^{-}$ (blue) overlaid in a composite image. For the two end-members, Palsa A and collapsing front, four particles of the fine fractions of each layer were analyzed by correlative SEM and nanoSIMS, all showing the same spatial distribution of Fe, $\mathrm{C}$ and $\mathrm{Al}$ as shown by the four representatives (Figure S14-S15).

FT-ICR-MS analyses showed that, in the intact palsa, the reactive Fe-associated OC had a higher relative abundance of aliphatic species than the reactive Fe-associated OC at the

311 collapsing front (Figure 4, un-processed van Krevelen diagrams in Figure S17). This more 312 aliphatic-like fraction could represent amino sugar-like, carbohydrate-like and lignin-like 313 compounds $(\mathrm{O} / \mathrm{C} \text { range: } 0.3 \text { to } 0.6, \mathrm{H} / \mathrm{C} \text { range: } 1.0 \text { to } 1.5)^{52,53}$. A higher fraction of aromatics 314 was associated with reactive Fe phases at the collapsing front compared to the organics bound 
315 by reactive $\mathrm{Fe}$ in the intact palsa (Figure 4). In general, it should be noted that the amounts $316(\mathrm{mg} / \mathrm{g})$ of reactive Fe-associated OC are decreasing along the palsa hillslope (Figure 3 and Table

317 S5). The higher relative abundance of the more aliphatic compounds associated with reactive

318 Fe in the intact palsa is lost during reductive dissolution to the surrounding porewater along the 319 palsa hillslope, thus the aliphatic fraction most likely contributes to the aqueous $\mathrm{Fe}^{2+}$ and DOC 320 pulse at the collapsing front (Figure 4). Loosely bound OC (salt extractable) appeared in lower 321 quantities and showed less defined but similar identity of organic fractions to the reactive Feassociated OC (Figure S18, Table S5 and S7).

Porewater extracted from the same soil interface (transition zone), where the rusty carbon sink is lost along the palsa hillslope (Figures 1 and 2), contained a higher relative abundance of more aliphatic species and more aromatic species compared to porewater extracted at the collapsing front (Figure 4; un-processed van Krevelen diagrams in Figure S17). At the collapsing front, an increased relative abundance of organic molecules, potentially representing tannin-like compounds ( $\mathrm{O} / \mathrm{C}$ range: 0.5 to $0.9, \mathrm{H} / \mathrm{C}$ range: 0.5 to 1.4$)^{52,53}$, is observed (Figure 4 ; Figure S17). The more aliphatic species had a lower relative abundance in the DOC at the collapsing front, whereas a higher relative abundance of more aromatic species was observed (Figure 4).This could indicate decomposition processes that occur in the palsa hillslope porewater that yield smaller organic compounds, uptake by native microbes, assimilation of organic carbon into biomass and/or further metabolism, and ultimately emissions of GHGs by microbial respiration. Porewater analysis along a replicate palsa hillslope showed the same identity of aliphatic and aromatic species in intact palsa and at the collapsing front (Figure S19).

Further decomposition of DOC along the palsa hillslope is supported by an increasing nominal oxidation state of carbon (NOSC) of the DOC in the porewater at the transition zone from the palsa towards the collapsing front from $0.12 \pm 0.04$ to $0.24 \pm 0.04$ (Figure 4). As the DOC becomes more oxidized, the NOSC increases at the collapsing front. This is in line with an 
340 increasing average molecular weight (MW) from $591.24 \pm 7.70$ in palsa to $614.80 \pm 0.40$ at the

341 collapsing front (Figure $4 \mathrm{~b}$ and Figure S20). NOSC values slightly decreased in the bog to

$3420.20 \pm 0.02$ due to the overall loss of organic carbon mainly as $\mathrm{CO}_{2}$ and, consequently,

343 enrichment of less decomposed and more reduced DOC in the porewater. The double-bond

344 equivalents (DBE, the number of rings plus double bonds to carbon, calculated from the neutral

345 elemental composition $\left.{ }^{54}\right)$, remained stable along the palsa hillslope $(0.39 \pm 0.08)$. The DBE

346 along the palsa hillslope showed lower values than previously reported for bog and $\mathrm{fen}^{44}$,

347 indicating that bog and fen DOC is overall more unsaturated compared to DOC released along 348 the palsa hillslope.

349 The further decomposition of released organic carbon contributes to acetate formation (Figure

350 4) at the collapsing front, probably by pyruvate fermentation, indicated by MetaCyc ontology

351 predictions (Figure S12). Along the palsa hillslope, acetate in the porewater at the transition 352 zone between organic and mineral horizons significantly increased (unpaired $t$-test, $N=8, \alpha=$ $3530.05, p=0.0024)$ from $6.24 \pm 0.34 \mathrm{mg} \mathrm{C} / \mathrm{L}(3.56 \%$ of the total DOC) in the palsa to $61.70 \pm 42.56$ $354 \mathrm{mg} \mathrm{C} / \mathrm{L}(10.33 \%$ of the total DOC) at the collapsing front, the highest acetate concentrations 355 observed across the whole thaw gradient ${ }^{19}$. Further into the bog, the acetate concentrations 356 significantly decreased from $15.13 \pm 6.53$ to $6.10 \pm 1.44 \mathrm{mg} \mathrm{C} / \mathrm{L}$.

357 Previous studies at Stordalen mire focused on the soil organic carbon quantity and identity as 358 well as on dissolved organic matter composition (DOM) and DOC transport along the thaw 359 gradient. These analyses have highlighted shifts towards faster decomposition from partially360 thawed bog to fully-thawed fen with an increasing proportion of carbon released as $\mathrm{CH}_{4}{ }^{40,44,55}$.

361 Processes occurring at the transition between palsa and bog had not been studied, thus enhanced 362 production of acetate and its promotion of methanogenesis at this transition has been 363 overlooked. 
364 Our data showed that reactive Fe at the redox boundary between organic and mineral horizons

365 can bind aliphatic organic carbon, probably by downward cycling of DOM (defined as

366 continuous sorption and precipitation of DOM, as well as of microbial processing, desorption

367 and dissolution proportions of more recent plant-derived compound $s^{56,57}$ ) which is released

368 during reductive dissolution into the surrounding porewater. Lower molecular weight

369 compounds, aliphatic compounds or compounds poor in carboxyl functional groups show lower

370 binding strength to $\mathrm{Fe}$ minerals than higher molecular weight compounds, aromatics, or

371 compounds rich in carboxyl functionalities ${ }^{57}$. This is also supported by the leachable OC

372 extractions (same ionic strength and $\mathrm{pH}$ as the sodium dithionite extraction; Figure S18). Thus,

373 these compounds are not protected from microbial degradation along the palsa hillslope. The

374 previously $\mathrm{Fe}$-associated aliphatic fraction becomes more bioavailable to microorganisms when

375 it is released from mineral associations ${ }^{57}$. This likely contributes to promotion of microbial

376 growth and respiration of DOM during permafrost thaw ${ }^{56,58-60}$. Relative to aromatic compounds,

377 aliphatic compounds are expected to be even more labile to microorganisms ${ }^{56,59,60}$, which is

378 supported by the overall loss of this more aliphatic carbon fraction in the porewater at the

379 collapsing front (Figure 4) with only minor quantities of aromatic organic molecules remaining

380 preserved by reactive Fe minerals after palsa collapse (Figure 3 and Figure 4). Kawahigashi et

381 al. showed that aromatic DOC was preferentially retained by mineral horizons in Siberian

382 tundra containing reactive $\mathrm{Fe}^{35}$.

383 Our data clearly suggests that the loss of this rusty carbon sink directly contributes to high DOC

384 concentrations along the palsa hillslope and provides a bioavailable organic carbon source that

385 stimulates microbial respiration and promotes GHG emissions. 
a Fate of reactive Fe associated organic carbon and released organic carbon into the porewater

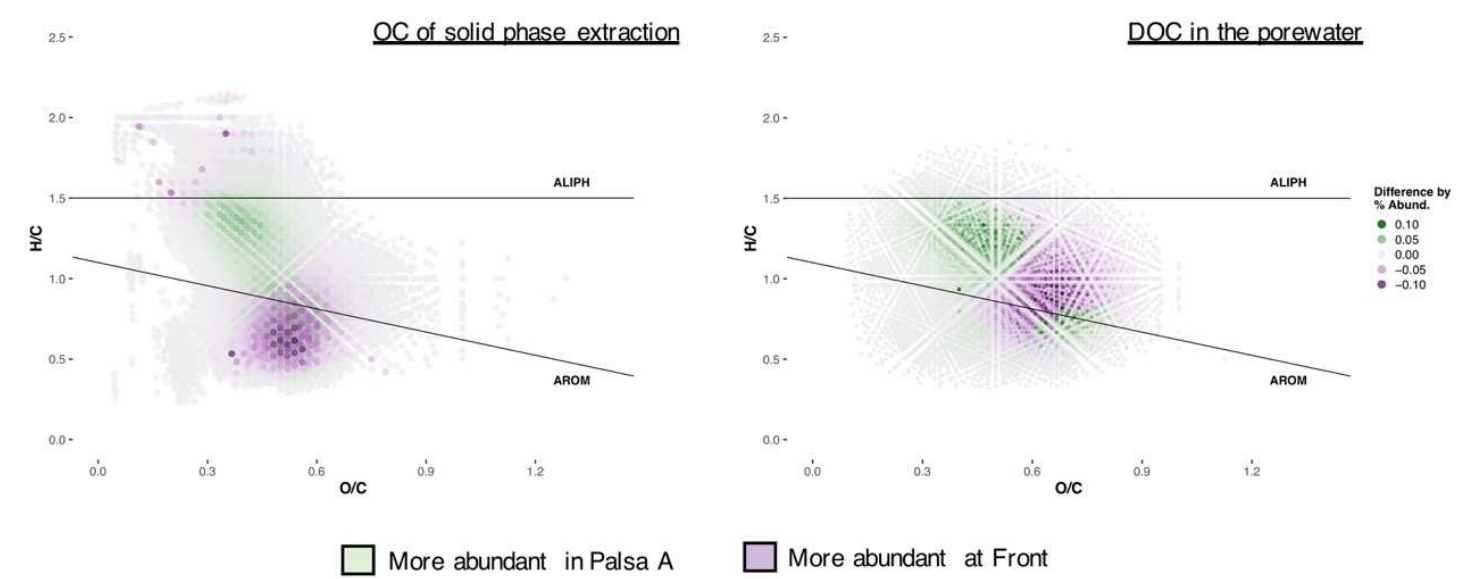

b Redox properties and molecular weight of released organic carbon into the porewater along the palsa hillslope

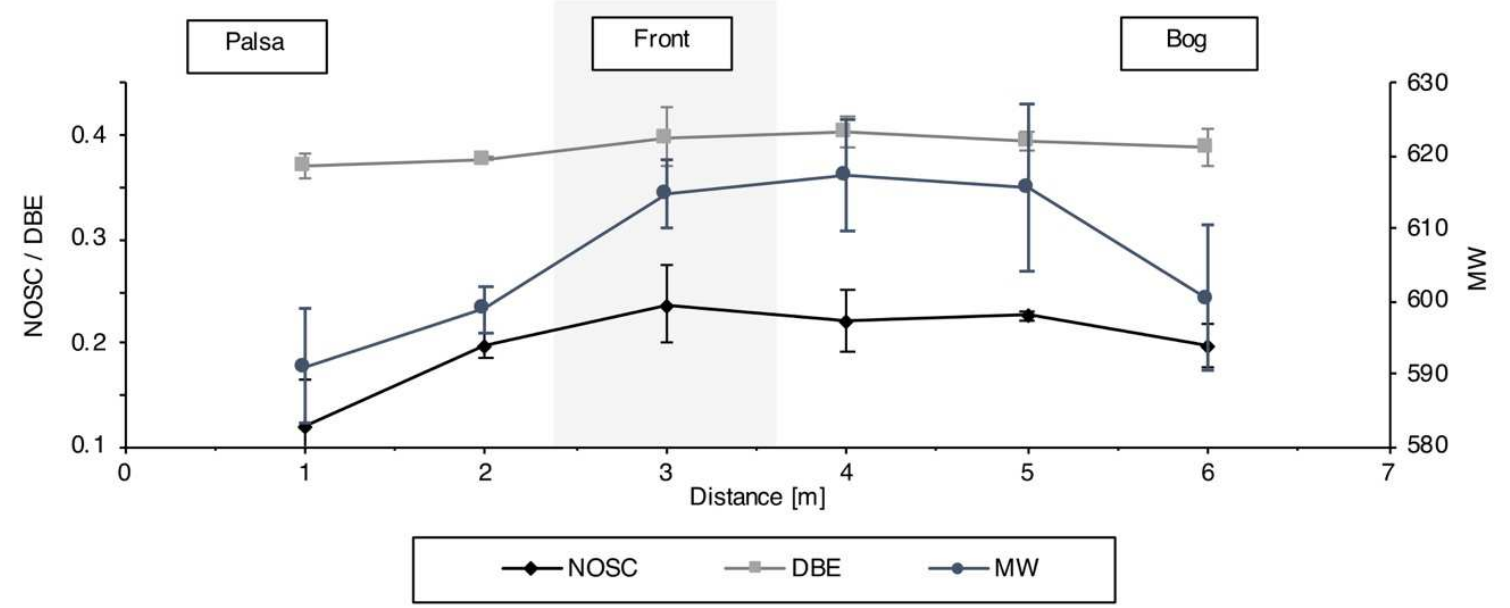

c Acetate formation along the palsa hillslope

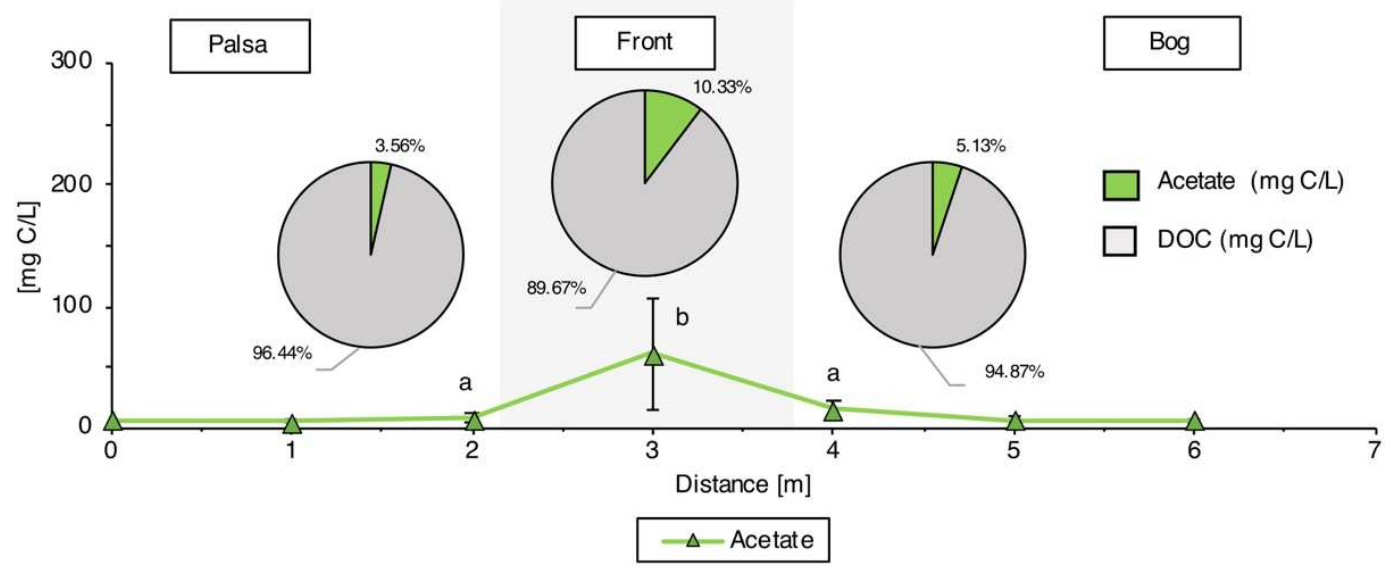

387 Figure 4. Bioavailability of reactive iron (Fe)-associated organic carbon (OC) released

388 along the palsa hillslope. a, Composition of reactive Fe-associated OC and OC released into

389 the porewater. Fe-bound carbon in palsa soils, underlain by intact permafrost, is comprised of 
more aliphatic species (class 1, green) and more aromatic species (class 2, purple). This is lost with reductive dissolution into the porewater. Towards the collapsing front into the bog, the remaining Fe-associated OC fraction (purple) is comprised of less bioavailable organic compounds which are likely associated with clay minerals (common in Palsa A, Front and Bog).

394 Dissolved OC, which is only found in Palsa A, is enriched in more aliphatic compounds (green).

395 Towards Front and Bog, only more aromatic species (purple) remain (Figures S17-S19, Table S5). B, Redox properties and molecular weight of released organic carbon into the porewater

397 along the palsa hillslope (Figure S20). Reported values and error bars represent the average and 398 the range of duplicate porewater analysis along two palsa hillslopes (Figures S1 and Figure S4). 399 a, Acetate formation along the palsa hillslope. Following further decomposition of the dissolved 400 OC, highly bioavailable acetate $[\mathrm{mg} \mathrm{C} / \mathrm{L}]$ is formed which then is again used to further reduce 401 present reactive $\mathrm{Fe}(\mathrm{III})$ to $\mathrm{Fe}^{2+}$ coupled to acetate oxidation and $\mathrm{CO}_{2}$ formation. Reported values and error bars represent the average and standard deviation of 8 palsa to bog hillslopes, sampled in June/July 2019 (Figures S1 and Figure S4). Different small letters above data mean 404 significant differences $(\mathrm{P}<0.05$, one-way ANOVA: TukeyHSD test).

Implications for the carbon cycle in thawing permafrost peatlands. There is a substantial need to piece together carbon sources and sinks in thawing permafrost environments to better understand and quantitatively predict the overall climate impact of permafrost thaw ${ }^{61}$. One such 409 carbon sink or source are Fe-OC associations ${ }^{36}$, which sequesters organic carbon in intact 410 permafrost soils ${ }^{20}$ but releases it with complete permafrost thaw ${ }^{19}$. Our data now showed that 411 the release of the $\mathrm{OC}$ from the rusty carbon sink turns the $\mathrm{OC}$ into a source of labile $\mathrm{DOC}, \mathrm{CO}_{2}$ 412 and $\mathrm{CH}_{4}$ even before permafrost-supported palsas have completely collapsed. With increasing 413 abrupt thaw, occurring in $20 \%$ of the permafrost zone, new active hillslope features are formed ${ }^{62}$ 414 and thus could speed up the loss of the rusty carbon sink in currently intact permafrost 
415 environments. Newest estimates showed that collapsing fronts will occupy $3 \%$ of abrupt thaw 416 terrain by 2300 , but could emit one-third of abrupt thaw carbon losses ${ }^{62}$. Ultimately, interlinked 417 processes of iron- and carbon cycling in thawing permafrost environments need to be integrated 418 into existing climate models to better understand and predict GHG emissions of thawing 419 permafrost areas and thus better estimate its overall climate impact. For this, it is crucial to 420 further determine co-occurring $\mathrm{Fe}(\mathrm{III})$ reduction rates and $\mathrm{CO}_{2}$ and $\mathrm{CH}_{4}$ production rates 421 following Fe mineral dissolution.

422 
424 Site information. Stordalen Mire (68 22' N, 19 03' E) is a subarctic peatland in northern

425 Sweden underlain by discontinuous permafrost. The mire consists of three distinct sub-habitats:

426 (1) palsa (intact permafrost) with ericaceous and woody plants; (2) ombrotrophic peatland or 427 bog (intermediate thaw) with Sphagnum spp., sedges and shrubs and (3) minerotrophic peatland 428 or fen (fully thawed) with sedges, mainly Eriophorum spp ${ }^{45}$ (Figure S1). Generally, palsas and 429 bogs are only fed by precipitation and melt water and have more acidic surface waters $(\mathrm{pH} \sim 4)$.

430 Fens are fed by surface water and groundwater, and maintain slightly acidic to alkaline $\mathrm{pH}^{40}$.

431 The areal extent of intact palsa across Stordalen mire has declined significantly since 1970 due 432 to progressive warming in the Arctic, while fen habitats have expanded ${ }^{63}$. It is also predicted 433 that the whole mire might be free of permafrost as early as $2050^{64,65}$.

434 Gas measurements. To measure $\mathrm{CO}_{2}$ emissions along the palsa hillslope, two eosense instruments (eosFD Forced Diffusion chamber in conjunction with the eosLink-FD software, EOSENSE INC, Dartmouth, Canada) were installed (Figures S1 and S2): (1) at the top of the 437 palsa hillslope (spot: Palsa A) and (2) at the transition to bog (spot: Front). The collar was situated in a flat location and inserted to near full depth. A centimeter of space was left to aid in installation of the eosFD itself as well as collar retrieval. The collar area was cleared of any rocks or debris, larger vegetation was removed or avoided. The eosFD was deployed in the

441 installed collar. The collars were deployed at least 24 hours prior to the start of the eosFD 442 measurement collection to avoid disturbance-related fluxes in the early portion of the data collection. The eosFD samples gases from the atmospheric and soil cavities within the device.

444 Briefly, gas is pulled from the atmospheric cavity to the sensor for 20 seconds to purge the sensor cavity, then sampled every 10 minutes for five samples. Gas is then pulled from the soil 446 cavity for 20 seconds, then pulsed every 10 minutes for five samples. Forced diffusion flux is 447 calculated as follows: 


$$
\frac{V}{A} * \frac{\partial C}{\partial t}=F s-D\left(\frac{\Delta C}{L}\right)
$$

449 (volume/surface area scaled rate of change in flux rate equal to the flux from the soil surface 450 (Fs) minus the difference in concentration, $\Delta \mathrm{C}$ (scaled by both the path length $\mathrm{L}$ and the 451 diffusivity of the interface (membrane), D)).

452 The change in the flux rate over the timespan of the concentration measurements (around 60 seconds) is assumed to be zero (steady state):

$$
\frac{V}{A} \frac{\partial C}{\partial t}=0
$$

This assumption results in a linear dependence with the path length and interface (membrane) diffusivity being constant and represented by a single coefficient, G:

$$
F s=G \Delta C
$$

Furthermore, carbon dioxide and methane emissions along the palsa hillslope were measured in triplicate using plastic chambers sealed with a rubber stopper (Figures S1 and S2), as

460 described previously ${ }^{66}$. The metal frames were pushed into the ground at least 24 hours before the measurements to avoid collecting gas emissions from the soil during installation. Again rocks, debris and larger vegetation was avoided. Deionized water was used in the frames to seal

463 off the chambers from ambient air. Gas chamber samples were collected with a gas-tight syringe

464 (1100TLL 100 mL Gastight, Hamilton, Reno, NV, USA) and directly transferred into evacuated $46512 \mathrm{~mL}$ exetainer vials ${ }^{67}$ until analyzed. The sampling was done every $5 \mathrm{~min}$ for a total period 466 of 30 mins in duplicates for palsa and front and in triplicates for bog. All gas samples from the 467 field and standard gases used for calibration were measured with a gas chromatograph (Hewlett 468 Packard, 5890 Series II) equipped with an electron capture detector ( $\left.{ }^{63} \mathrm{Ni}-\mathrm{ECD}\right)$. 
Sample collection. In July 2019, cores were taken along three palsa hillslopes (Figure S1 and Figure S7), gently collapsing into bog, following the expected hydrological flow described previously ${ }^{40}$. A Humax corer of $50 \mathrm{~cm}$ length and 3-cm diameter with inner liners was used to sample the active layer ${ }^{19}$. The cores for mineral analysis were directly split after sampling under $100 \% \mathrm{~N}_{2}$ atmosphere in a glove bag and subsamples stored at $-20^{\circ} \mathrm{C}$ until analysis. The cores

474 for microbial community analysis were split directly in the field, immediately frozen with liquid nitrogen and stored at $-80^{\circ} \mathrm{C}$ until further processing. As previously described ${ }^{19}$, the cores were split into three soil horizons based on texture and color changes: (1) A peat or organic horizon, followed by (2) a transition zone between the organic-rich and mineral-rich layer and (3) a 478 mineral horizon.

In July and September 2019, porewater samples were collected from 30 and $60 \mathrm{~cm}$ depth below 480 the peat surface along the palsa hillslope (8 transects, Figure S1 and Figure S4) using a luer 481 lock syringe connected to a lysimeter with an effective pore size of 2.5 microns (Simpler Luer482 Lock Micro Samplers, Model 1910LL, Soilmoisture Equipment Corp., Santa Barbara, CA). Prior to use, syringes and lysimeters were rinsed 10 times with $50 \mathrm{~mL}$ MiliQ water and air dried. Syringe filters $\left(0.22 \mu \mathrm{m}, \mathrm{PES}\right.$, Merck $^{\mathrm{TM}}$ Steritop $^{\mathrm{TM}}$, Millipore $)$ were pre-rinsed with 120 $\mathrm{mL}$ MilliQ water each to avoid leaching residuals of the filters. The syringes were flushed three times with $\mathrm{N}_{2}$ and sealed till further use. Syringe filters $(0.22 \mu \mathrm{m})$ were flushed three times with

$487 \quad \mathrm{~N}_{2}$ and placed into a SCHOTT bottle with $\mathrm{N}_{2}$ atmosphere till further use. The lysimeters were installed in the soil, pre-flushed by pulling porewater with a syringe and the first $2 \mathrm{~mL}$ 489 discharged. Immediately afterwards, the $\mathrm{N}_{2}$ flushed syringes were unsealed, nitrogen gas 490 pushed out, and then tightly connected to the installed lysimeter. To avoid direct sunlight exposure, syringes were covered with white cotton bags during the time of porewater extraction.

492 After 3-4 hours, the samples were filtered through a $0.22 \mu \mathrm{m}$ syringe filter into stoppered, $\mathrm{N}_{2}$ 
flushed glass vials, wrapped in aluminum foil to avoid any sunlight exposure. The first $1 \mathrm{~mL}$

494 filtrate from each sample was disposed. The samples were stored at $4^{\circ} \mathrm{C}$ till further analysis.

495 Selective iron and carbon extractions. To extract reactive Fe and associated OC, selective 496 dissolutions were conducted as described previously ${ }^{19}$. Briefly, a sodium bicarbonate (0.11 M) 497 sodium dithionite $(0.27 \mathrm{M})$ trisodium citrate $(0.27 \mathrm{M})$ solution was used to reductively dissolve 498 reactive $\mathrm{Fe}$ and associated organic carbon. As described in Lalonde et al. ${ }^{11}$, a sodium 499 bicarbonate $(0.11 \mathrm{M})$ sodium chloride $(1.85 \mathrm{M})$ solution was used as a control experiment to 500 distinguish between Fe and OC readily desorbed (leachable OC) and organic carbon associated 501 with reactive Fe and only dissolved during reductive dissolution with dithionite. The citrate background in the extract also needs to be subtracted to receive the reactive Fe-associated OC.

503 Thus, only the control corrected values are discussed:

Reactive Fe - associated OC

$$
=\text { DOC }(\text { dithionite citrate })-\text { DOC }(\text { blank citrate })-\text { DOC }(\text { sodium chloride })(2)
$$

507 For each soil horizon (organic horizon, transition zone, mineral horizon), $0.3 \mathrm{~g}$ dry soil was weighed into $10 \mathrm{~mL}$ glass vials with $6.25 \mathrm{~mL}$ extractant and $\mathrm{N}_{2}$ headspace. After 16 hours at room temperature on a rolling shaker, samples were centrifuged at room temperature for $10 \mathrm{~min}$ at $5300 \mathrm{~g}$. The supernatant was decanted and further analyzed for total Fe and DOC.

511 Geochemical analysis. To determine total $\mathrm{Fe}$ and $\mathrm{Fe}(\mathrm{II})$, porewater or extract was acidified in

$5121 \mathrm{M} \mathrm{HCl}$ and quantified spectrophotometrically in triplicates with the ferrozine assay ${ }^{68}$. DOC 513 was measured in triplicates with a total organic carbon analyzer (High TOC II, Elementar,

514 Elementar Analysensysteme GmbH, Germany). Inorganic carbon was removed by acidification with $2 \mathrm{M} \mathrm{HCl}$ addition prior to analysis. High performance liquid chromatography (HPLC; 
517 VP detectors; Shimadzu, Japan) was used to determine the fatty acid concentrations. To further

518 quantify other elements in the porewater (i.e. phosphorous and sulfur) the samples were

519 acidified in $1 \%(\mathrm{v} / \mathrm{v}) \mathrm{HNO}_{3}$ and analyzed in triplicates by inductively coupled plasma mass

520 spectrometry (ICP-MS/MS Agilent 8900). A flow injection analysis (FIA) instrument equipped

521 with a dialysis membrane for removal of Fe to prevent side reactions during measurement (Seal

522 Analytical, Germany) was applied for quantification of $\mathrm{NH}_{4}{ }^{+}, \mathrm{NO}_{3}{ }^{-}$and $\mathrm{NO}_{2}{ }^{-}$concentrations.

523 Correlative SEM and nanoSIMS analysis. The free particles of the fine fraction of each

524 organic horizon, transition zone and mineral horizon in cores Palsa A (referred to intact palsa),

525 Palsa B (referred to more collapsed palsa) and Front (referred to collapsing front) along the

526 palsa hillslope were analyzed using correlative SEM and nanoSIMS, as described

527 previously ${ }^{19,69,70}$. Briefly, subsamples of each layer $(1 \mathrm{mg})$ were dispersed in anoxic deionized

528 water and gently shaken to obtain the free organo-mineral particles. All larger particles and

529 aggregates were allowed to settle. A drop of $100 \mu 1$ of the suspension was placed on a silica

530 wafer and dried in an anoxic glovebox $\left(\mathrm{N}_{2}\right.$ atmosphere). Finally, samples were sputter-coated

531 with $\sim 30 \mathrm{~nm} \mathrm{Au/Pd}$ conductive layer using a Bal-Tec SCD005 sputter coater (Baltec GmbH,

532 Germany). To characterize the organo-mineral particles of the fine fraction by size and

533 crystallinity and identify representative particles, a field emission scanning electron microscope

534 (FE-SEM; Jeol JSM-6500F), equipped with secondary electron detector, was used prior to 535 nanoSIMS analysis. The acceleration voltage was set to $5 \mathrm{kV}$, with a working distance of 10

$536 \mathrm{~mm}$. The nanoSIMS analysis were performed at the Cameca nanoSIMS 50L of the Chair of

537 Soil Science (TU München, Germany). As described previously ${ }^{19}$, a primary ion beam ( 2 pA)

538 was set at a lateral resolution $\sim 100 \mathrm{~nm}$ and scanned over the samples with ${ }^{12} \mathrm{C}^{-},{ }^{16} \mathrm{O}^{-},{ }^{12} \mathrm{C}^{14} \mathrm{~N}^{-},{ }^{31} \mathrm{P}^{-}$ $539,{ }^{32} \mathrm{~S}^{-},{ }^{27} \mathrm{Al}^{16} \mathrm{O}^{-}$and ${ }^{56} \mathrm{Fe}^{16} \mathrm{O}^{-}$secondary ions collected using electron multipliers. 
541 Mössbauer spectroscopy. The soil samples for ${ }^{57} \mathrm{Fe}$ Mössbauer spectroscopy were collected 542 under the protection of $100 \% \mathrm{~N}_{2}$. Samples from three thaw stages were measured, including 543 Palsa A, Bog and Fen (both wetland cores obtained by a previous campaign see Patzner et al. ${ }^{19}$ ) 544 of transition zone and mineral horizon (Figure S16 and Table S7). The samples were dried 545 anoxically before loading into a Plexiglass holder. The prepared samples were stored anoxically 546 at $-20^{\circ} \mathrm{C}$ until measurement. Mössbauer spectroscopy was performed in a standard transmission setup (Wissel, Wissenschaftliche Elektronik $\mathrm{GmbH}$ ), and absorption spectra were collected at 77 and $6 \mathrm{~K}$ controlling with a closed-cycle cryostat (SHI-850-I, Janis Research Co). The spectra

549 were calibrated with $\alpha^{57} \mathrm{Fe}^{0}$ foil at $295 \mathrm{~K}$, and fitted using the Voigt Based Fitting (VBF) ${ }^{71}$ 550 routine in the Recoil software (University of Ottawa, Canada). Results are shown in the Figure S16 and Table S7.

TOC and TN analysis. As described previously ${ }^{19}$, total organic carbon (TOC) and total organic nitrogen (TN) were quantified by an Elementar vario El (Elementar Analaysysteme, GmbH,

554 Germany). Soil samples were dried at $60^{\circ} \mathrm{C}$ until no further weight loss was observed. The dried soils were ground and acidified with $16 \% \mathrm{HCl}$ to remove the inorganic carbon. After washing with deionized water, followed by drying, the TOC and TN content was analyzed. Results of $557 \mathrm{C} / \mathrm{N}$ ratios are shown in the SI (Figure S10).

Microbial community analysis. Total RNA and DNA was extracted using the PowerSoil ${ }^{\circ}$ RNA and DNA isolation kit as described by the manufacturer (MO BIO Laboratories, Carlsbad,

560 CA, USA), with the following modifications: $2-3 \mathrm{~g}$ of soil was used from each soil horizon; 10 561 min bead-beating; centrifugation steps at maximal speed $(7000 \times \mathrm{g})$ at $4^{\circ} \mathrm{C}$; and longer 562 incubation times at $-20^{\circ} \mathrm{C}(1.5 \mathrm{~h})$. RNA and DNA were eluted in $50 \mu 1 \mathrm{RNase} / \mathrm{DNase}-\mathrm{Free}$ 563 water. RNA and DNA concentrations were determined using a Qubit ${ }^{2}$ 2.0 Fluorometer with 564 RNA and DNA HS kits (Life Technologies, Carlsbad, CA, USA). Subsequent DNA digestion 
and reverse transcription reactions were performed using a Reverse Transcriptase (Invitrogen,

566 Life Technologies) as described previously by Otte et al., 2018 ${ }^{48}$. Quantitative PCR (qPCR)

567 specific for the $16 \mathrm{~S}$ rRNA (gene) of bacteria and archaea was performed as described 568 previously $^{48}$. Microbial $16 \mathrm{~S}$ rRNA (genes) were amplified using primers $515 \mathrm{~F}$ and $806 \mathrm{R}^{72}$. 569 Quality and quantity of the purified amplicons were determined using agarose gel 570 electrophoresis and Nanodrop (NanoDrop 1000, Thermo Scientific, Waltham, MA, USA). 571 Subsequent library preparation steps (Nextera, Illumina) and sequencing were performed by 572 Microsynth AG (Switzerland) using the $2 \times 250 \mathrm{bp}$ MiSeq Reagent Kit v2 on an Illumina MiSeq 573 sequencing system (Illumina, San Diego, CA, USA). From 10,112 to 396,483 (average $574113,374)$ read pairs were generated per sample in three separate sequencing runs on the same 575 MiSeq machine, resulting in total in 8.6 million read pairs. Quality control, reconstruction of 576 16S rRNA (gene) sequences and taxonomic annotation was performed with nf-core/ampliseq v1.1.2 $2^{73,74}$ with Nextflow v20.10.075 using containerized software with singularity v3.4. $2^{76}$. Data

578 from the three sequencing runs were treated initially separately by the pipeline using the option 579 "mulipleSequencingRuns" and ASV tables were merged. Primers were trimmed, and 580 untrimmed sequences were discarded $(<25 \%$, on average $7.7 \%)$ with Cutadapt v2.677. Adapter and primer-free sequences were imported into QIIME2 version 2019.10.078, processed with DADA2 version $1.10 .0^{79}$ to eliminate PhiX contamination, trim reads (before the median 583 quality drops below 35, i.e. position 230 in forward reads and 174 in reverse reads), correct 584 errors, merge read pairs, and remove PCR chimeras; ultimately, in total 9,576 amplicon 585 sequencing variants (ASVs) were obtained across all samples. Alpha rarefaction curves were produced with the QIIME2 diversity alpha-rarefaction plugin, which indicated that the richness

587 of the samples had been fully observed. A Naive Bayes classifier was fitted with 16S rRNA

588 (gene) sequences extracted with the PCR primer sequences from the QIIME compatible, 99\%589 identity clustered SILVA v132 database ${ }^{80}$. ASVs were classified by taxon using the fitted 
classifier $^{81} .225$ ASVs that classified as chloroplasts or mitochondria were removed, totalling to $<7 \%$ (average $0.6 \%$ ) relative abundance per sample, and the remaining 9,351 ASVs had their abundances extracted by feature-table (https://github.com/qiime2/q2-feature-table).

Pathways, i.e. MetaCyc ontology predictions, were inferred with PICRUSt2 version 2.2.0-b (Phylogenetic Investigation of Communities by Reconstruction of Unobserved States) ${ }^{82}$ and MinPath (Minimal set of Pathways) $)^{83}$ using ASVs and their abundance counts. Inferring metabolic pathways from 16S rRNA amplicon sequencing data is certainly not as accurate as measuring genes by shotgun metagenomics, but it yields helpful approximations to support hypotheses driven by additional microbiological and biogeochemical analyses ${ }^{82}$.

599 FT-ICR-MS analysis. Soil extracts and DOM in the porewater were analyzed with FT-ICR 600 MS to identify and monitor compositional changes in the mineral-associated organic carbon 601 fraction and the mobile, DOC fraction. All of the samples were prepared for FT-ICR-MS 602 analysis by solid phase extraction (SPE) under $\mathrm{N}_{2}$ atmosphere (glove bag) following the 603 procedure described by Dittmar et al., $2008^{84}$ and Li et al., $2016^{85}$ with some modifications. In 604 brief, $1 \mathrm{~g}, 3 \mathrm{~mL}$ Bond Elut PPL cartridges (part\#12102148, Aglient Technologies, Santa Clara, 605 CA, USA) were conditioned with $5 \mathrm{~mL}$ of HPLC grade methanol (Simga-Aldrich, Rehovot, 606 Israel), followed by $5 \mathrm{~mL}$ of $0.01 \mathrm{M} \mathrm{HCl}$. Each sample was acidified to $\mathrm{pH} \sim 2.5$ and then loaded 607 onto the SPE columns, loading volume was adjusted to load a total of $0.5 \mathrm{mg} \mathrm{C}$ based on the 608 TOC content. After sample loading, the SPE cartridges were rinsed with $5 \mathrm{~mL}$ of $0.01 \mathrm{M} \mathrm{HCl}$ 609 followed by drying with $\mathrm{N}_{2}$ for 3-5 mins. Finally, the samples were eluted with $1 \mathrm{~mL}$ of HPLC 610 grade methanol and stored in airtight amber sample vials wrapped in aluminum foil at $4^{\circ} \mathrm{C}$.

611 There was no additional dilution of the samples performed prior to analysis by negative ion 612 electrospray ionization. 
613 The samples were analyzed with a custom-built FT-ICR mass spectrometer, equipped with a

614 21T superconducting solenoid magnet and a modular software package for data acquisition

615 (Predator) $^{86}$. Sample solution was infused via a microelectrospray source ${ }^{87}$ (50 $\mu \mathrm{m}$ i.d. fused

616 silica emitter) at $500 \mathrm{~nL} / \mathrm{min}$ by a syringe pump. Typical conditions for negative ion formation

617 were: emitter voltage, $-3.0 \mathrm{kV}$; S-lens RF level, 45\%; and heated metal capillary temperature,

$618350{ }^{\circ} \mathrm{C}$. Ions were initially accumulated in an external multipole ion guide (1-5 ms) and released

$619 \mathrm{~m} / \mathrm{z}$-dependently ${ }^{88}$. Ions were excited to $\mathrm{m} / \mathrm{z}$-dependent radius to maximize the dynamic range

620 and number of observed mass spectral peaks $(32-64 \%)^{89}$, and excitation and detection were

621 performed on the same pair of electrodes ${ }^{90}$. The dynamically harmonized ICR cell in the $21 \mathrm{~T}$

622 FT-ICR is operated with $6 \mathrm{~V}$ trapping potential ${ }^{11,92}$. Time-domain transients (100 time-domain

623 acquisitions for all experiments) of 3.1 seconds were acquired with the Predator data station

624 that handled excitation and detection only, initiated by a TTL trigger from the commercial

625 Thermo data station ${ }^{93}$. Mass spectra were phase-corrected ${ }^{94}$ and internally calibrated with 10 -

62615 highly abundant homologous series that span the entire molecular weight distribution $(\sim 150$

627 to $1300 \mathrm{~m} / \mathrm{z}$ ) based on the "walking" calibration method ${ }^{95}$. Experimentally measured masses

628 were converted from the International Union of Pure and Applied Chemistry (IUPAC) mass

629 scale to the Kendrick mass scale ${ }^{96}$ for rapid identification of homologous series for each

630 heteroatom class $^{97}$. Peaks with signal to noise ratios greater than 6 times the noise at the baseline

631 root-mean-square (rms) noise at $\mathrm{m} / \mathrm{z}, 500$ were exported to custom software (PetroOrg@) for

632 additional formula and elemental composition assignment ${ }^{98}$. All assigned formulas were part of

$633 \mathrm{a} \geq 3$ peak carbon series and had less than $\pm 0.3 \mathrm{ppm}$ mass error. A LOD of $6 \sigma$ was considered

634 sufficient to minimize ionization difference effects between samples, and therefore biasing by

635 large numbers of low abundance peaks. To further identify macro compositional shifts, analysis

636 of differences between samples was performed only on peaks with $\geq 20 \%$ difference in relative

637 abundance. Additionally, modified aromaticity index (ModAl) was calculated according to 
638 Koch \&Dittmar $^{84}$ and nominal oxidation state of carbon (NOSC) was calculated according to La

639 Rowe\&Van Cappellen ${ }^{99}$. Data processing post formula assignment was performed with 640 RStudio utilizing R software (V4.0.3).

641 Statistical analysis. The geochemical parameters were checked with the test of homogeneity.

642 Then a one-way analysis of variance (ANOVA) was used to identify differences in the

643 geochemical parameters along the palsa hillslope, combined with a post-hoc test to identify

644 significant differences between the different sampling spots along the palsa hillslope (from 645 palsa to collapsing front to bog). Based on Gloor et al..$^{100}$ no statistical analysis (such as e.g. 646 one-way ANOVA or unpaired t-test) were chosen for the compositional data obtained by $16 \mathrm{~S}$

647 rRNA Amplicon (gene) sequencing. 
650 The data that support the finding of this study are included in a compressed Source Data file at 651 Zenodo (doi link will be included after acceptance of the manuscript) and raw sequencing data 652 was deposited at the Sequence Reads Archive (SRA, reviewer link included 653 https://www.ncbi.nlm.nih.gov/bioproject/PRJNA725216, final link will be included after 654 acceptance of the manuscript). All FT-ICR MS data (raw files and calibrated peak lists) are 655 available at the Open Science Framework (link will be included after acceptance of the 656 manuscript). Other data are included in the Supplementary Information. Pre-processed data are 657 available upon request. 


\section{AUTHOR INFORMATION:}

\section{Corresponding author:}

660 e-mail: casey.bryce@bristol.ac.uk

\section{Author Contributions:}

662 The original hypothesis was formulated by M.S.P., C.B. and A.K. M.S.P, C.B. and A.K. 663 designed the project, interpreted the data and wrote the manuscript. M.S.P, C.B. and M.L. 664 collected the samples. M.S.P and M.L gathered the data presented in the main text. A.M. 665 conducted the FT-ICR-MS measurements and contributed to the data interpretation. T.B. and 666 R.Y. contributed to the data analysis and interpretation. Z.Z. performed the Mössbauer 667 spectroscopy and helped interpreting the results. H. J helped collecting the porewater samples 668 and data interpretation. C.H. and C.W.M., together with M.S.P., collected, analyzed and 669 interpreted the nanoSIMS data. D.S. processed the amplicon sequencing data and, together with

670 S.K., helped with interpretation of the microbial community results. T.S. contributed to project 671 design and data interpretation. All authors contributed to the preparation of the manuscript and 672 have given approval to the final version of the manuscript.

\section{Notes:}

674 The authors declare no competing interests.

\section{ACKNOWLEDGEMENTS:}

676 We are grateful for assistance in field work and sampling by Sara Anthony and the Arctic

677 Research station (Abisko Sweden), especially thankful to Jennie Wikström, Eric Lundin, Niklas

678 Rakos and Alexander Meire. We are thankful to Mette Svenning (Arctic University of Norway,

679 Tromsø, Norway) for providing the gas chambers with the plastic lids. We thank EOSENSE 
680 INC, Dartmouth, Canada for getting the chance to use the EOSENSE gas chambers for our 681 research. We thank Miroslava Malusova and Katrin Wunsch for assistance in the lab, Timm 682 Bayer for his help during SEM analysis and Johann Lugmeier for assistance during nanoSIMS 683 analysis. The authors acknowledge infrastructural support by the Deutsche 684 Forschungsgemeinschaft (DFG, German Research Foundation) under Germany's Excellence 685 Strategy, cluster of Excellence EXC2124, project ID 390838134. This work was supported by 686 the University of Tuebingen (Programme for the Promotion of Junior Researchers award to 687 Casey Bryce) and by the German Academic Scholarship Foundation (scholarship to Monique 688 Patzner). S.K. is funded by an Emmy-Noether fellowship from the DFG (grant number 689 326028733). D.S was funded by the Institutional Strategy of the University of Tuebingen (DFG, 690 ZUK63). The National High Magnetic Field Laboratory is supported by the National Science 691 Foundation Divisions of Chemistry and Materials Research through DMR-1644779, Florida 692 State University, and the State of Florida.

693 
6951 Ping, C. L., Jastrow, J. D., Jorgenson, M. T., Michaelson, G. J., Shur, Y. L. Permafrost 696 soils and carbon cycling Soil 1, 147-171 (2015).

6972 Schuur, E. A. G. et al. Climate change and the permafrost carbon feedback. Nature 520, 698 171-179(2015).

6993 Hugelius, G. et al. Estimated stocks of circumpolar permafrost carbon with quantified 700 uncertainty ranges identified data gaps. Biogeosciences 11, 6573-6593 (2014).

701

4 Nowinski, N., Taneva, L., Trumbore, S., Welker, J. Decomposition of old organic 702 matter as a result of deeper active layers in a snow depth manipulation experiment. Oecologia 163, 785-792 (2010).

704 Vonk, J. E., Mann, P. J., Davydov, S., Davydova, A., Spencer, R. G. M., Schade, J. 705 High biolability of ancient permafrost carbon upon thaw. Geophys Res Lett 40, 26892693 (2013).

Henkner, J., Scholten, T., Kühn, P. Soil organic carbon stocks in permafrost-affected soils in West Greenland. Geoderma 282, 147-159 (2016).

7 Hemingway, J. D., Rothman, D.H., Grant, K.E., Rosengard, S.Z., Eglinton, T.I., Derry, 710 L.A., Galy, V.V. Mineral protection regulates long-term global preservation of natural organic carbon. Nature 570, 228-231 (2019). Kleber, M., Mikutta, R., Torn, M. S., Jahn, R. Poorly crystalline mineral phases protect organic matter in acid subsoil horizons. Eur J Soil Sci 56, 717-725 (2005). Baldock, J. A., Skjemstad, J.O. Role of soil matrix and minerals in protecting natural organic materials against biological attack. Org Geochem 31, 697-710 (2000). Kleber, M. et al. Mineral-Organic Associations: Formation, Properties, and Relevance

71811 Lalonde, K., Mucci, A., Ouellet, A., Gelinas, Y. Preservation of organic matter in sediments promoted by iron. Nature 483, 198-200 (2012).

12 Wagai, R., Mayer, L. M., Kitayama, K., Shirato, Y. Association of organic matter with iron and aluminum across a range of soils determined via selective dissolution techniques coupled with dissolved nitrogen analysis. Biogeochemistry 112, 95-109 (2013). 
72413 Kogel-Knabner, I. et al. Organo-mineral associations in temperate soils: Integrating biology, mineralogy, and organic matter chemistry. J Plant Nutr Soil Sc 171, 61-82 (2008).

14 Lipson, D. A., Jha, M., Raab, T. K., Oechel, W. C. Reduction of iron (III) and humic substances plays a major role in anaerobic respiration in an Arctic peat soil. J Geophys Res-Biogeo 115, G00I06 (2010).

15 Lovely, D. R., Phillips, E. J. Novel mode of microbial energy metabolism: organic carbon oxidation coupled to dissimiliatory reduction of iron or mangenese. Appl Environl Microbiol 57, 1536-1540 (1988).

Asano, M. \& Wagai, R. Evidence of aggregate hierarchy at micro- to submicron scales in an allophanic Andisol. Geoderma 216, 62-74005 (2014).

Totsche, K. U. et al. Microaggregates in soils. J Plant Nutr Soil Sc 181, 104-136 (2018). of organic matter accumulation in tropical soils. Geoderma 306, 206-216 (2017).

19 Patzner, M. S. et al. Iron mineral dissolution releases iron and associated organic carbon during permafrost thaw. Nat Commun 11, 6329 (2020).

$20 \mathrm{Mu}, \mathrm{C}$. C. et al. Soil organic carbon stabilization by iron in permafrost regions of the Qinghai-Tibet Plateau. Geophys Res Lett 43, 10286-10294 (2016).

21 Shelef, E., Rowland, J.C., Wilson, C.J., Hilley, G.E., Mishra, U., Altmann, G.L., Ping, C.L. Large uncertainity in permafrost carbon stocks due to hillslope soil deposits. Geophys Res Lett 44, 6134-6144 (2017).

22 Perryman, C. K. M. et al. Thaw Transitions and Redox Conditions Drive Methane Oxidation in a Permafrost Peatland. J Geophys Res-Biogeo 125 (2020).

23 Kappler, A., Bryce, C., Mansor, M., Lueder, U., Byrne, J.M., Swanner, E. An evolving view on biogeochemical cycling of iron. Nat Rev Microbiol (2021). methanogenesis by ferric iron. FEMS Microbiol Ecol 49, 261-268 (2004). pH correspond to methane production in Arctic Alaska soils. Method Enzymol 19, 33983410 (2017). natural organic materials against biological attack. Org Geochem 31, 697-7102000). 
75627 Christensen, B. T. Physical fractionation of soil and structural and functional 757 complexity in organic matter turnover. Eur J Soil Sci 52, 345-353 (2001).

75828 Sanderman, J., Maddern, T., Baldock, J. Similar composition but differential stability 759 of mineral retained organic matter across four classes of clay minerals. Biogeochemistry $760 \quad \mathbf{1 2 1}, 409-424(2014)$.

76129 Six, J. et al. Sources and composition of soil organic matter fractions between and $762 \quad$ within soil aggregates. Eur J Soil Sci 52, 607-618 (2001).

76330 Daugherty, E. E. et al. Hydrogeomorphic controls on soil carbon composition in two 764 classes of subalpine wetlands. Biogeochemistry 145, 161-175 (2019).

Crump, B., Kling, G., Bahr, M., Hobbie, J. Bacterioplankton community shifts in arctic lake corrleate with seasonal changes in organic matter sources. Appl Environ Microbiol 69, 2253-2268 (2003).

Judd, K. E., Crump, B.C., Kling, G.W. Variation in dissolved organic matter controls bacterial production and community composition. Ecology 87, 2068-2079 (2006). organic matter by mineral soils of the Siberian forest tundra. Global Change Biol 12, 1868-1877 (2006).

$77837 \quad$ McCalley, C. K. et al. Methane dynamics regulated by microbial community response to permafrost thaw. Nature 514, 478-481 (2014).

Mondav, R. et al. Discovery of a novel methanogen prevalent in thawing permafrost. Nat Commun 5, 3212 (2014).

Singelton, C. M et al. Methanotrophy across a natural permafrost thaw environment. The ISME Journal 12, 2544-2558 (2018).

Olefeldt, D. \& Roulet, N. T. Effects of permafrost and hydrology on the composition and transport of dissolved organic carbon in a subarctic peatland complex. J Geophys Res-Biogeo 117, G01005 (2012). 
41 Tang, J. et al. Drivers of dissolved organic carbon export in a subarctic catchment: Importance of microbial decomposition, sorption-desorption, peatland and lateral flow Sci Total Environ 622-623, 260-274 (2018).

Lynch, L. M. et al. Dissolved organic matter chemistry and transport along an Arctic tundra hillslope. Global Biogeochem Cy 33, 47-62 (2019).

Lipson, D. A., Raab, T.K., Goria, D., Zlamal, J. The contribution of Fe(III) and humic acid reduction to ecosystem respiration in drained thaw lake basins of the Arcitc Coastal Plain. Global Biogeochem Cy 27, 399-409 (2013).

44 Hodgkins, S. B. et al. Changes in peat chemistry associated with permafrost thaw increase greenhouse gas production. P Natl Acad Sci USA 111, 5819-5824 (2014). fluxes and net radiative forcing. Global Change Biol 12, 2352-2369 (2006). permafrost. Nature 560, 49-54 (2018).

802

803

Pallud, C., Rhoades, C. C., Schneider, L., Dwivedi, P., Borch, T. Temperature-induced iron (III) reduction results in decreased dissolved organic carbon export in subalpine wetland soils, Colorado, USA. Geochim Cosmochim Ac 280, 148-160 (2020).

806 Otte, J. M. et al. The distribution of active iron-cycling bacteria in marine and freshwater sediments is decoupled from geochemical gradients. Method Enzymol 20, 2483-2499 (2018).

Weber, K. A., Achenbach, L. A., Coates, J. D. Microorganisms pumping iron: anaerobic

80950 Emerson, D., Scott, J. J., Benes, J., Bowden, W. B. Microbial iron oxidation in the Arctic tundra and its implications for biogeochemical cycling. Appl Environ Microbiol 81,

81251 Loh, H. Q., Hervé, V., Brune, A. Metabolic potential for reductive acetogenesis and a 813 novel energy-converting [NiFe] Hydrogenase in Bathyarchaeia from termite guts - a 814 genome-centric analysis. Front Microbiol 11, 635786 (2021).

81552 Tfaily, M. M.. Advanced solvent based methods for molecular characterization of soil 816 organic matter by high-resolution mass spectrometry. Anal Chem 87, 5026-5215 (2015).

81753 Tfaily, M. M. et al. Sequential extraction protocol for organic matter from soils and 818 sediments using high resolution mass spectrometry. Anal. Chim. Acta 972, 54-61 819 (2017). 
82054 McLafferty, F. W., Choi, J., Tureček, F. \& Turecek, F. Interpretation Of Mass Spectra. 821 University Science Books, ISBN 0-935702-25-3 (1993).

82255 AminiTabrizi, R. et al. Controls on soil organic matter degradation and subsequent 823 greenhouse gas emissions across a permafrost thaw gradient in Northern Sweden. $824 \quad$ Frontiers in Earth Science 8, 557961 (2020).

82556 Ward, P. C., Cory, R. M. Chemical composition of dissolved organic matter draining 826 permafrost soils. Geochim Cosmochim Ac 167, 63-67 (2015).

82757 Kaiser, K., Kalbitz, K. Cycling downwards - dissolved organic matter in soils. Soil Biol 828

82958 Fuchs, G., Boll, M., Heider, J. Microbial degradation of aromatic compounds - From $830 \quad$ one strategy to four. Nat Rev Microbiol 9, 803-816 (2011).

83159 Abbott, B. W., Larouche, J. R., Jones, J. B., Bowden, W. B., Balser, A. W. Elevated 832 dissolved organic carbon biodegradability from thawing and collapsing permafrost. $J$ 833 Geophys Res 119, 2049-2063 (2014).

83460 Mann, P. J., Davydova, A., Zimov, N., Spencer, R.G.M., Davydov, S., Bulygina, E., 835 Zimov, S., Holmes, R.M. Controls on the composition and lability of dissolved organic 836 matter in Siberia’s Kolyma River basin. J Geophys Res 117 (2012).

83761 When permafrost thaws. Nat Geosci 13, 765 (2020).

83862 Turetsky, M. R. et al. Carbon release through abrupt permafrost thaw. Nat Geosci 13, 839 138-143(2020).

84063 Malmer, N., Johansson, T., Olsrud, M., Christensen, T. R. Vegetation, climatic changes 841 and net carbon sequestration in a North-Scandinavian subarctic mire over 30 years. 842 Global Change Biol 11, 1895-1909 (2005).

84364 Fronzek, S., Carter, T. R., Raisanen, J., Ruokolainen, L., Luoto, M. Applying 844 probabilistic projections of climate change with impact models: a case study for sub845 arctic palsa mires in Fennoscandia. Climatic Change 99, 515-534 (2010).

84665 Parviainen, M., Luoto, M. Climate envelopes of mire complex types in Fennoscandia. 847 Geogr Ann A 89a, 137-151 (2007).

84866 Liebner, S. et al. Shifts in methanogenic community composition and methane fluxes 849 along the degradation of discontinuous permafrost. Front Microbiol 6, 356 (2015).

85067 Glatzel, S., Well, R. Evaluation of septum-capped vials for storage of gas samples 851 during air transport. Environ Monit Assess 136, 307-311 (2008). 
85268 Stookey, L. L. Ferrozine - a New Spectrophotometric Reagent for Iron. Anal Chem 42, 853 779-781 (1970).

85469 Kopittke, P. M. et al. Nitrogen-rich microbial products provide new organo-mineral 855 associations for the stabilization of soil organic matter. Global Change Biol 24, 1762$8561770(2018)$.

85770 Keiluweit, M. et al. Nano-scale investigation of the association of microbial nitrogen 858 residues with iron (hydr)oxides in a forest soil O-horizon. Geochim Cosmochim Ac 95, 859 213-226 (2012).

86071 Rancourt, D. G., Ping, J.Y. Voigt-based methods for arbitrary-shape static hyperfine 861 parameter distributions in Mössbauer spectroscopy. Nucl Instrum Methods Phys Res $862 \quad$ Sect B 58, 85-97 (1991).

86372 Caporaso, J. G. et al. QIIME allows analysis of high-throughput community sequencing 864 data. Nat Methods 7, 335-336 (2010).

86573 Ewels, P. A. et al. The nf-core framework for community-curated bioinformatics 866 pipelines. Nat Biotechnol 38, 276-278 (2020).

86774 Straub, D. et al. Interpretations of environmental microbial community studies are 868 biased by the selected 16S rRNA (gene) amplicon sequencing pipeline. Front Microbiol $869 \quad \mathbf{1 1}, 550420(2020)$.

87075 Di Tommaso, P. et al. Nextflow enables reproducible computational workflows. Nat $871 \quad$ Biotechnol 35, 316-319 (2017).

87276 Kurtzer, G. M., Sochat, V., Bauer, M. W. Singularity: Scientific containers for mobility 873 of compute. PLoS One 12, e0177459 (2017).

87477 Martin, M. Cutadapt removes adapter sequences from high-throughput sequencing 875 reads. EMBnet journal 17, 3 (2011).

87678 Bolyen, E. et al. Reproducible, interactive, scalable and extensible microbiome data 877 science using QIIME 2. Nat Biotechnol 37, 852-857 (2019).

87879 Callahan, B. J.et al. DADA2: High-resolution sample inference from Illumina amplicon 879 data. Nat Methods 13, 581-583 (2016).

$88080 \quad$ Pruesse, E. et al. SILVA: a comprehensive online resource for quality checked and 881 aligned ribosomal RNA sequence data compatible with ARB. Nucleic Acids Res 35, $882 \quad$ 7188-7196 (2007).

88381 Bokulich, N. A. et al. Optimizing taxonomic classification of marker-gene amplicon 884 sequences with QIIME 2's q2-feature-classifier plugin. Microbiome 6, 90 (2018). 
88582 Langille, M. G. I. et al. Predictive functional profiling of microbial communities using 886 16S rRNA marker gene sequences. Nat Biotechnol 31, 814-821 (2013).

88783 Ye, Y., Doak, T.G. A Parsimony Approach to Biological Pathway 888 Reconstruction/Inference for Genomes and Metagenomes. PLoS Comput. Biol. 5, $889 \quad$ e1000465 (2009).

89084 Dittmar, T., Koch, B., Hertkorn, N., Kattner, G. A simple and efficient method for the 891 solid-phase extraction of dissolved organic matter (SPE-DOM) from seawater. Limnol 892 Oceanogr-Meth 6, 230-235 (2008).

89385 Li, Y. et al. Proposed Guidelines for Solid Phase Extraction of Suwannee River 894 Dissolved Organic Matter. Anal Chem 88, 6680-6688 (2016).

89586 Blakney, G. T., Hendrickson, C. L., Marshall, A. G. Predator data station: A fast data 896 acquisition system for advanced FT-ICR MS experiments. Int J Mass Spectrom 306, 897 246-252 (2011).

89887 Emmett, M. R., White, F. M., Hendrickson, C. L., Shi, S. D.-H., Marshall, A. G. 899 Application of micro-electrospray liquid chromatography techniques to FT-ICR MS to 900 enable high-sensitivity biological analysis. J Am Soc Mass Spectrom 9, 333-340 (1998).

90188 Kaiser, N. K., Savory, J. J., Hendrickson, C. L. Controlled ion ejection from an external 902 trap for extended $m / z$ range in FT-ICR mass spectrometry. J Am Soc Mass Spectrom 25, 903 943-949 (2014).

90489 Kaiser, N. K., McKenna, A. M., Savory, J. J., Hendrickson, C. L., Marshall, A. G. 905 Tailored ion radius distribution for increased dynamic range in FT-ICR mass analysis 906 of complex mixtures. Anal Chem 85, 265-272 (2013).

90790 Chen, T., Beu, S. C., Kaiser, N. K., Hendrickson, C. L. Note: Optimized circuit for 908 excitation and detection with one pair of electrodes for improved Fourier transform ion 909 cyclotron resonance mass spectrometry. Rev Sci Instrum 85, 066107 (2014).

91091 Boldin, I. A. \& Nikolaev, E. N. Fourier transform ion cyclotron resonance cell with 911 dynamic harmonization of the electric field in the whole volume by shaping of the 912 excitation and detection electrode assembly. Rapid Commun Mass Spectrom 25, 122$913126(2011)$.

91492 Kaiser, N. K., Quinn, J. P., Blakney, G. T., Hendrickson, C. L., Marshall, A. G. A Novel 9159.4 Tesla FT ICR mass spectrometer with improved sensitivity, mass resolution, and 916 mass range. J Am Soc Mass Spectrom 22, 1343-1351 (2011). 
91793 Blakney, G. T., Hendrickson, C. L., Marshall, A. G. Predator data station: A fast data 918 acquisition system for advanced FT-ICR MS experiments. Int J Mass Spectrom 306, 919 246-252 (2011).

92094 Xian, F., Hendrickson, C. L., Blakney, G. T., Beu, S. C. \& Marshall, A. G. Automated 921 Broadband Phase Correction of Fourier Transform Ion Cyclotron Resonance Mass 922 Spectra. Anal Chem 82, 8807-8812 (2010).

92395 Savory, J. J. et al. Parts-Per-Billion Fourier transform ion cyclotron resonance mass 924 measurement accuracy with a "Walking" calibration equation. Anal Chem 83, 1732$9251736(2011)$.

92696 Kendrick, E. A mass scale based on $\mathrm{CH}_{2}=14.0000$ for high resolution mass 927 spectrometry of organic compounds. Anal Chem 35, 2146-2154 (1963).

92897 Hughey, C. A., Hendrickson, C. L., Rodgers, R. P., Marshall, A. G., Qian, K. N. 929 Kendrick mass defect spectrum: A compact visual analysis for ultrahigh-resolution $930 \quad$ broadband mass spectra. Anal Chem 73, 4676-4681 (2001).

93198 Corilo, Y. E. The Florida State University: Tallahassee, Fl, USA. PetroOrg (2012).

93299 LaRowe, D. E. \& Van Cappellen, P. Degradation of natural organic matter: A 933 thermodynamic analysis. Geochim Cosmochim Ac 75, 2030-2042 (2011).

934100 Gloor, G. B., Macklaim, J. M., Pawlowsky-Glahn, V., Egozcue, J. J. Microbiome 935 Datasets are compositional: and this is not optional Front Microbiol 8, 2224 (2017). 936 
Supplementary Information for

937

938

939

\section{Microbial iron(III) reduction during palsa collapse promotes greenhouse} gas emissions before complete permafrost thaw

Monique S. Patzner'1, Merritt Logan², Amy M. McKenna ${ }^{3}$, Robert B. Young ${ }^{2}$, Zhe Zhou ${ }^{1,4}$, Hanna Joss ${ }^{1}$, Carsten W. Mueller ${ }^{5,6}$, Carmen Hoeschen ${ }^{5}$, Thomas Scholten ${ }^{7}$, Daniel Straub $^{8,9}$, Sara Kleindienst ${ }^{8}$, Thomas Borch ${ }^{2}$, Andreas Kappler ${ }^{1,11}$ \& Casey Bryce ${ }^{1,12 *}$

${ }^{1}$ Geomicrobiology, Center for Applied Geosciences, University of Tuebingen, Schnarrenbergstrasse 94-96, 72076 Tuebingen, Germany.

${ }^{2}$ Department of Soil \& Crop Sciences and Department of Chemistry, Colorado State University, 307 University Ave, 80523-1170 Fort Collins, US.

${ }^{3}$ National High Magnetic Field Laboratory, Florida State University, Tallahassee, FL 323104005, US.

${ }^{4}$ Alfred-Wegener-Institute, Helmholtz Centre for Polar and Marine Research, Am Handelshafen 12, 27570 Bremerhaven, Germany

${ }^{5}$ Chair of Soil Science, TUM School of Life Sciences, Technical University of Munich, EmilRamann Strasse 2, 85354 Freising, Germany.

${ }^{6}$ Department of Geosciences and Natural Resource Management, University of Copenhagen, Øster Voldgade 10, 1350 Copenhagen, Denmark.

${ }^{7}$ Chair of Soil Science and Geomorphology, Rümelinstraße 19-23, 72070 Tübingen, University of Tuebingen, Germany.

${ }^{8}$ Microbial Ecology, Center for Applied Geosciences, University Tuebingen, Schnarrenbergstrasse 94-96, 72076 Tuebingen, Germany.

${ }^{9}$ Quantitative Biology Center (QBiC), University Tuebingen, Auf der Morgenstelle 10, 72076 Tuebingen, Germany. 
${ }^{11}$ Cluster of Excellence: EXC 2124: Controlling Microbes to Fight Infection, Tübingen, Germany.

${ }^{12}$ School of Earth Sciences, University of Bristol, Wills Memorial Building, Queens Road Bristol BS8 1RJ, UK.

*Corresponding Author: Casey Bryce 


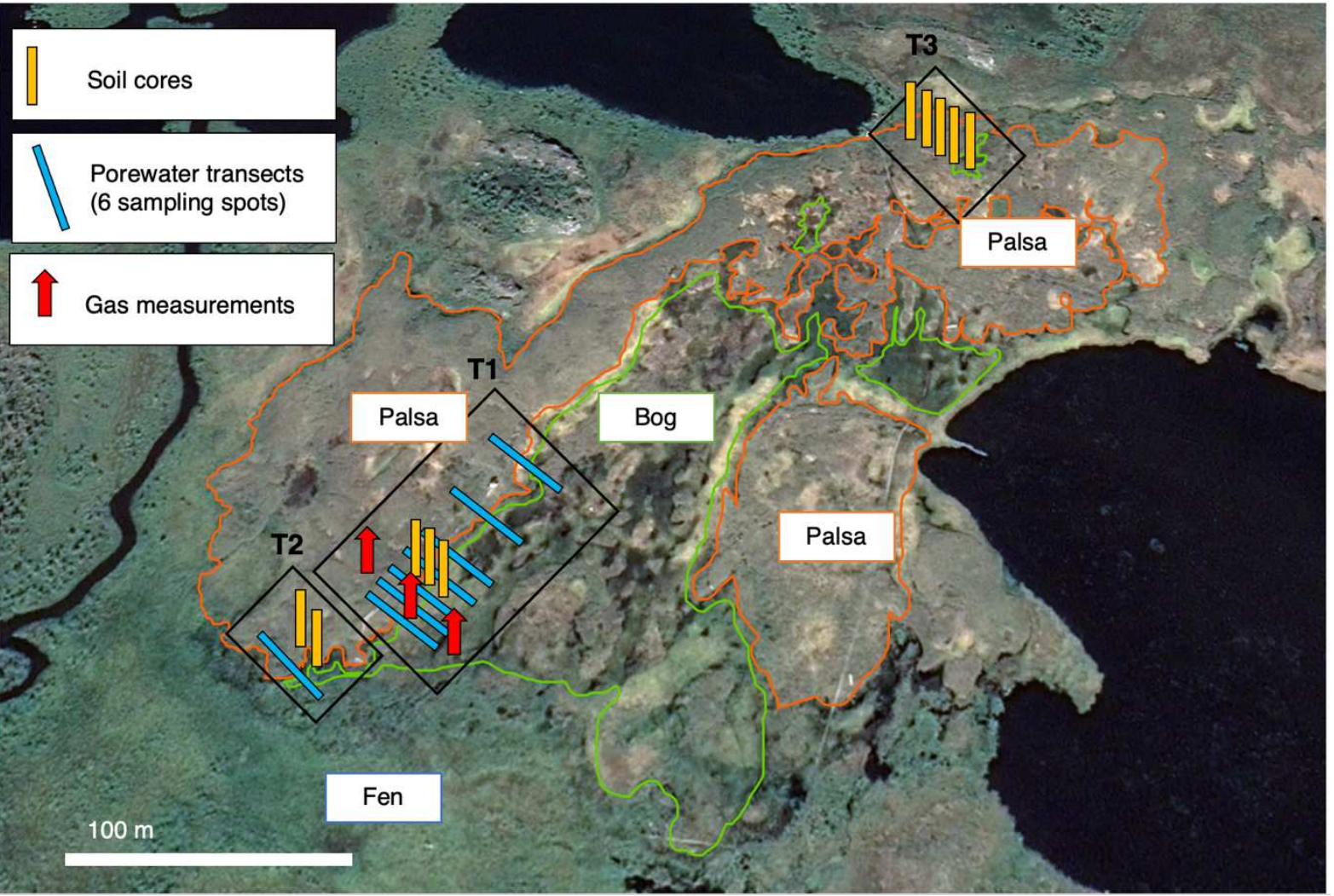

940

941

942 Figure S1. Field site and sample collection. Soil cores (yellow), porewater samples (blue) and 943 gas samples (red) were taken in three transects (T1, T2 and T3) along palsa hillslopes into bog

944 at Stordalen mire, Abisko (Sweden). Background picture was taken by GoogleEarth in 2019. 


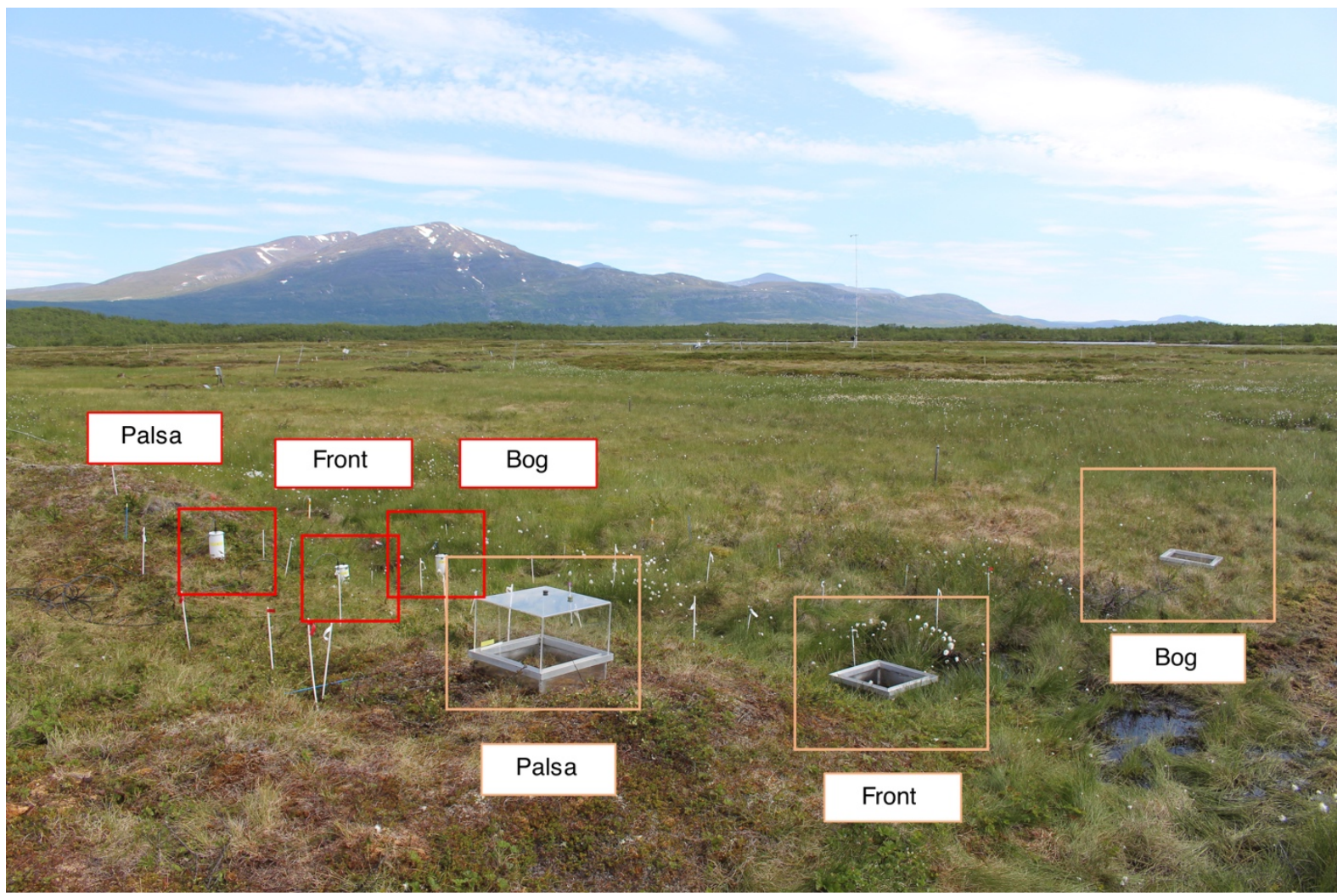

948 Figure S2. Gas sampling along palsa hillslopes. In transect 1 (see also Figure S1), Eosense 949 gas chambers (eosFD Forced Diffusion chamber in conjunction with the eosLink-FD software, 950 EOSENSE INC, Dartmouth, Canada) (red) were installed to measure carbon dioxide emissions 951 along the palsa hillslope $\left(68^{\circ} 21^{\prime} 18.70^{\prime \prime} \mathrm{N}, 19^{\circ} 2^{\prime} 38.00^{\prime \prime E}\right)$. Additional gas chambers with plastic 952 chambers, sealed with a rubber stopper, and metal frames (orange) were installed to obtain 953 replicate carbon dioxide and additionally methane emissions along the palsa hillslope into the 954 bog area. 


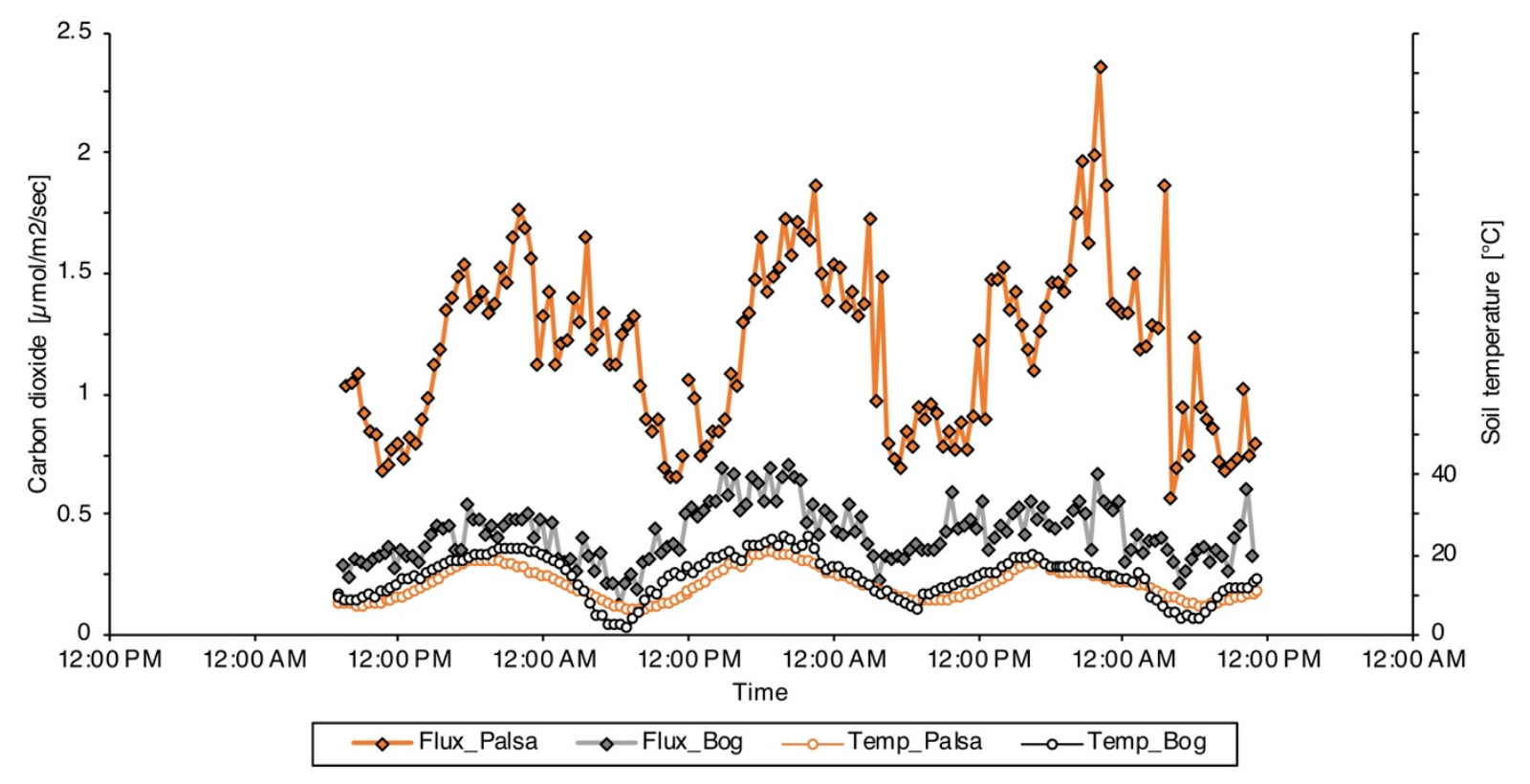

958 Figure S3. Carbon dioxide emissions along the palsa hillslope (palsa and bog). Eosense gas 959 chambers (eosFD Forced Diffusion chamber in conjunction with the eosLink-FD software, 960 EOSENSE INC, Dartmouth, Canada) were installed along the palsa hillslope and analysis 961 performed from the $8^{\text {th }}$ of July to $10^{\text {th }}$ of July 2019. Unfortunately, the second Eosense 962 instrument at the collapsing front (shown in Figure S2) was broken during shipment and thus 963 excluded in the analysis. The carbon dioxide emissions correlate with the surface soil 964 temperature (measured at $5 \mathrm{~cm}$ soil depth at palsa and bog), measured by Integrated Carbon 965 Observation System (ICOS) Sweden Abisko - Stordalen ${ }^{1}$. 


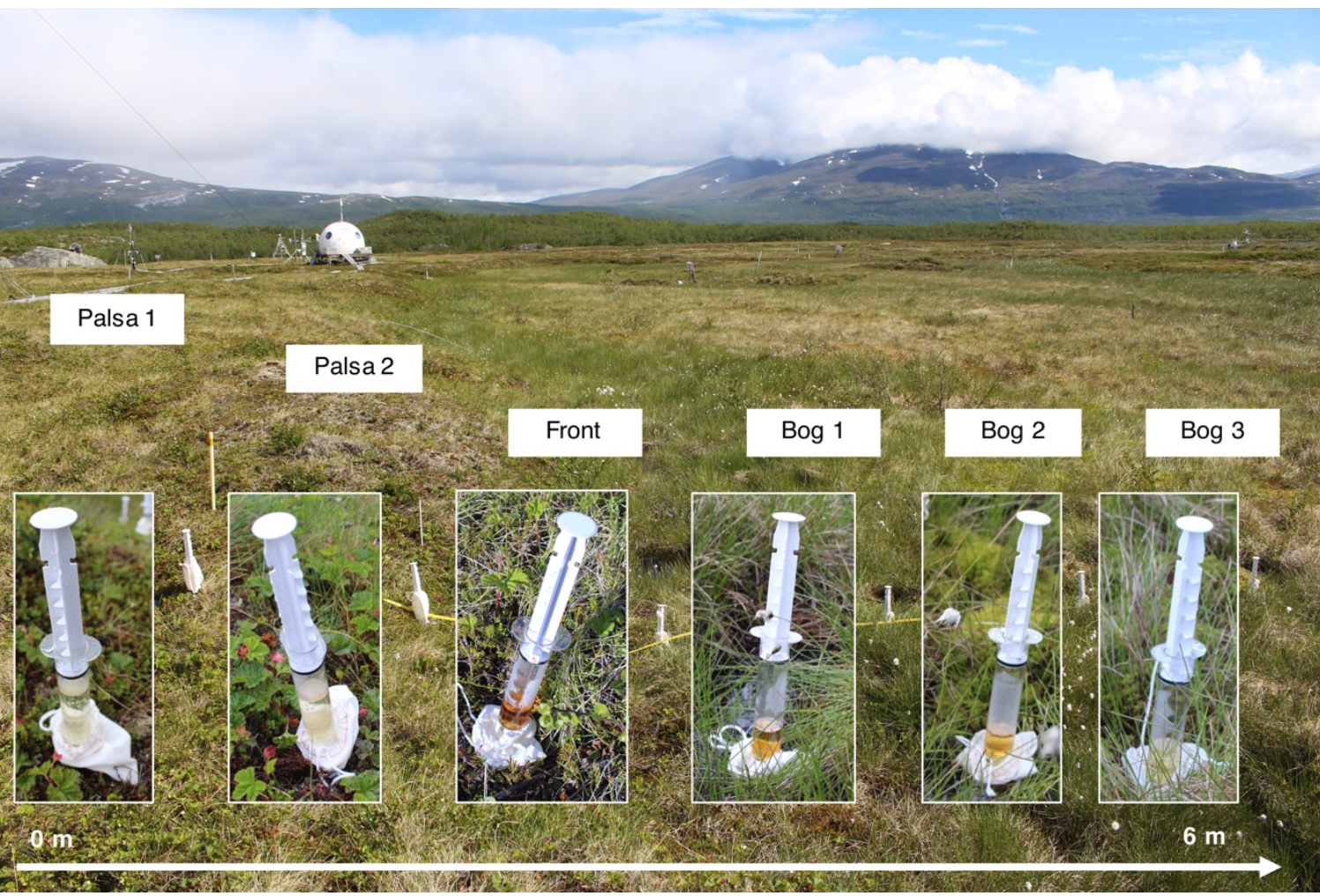

968

969 Figure S4. Porewater sampling along palsa hillslopes. Along eight palsa hillslopes,

970 porewater was extracted with lysimeters at six defined sampling points in July 2019. In

971 transect 1 (shown here, see also Figure S1), lysimeters were installed for 3-4 hours along the

972 palsa hillslope $\left(68^{\circ} 21^{\prime} 18.70^{\prime \prime} \mathrm{N}, 19^{\circ} 2^{\prime} 38.00^{\prime \prime} \mathrm{E}\right)$ at a distance of $1 \mathrm{~m}$ in between each other from

973 palsa to bog. The porewater with dark brown, reddish color at the collapsing front represents

974 the sample with the highest aqueous iron and dissolved organic carbon along the palsa hillslope 975 into bog.

976 


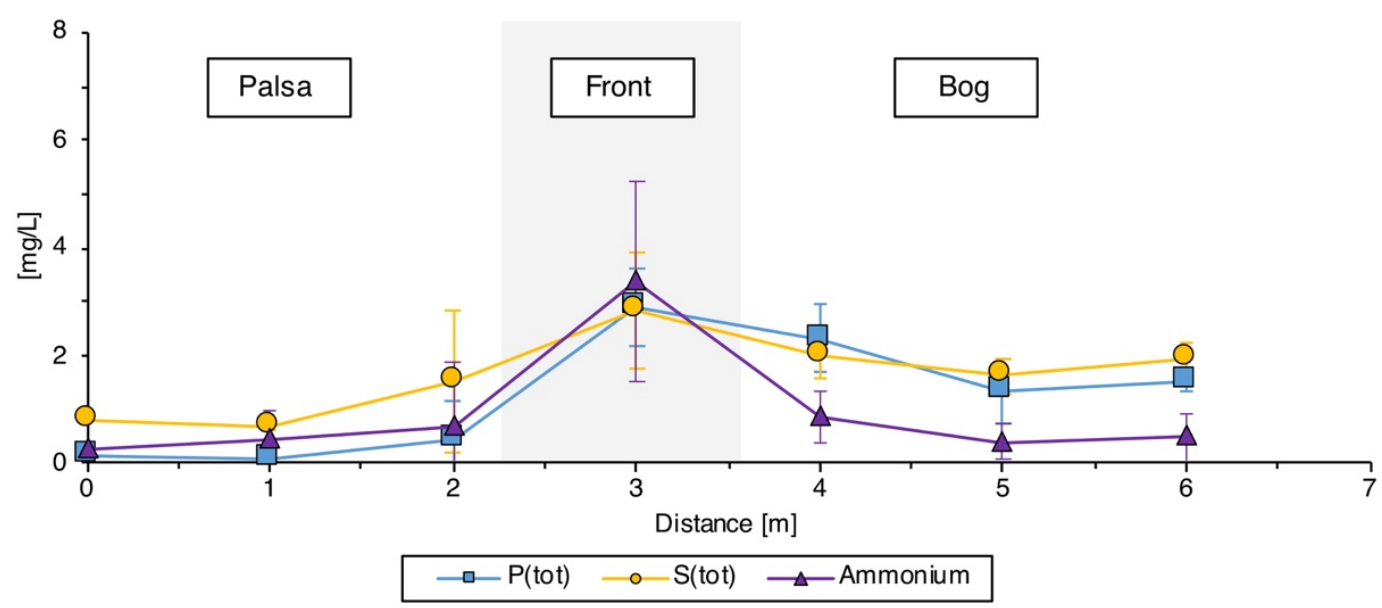

977

978

979 Figure S5. Aqueous total phosphorous (P(tot)), aqueous total sulfur (S(tot)) and 980 ammonium concentrations in the porewater along the palsa hillslope $(30 \mathrm{~cm}$ depth, 981 transition zone). Aqueous concentrations are reported in $\mathrm{mg} / \mathrm{L}$ from palsa $(0-2.7 \mathrm{~m})$ to bog 982 (2.7-7 m). Reported values represent the average of six sampling spots for eight palsa hillslopes 983 (0-2.3 $\mathrm{m})$ to collapsing front $(2.3-3.6 \mathrm{~m})$ to bog (3.6-7 m), sampled in June/July (see also SI, 984 Figures S1 and Figure S4). Error bars represent the standard deviation of eight palsa hillslopes 985 (0-2.3 $\mathrm{m})$ to collapsing front (2.3-3.6 m) to bog (3.6-7 m), sampled in June/July (see also SI, 986 Figure S1).

987 

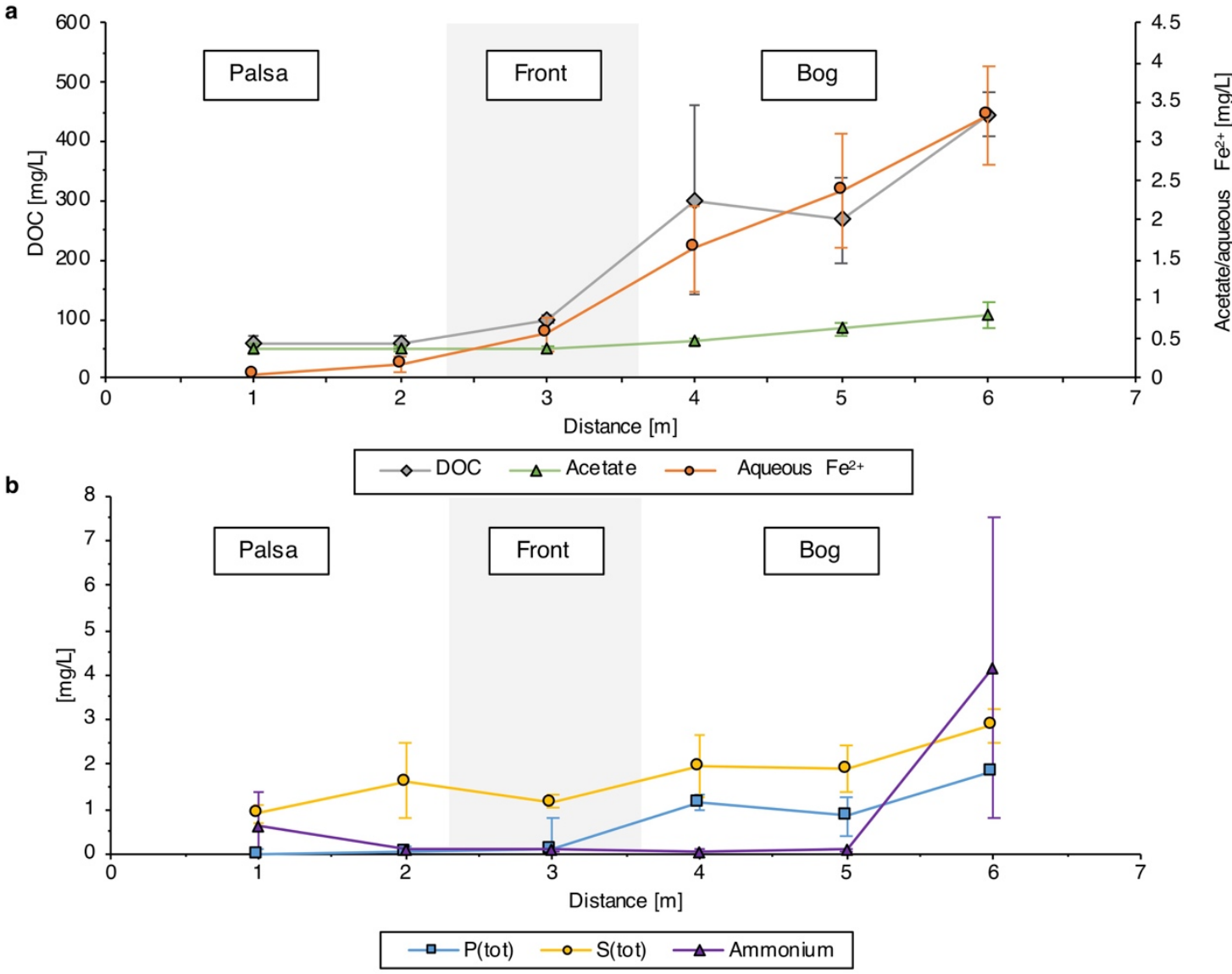

989

990 Figure S6. Porewater analysis along the palsa hillslope (60 cm, mineral horizon). a,

991 Dissolved organic carbon (DOC), acetate and aqueous $\mathrm{Fe}^{2+}$ in $\mathrm{mg} / \mathrm{L}$ and $\mathrm{b}$, aqueous total 992 phosphorous ( $\mathrm{P}(\mathrm{tot}))$, aqueous total sulfur $(\mathrm{S}(\mathrm{tot}))$ and ammonium concentrations along the 993 collapsing palsa hillslope into bog. Reported values represent the average of six sampling spots 994 for eight palsa hillslopes $(0-2.3 \mathrm{~m})$ to collapsing front $(2.3-3.6 \mathrm{~m})$ to bog $(3.6-7 \mathrm{~m})$, sampled in 995 June/July (see also SI, Figure S1). Error bars represent the standard deviation of eight palsa 996 hillslopes (0-2.3 m) to collapsing front (2.3-3.6 m) to bog (3.6-7 m), sampled in June/July (see 997 also SI, Figure S1).

998

999 


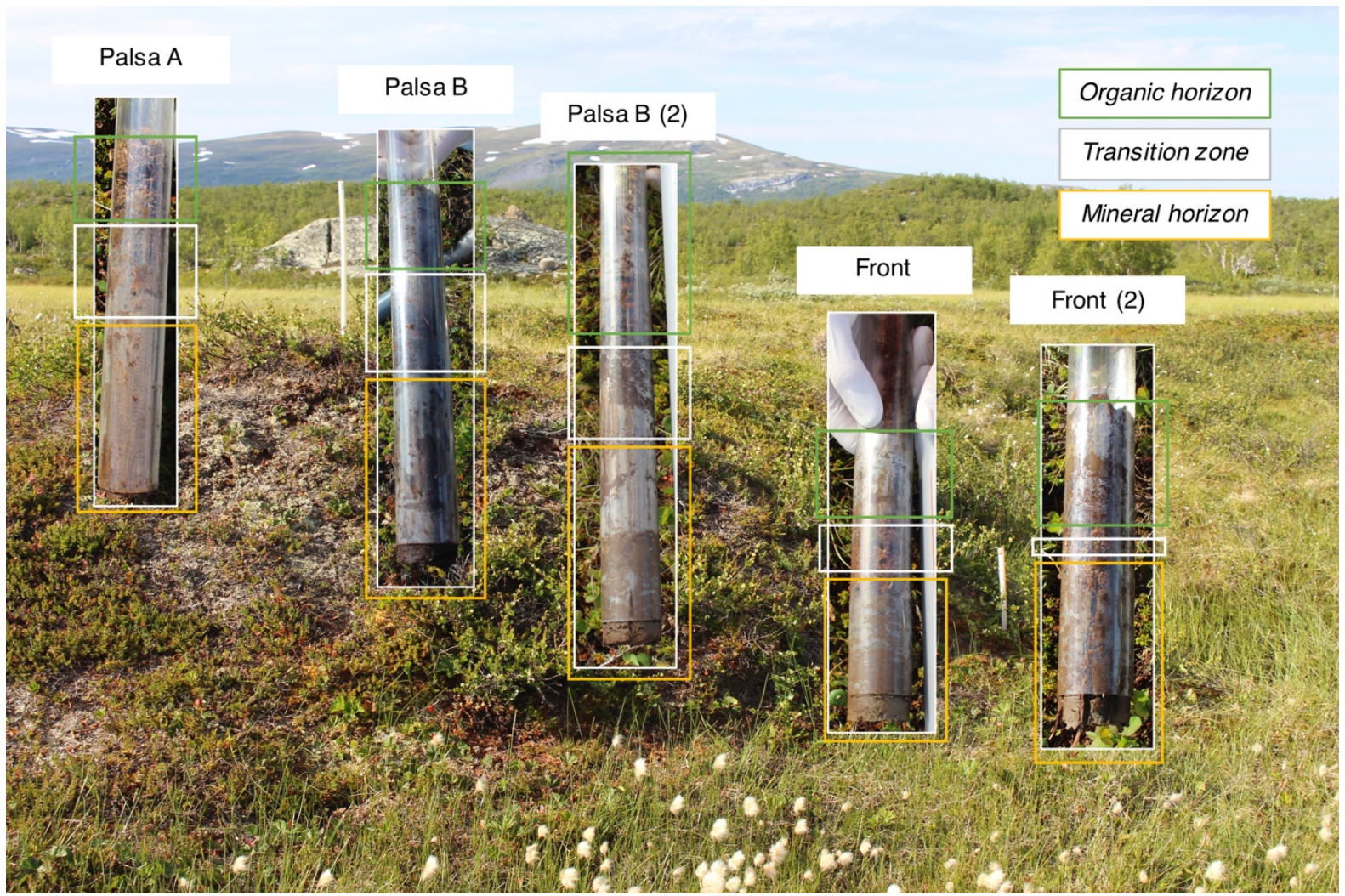

1002

1003 Figure S7. Coring along palsa hillslopes. Ten soil cores were taken along different palsa

1004 hillslopes to capture spatial heterogeneity of iron-carbon associations along the peatland mire.

1005 In transect 3 (shown here, see also Figure S1), five cores were taken along a palsa hillslope 1006 towards the collapsing front into bog $\left(68^{\circ} 21^{\prime} 27.33^{\prime \prime} \mathrm{N}, 19^{\circ} 3^{\prime} 1.91^{\prime \prime} \mathrm{E}\right)$, immediately frozen in

1007 liquid nitrogen and stored at $-80^{\circ} \mathrm{C}$ until analysis of iron-carbon associations and of present and 1008 active microbial community. 

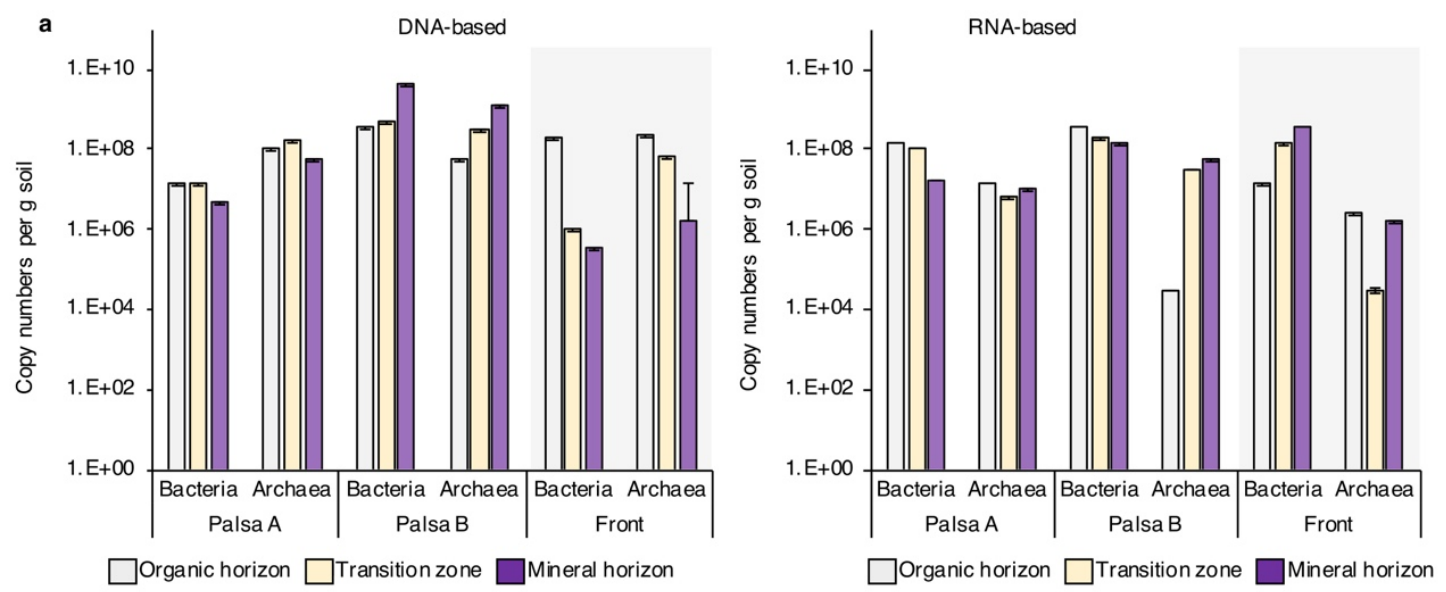

b
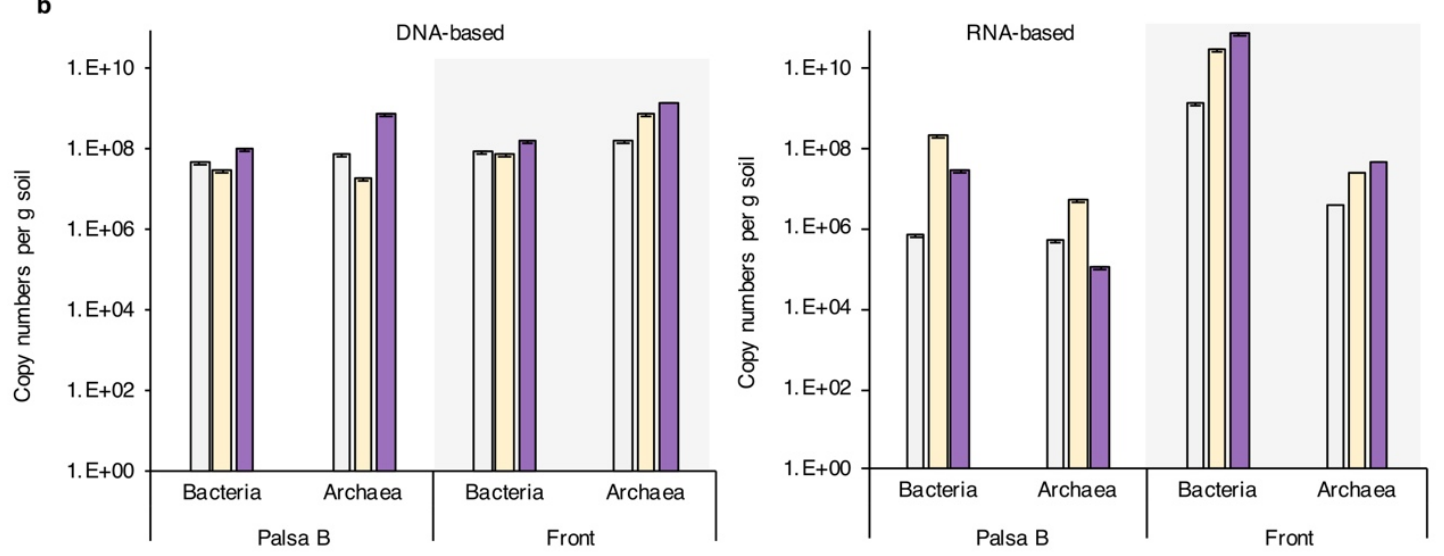

1012 Figure S8. Abundance of bacteria and archaea (copy numbers based on qPCR analysis 1013 specific for 16S rRNA genes; DNA-based on the left, RNA-based on the right). a, and b, show 1014 replicate analysis for Palsa A, Palsa B and Front (a), and Palsa A and Front (b). 


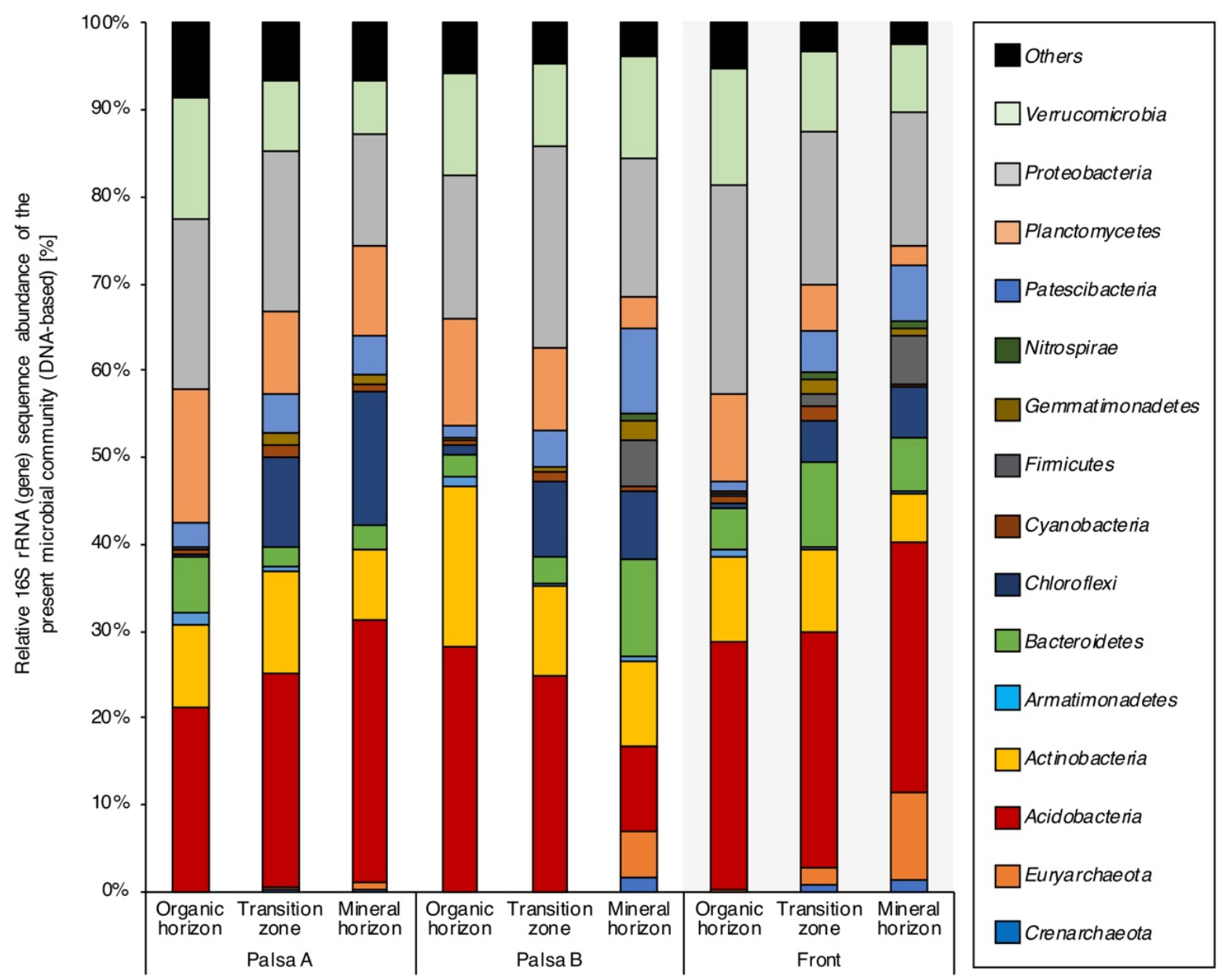

1016

1017

1018 Figure S9 Taxonomic identification of the microbial communities along the palsa hillslope

1019 based on 16S rRNA gene amplicon analysis (DNA-based). Data were averaged among triplicate

1020 analysis of each soil horizon (organic horizon, transition zone, mineral horizon). 

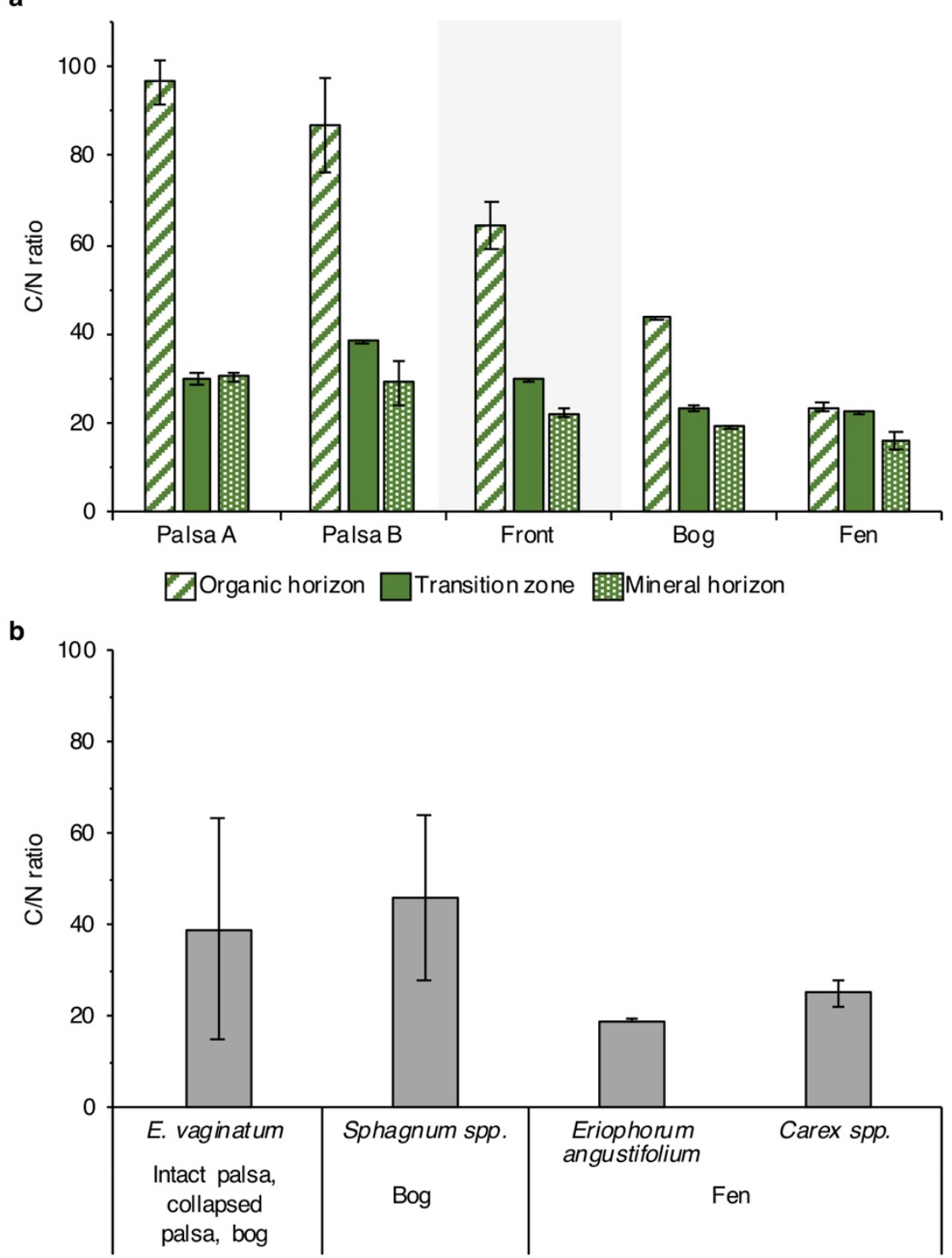

1024 Figure S10. C/N weight ratios of a, soil samples of distinguished soil horizon along palsa 1025 hillslope and thaw gradient, in comparison to b, living plant samples of dominant 1026 Stordalen species (modified and adapted from Hodgkins et al. ${ }^{2}$ ). Reported values represent 1027 the average of triplicate analysis of cores Palsa A, Palsa B, Front (transect 1, Figure S1) and 1028 Bog C and Fen E, which were previously puplished ${ }^{3}$. Error bars represent the standard deviation 1029 of triplicate analysis of cores Palsa A, Palsa B, Front (transect 1, Figure S1), one bog (Bog C) 1030 and one fen core (Fen E) (see also Patzner et al. ${ }^{3}$ ). 
1032 Table S1. Overview of iron(II)-oxidizing microorganisms that were cross-checked in the

1033 16S rRNA amplicon gene sequencing results (DNA- and RNA-based) in this study (adapted

1034 from Otte et al. ${ }^{4}$ and Weber et al. ${ }^{5}$, see also Dinh et al. ${ }^{6}$ and Berg et al. ${ }^{7}$ ).

1035

Iron(II)-oxidizing microorganisms (species or strains)

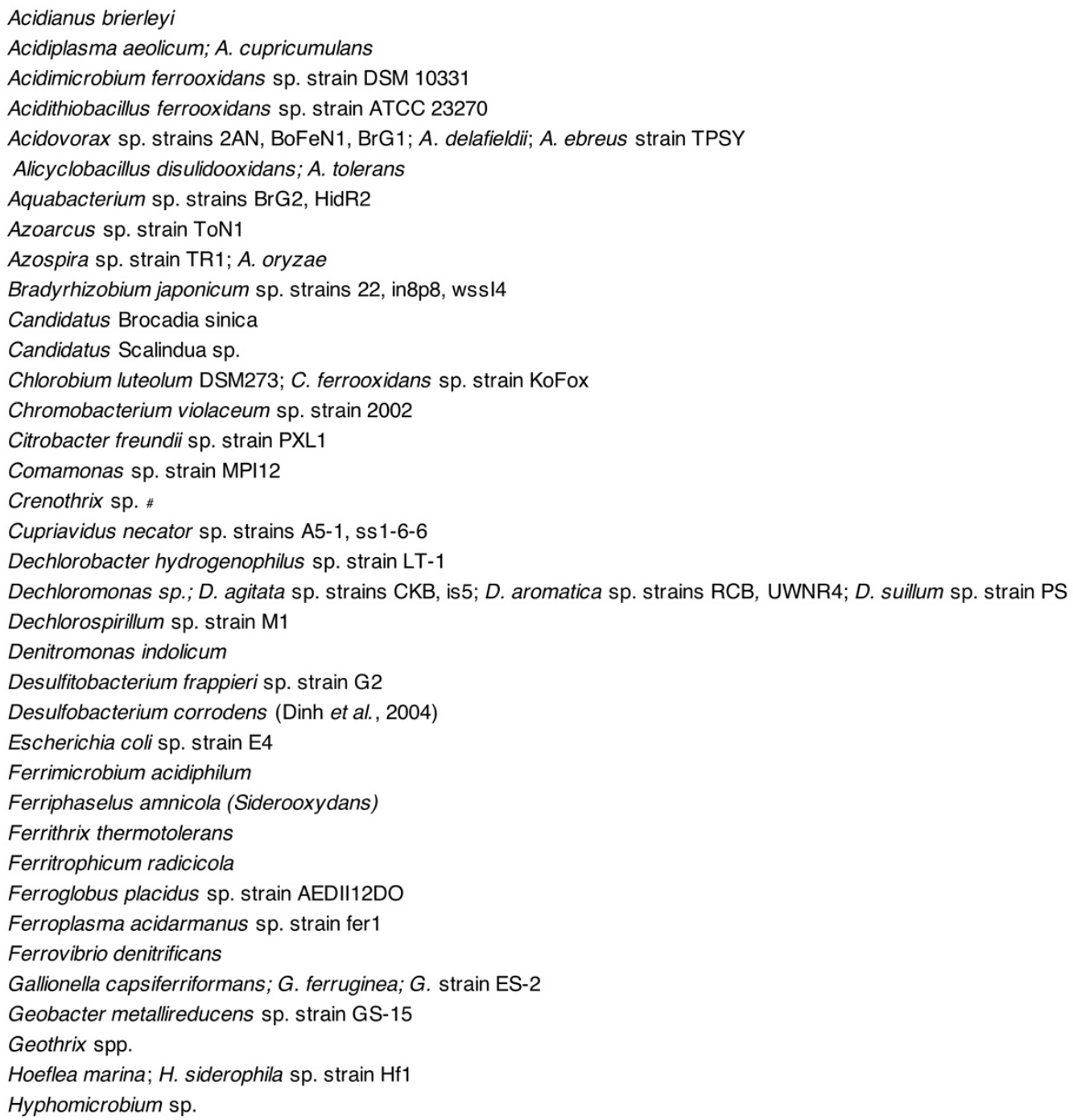


Hyphomonas sp.

Klebsiella-like sp. strain FW33AN

Leptospirillum ferrooxidans; L. ferriphilum

Leptothrix cholodnii; L. discophora

Magnetococcus sp. (Berg et al., 2016)

Magnetospirillum bellicus sp. strain VDY

Marinobacter aquaeolei sp. strain VT8

Mariprofundus ferrooxidans sp. strains PV-1, RL-1, JV-1, GSBS

Metallosphaera sedula sp. strain $\mathrm{J} 1$

Nocardioides sp. strain $\ln 31$

Paracoccus sp.; $P$. denitrificans; $P$. ferrooxydans sp. strain BDN-1; $P$. pantotrophus; $P$. versutus

Parvibaculum sp. strain MBN-A2

Pedomicrobium spp.

Propionivibrio militaris sp. strain MP

Pseudogulbenkiania ferrooxidans sp. strain 2002

Pseudomonas sp. strains LP-1, SZF15; P. stutzeri

Ralstonia solanacearum sp. strain in $4 \mathrm{ss} 52$

Rhodanobacter sp. strain MPN-A3

Rhodobacter sp. strain SW2; R. ferrooxydans

Rhodomicrobium vannieli

Rhodopseudomonas palustris strain TIE-1

Rhodovulum sp.; $R$. iodosum; $R$. robiginosum

Rubrivivax group sp. strains BrG4, BrG5

Siderocapsa sp.

Sideroxydans paludicola; S. lithotrophicus sp. strain ES-1

Sphaerotilus natans sp. strain DSM 6575

Sulfobacillus spp.

Sulfolobus acidocaldarius

Thauera aromatica sp. strain AR-1

Thermomonas sp. strain BrG3

Thiobacillus denitrificans

Thiodictyon sp.

Thiomicrospira denitrificans

Zixibacteria sp. strain RBG-1 
1040 Table S2. Overview of iron(III)-reducing microorganisms that were cross-checked in the

1041 16S rRNA amplicon gene sequencing results in this study (adapted from Otte $e t$ al. ${ }^{4}$ and

1042 Weber et al. ${ }^{5}$, see also Berg et al. ${ }^{7}$, Li et al. ${ }^{8}$, Holmes et al. ${ }^{9}$, Finneran et al. ${ }^{10}$ ).

1043

Iron(III)-reducing microorganisms (species or strains)

Acidithiobacillus ferrooxidans

Aeromonas hydrophila

Albidoferax ferrireducens

Alteromonas hydrophila

Anaeromyxobacter sp.

Bacillus infernus

Clostridium sp.

Deferribacter thermophilus

Desulfobacter propionicus

Desulfobacterium sp.

Desulfobulbus spp.

Desulfococcus spp.

Desulfotalea spp.

Desulfotomaculum sp. (Berg et al., 2016)

Desulfovibrio sp. (Li et al., 2016)

Desulfuromonas spp.

Desulfuromusa spp.

Ferribacterium limneticum

Ferrimonas balearica

Ferroglobus placidus

Geobacter spp.

Geoglobus sp.

Geothrix fermentans

Geovibrio ferrireducens

Malonomonas sp. (Holmes et al., 2004)

Myxococcales sp.

Pantoea agglomerans sp. strain Sp1

Pelobacter sp.

Pseudomonas sp.

Pseudorhodoferax (Berg et al., 2016)

Pyrobaculum sp.

Rhodobacter $\mathrm{sp}$.

Rhodoferax sp. (Finneran et al., 2003)

Shewanella colwelliana

Sinorhodobacter sp.

Sulfurospirillum barnesii

Thermoterrabacterium ferrireducens

Thermotoga maritima

Thermus sp. strain SA01

Thiobacillus ferrooxidans 
1046 Table S3. Overview of methanogenic microorganisms that were cross-checked in the 16S

1047 rRNA amplicon gene sequencing results in this study (see also Kim\&Whitman ${ }^{11}$ and

1048 Mondav et al. ${ }^{12}$ ).

1049

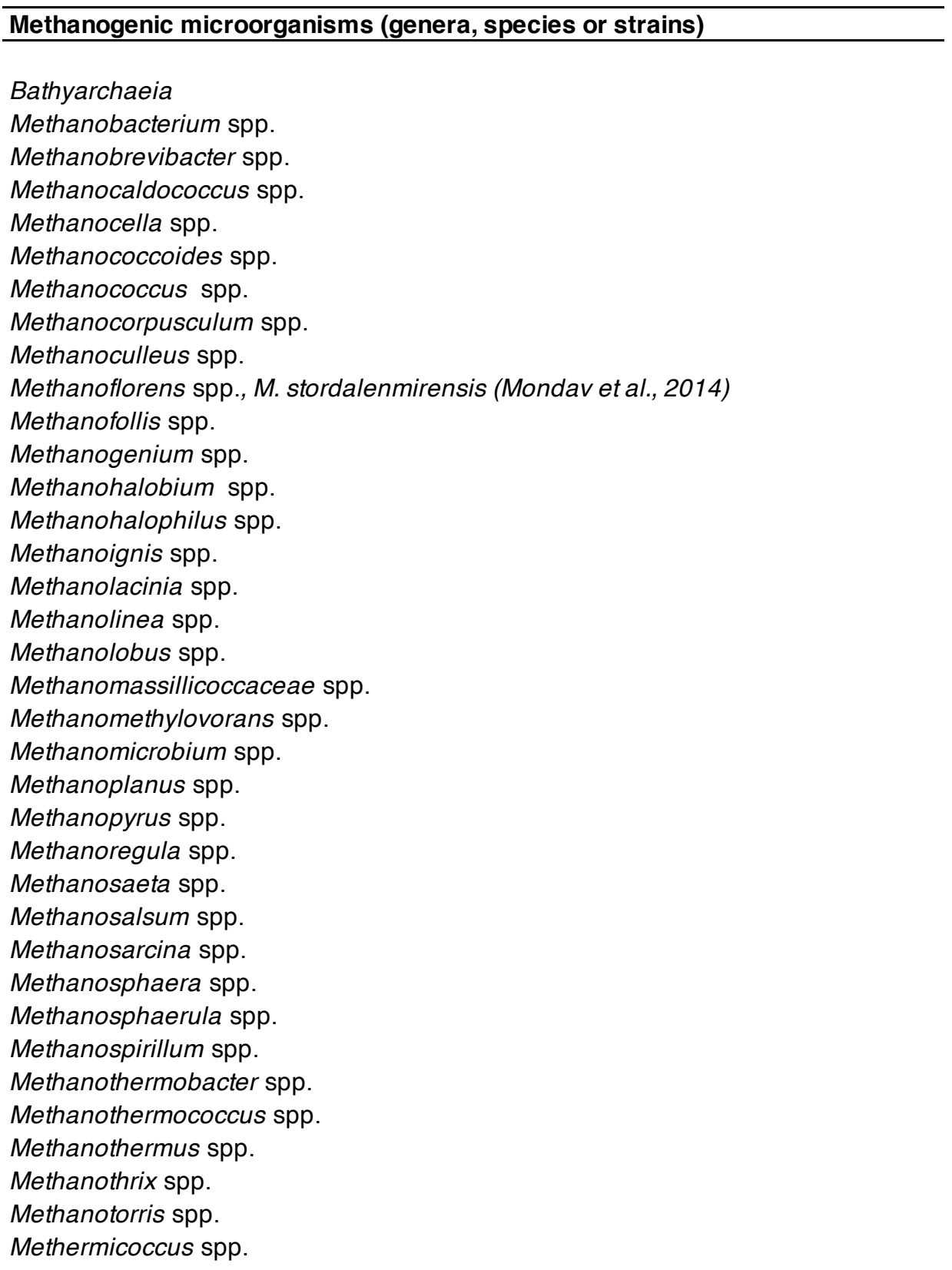


1052 Table S4. Overview of methanotrophic microorganisms that were cross-checked in the

1053 16S rRNA amplicon gene sequencing results (DNA- and RNA-based) in this study (see

1054 also Jiang et al..$^{13}$ and Singelton et al. ${ }^{14}$ ).

1055

Methanotrophic microorganisms (species or strains)

Acidimethylosilex spp.

Clonothrix spp., Clonothrix fusca

Crenotrhix spp., Crenothrix polyspora

Methlyosinus spp.

Methyloacida spp.

Methylobacter spp.

Methylobacterium spp.

Methylocaldum spp.

Methylocapsa spp.

Methylocella spp., Methylocella silvestris

Methylococcus spp.

Methylocystis spp.

Methylokorus spp.

Methylomonas spp.

Methylosphaera spp.

Methylothermus spp.

Methylovirgula spp.

Rhodoblastus spp.

Roseiarcus spp.

1056

1057 
a Iron-cycling microorganisms along the palsa hillslope

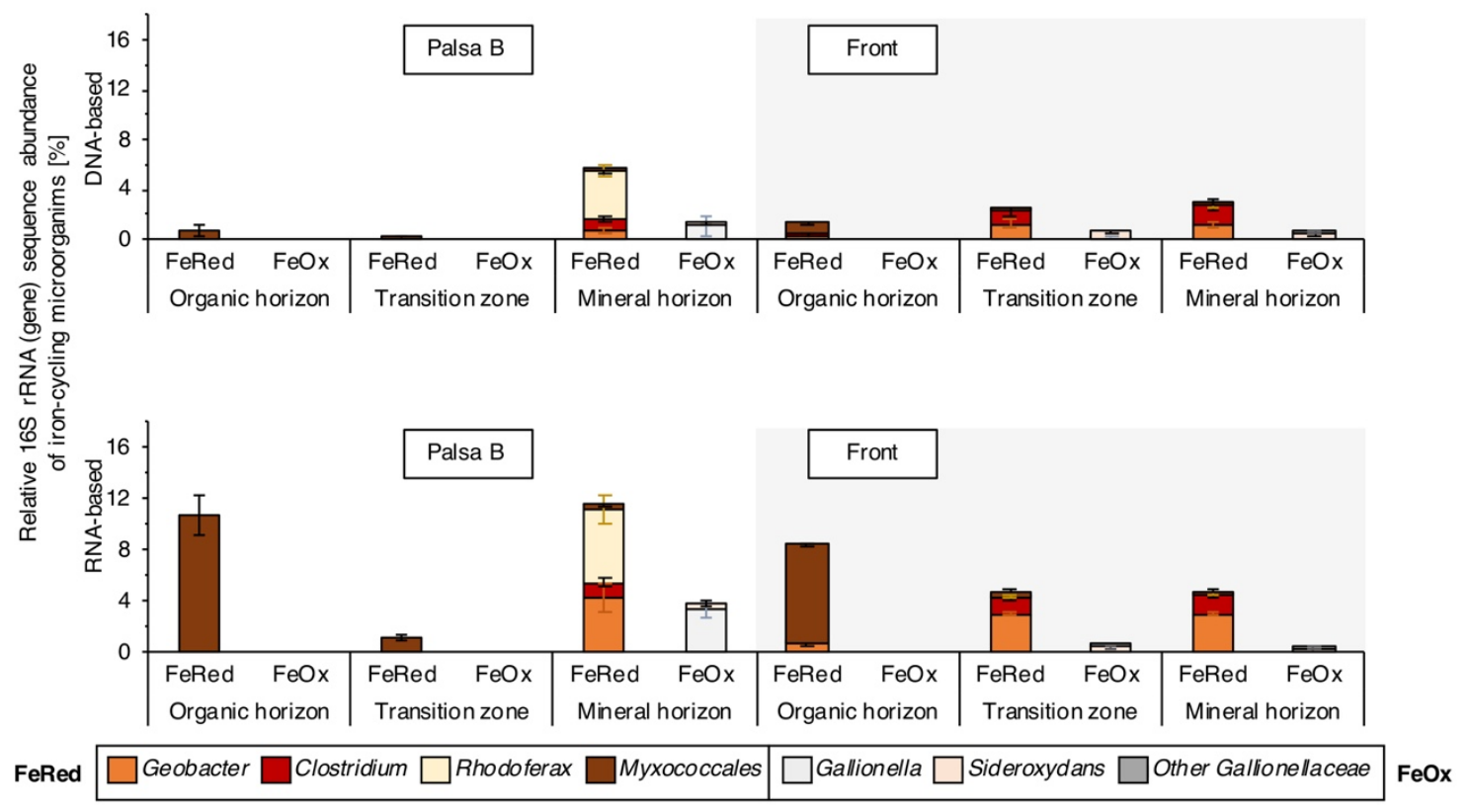

b Methane-cycling microorganisms along the palsa hillslope

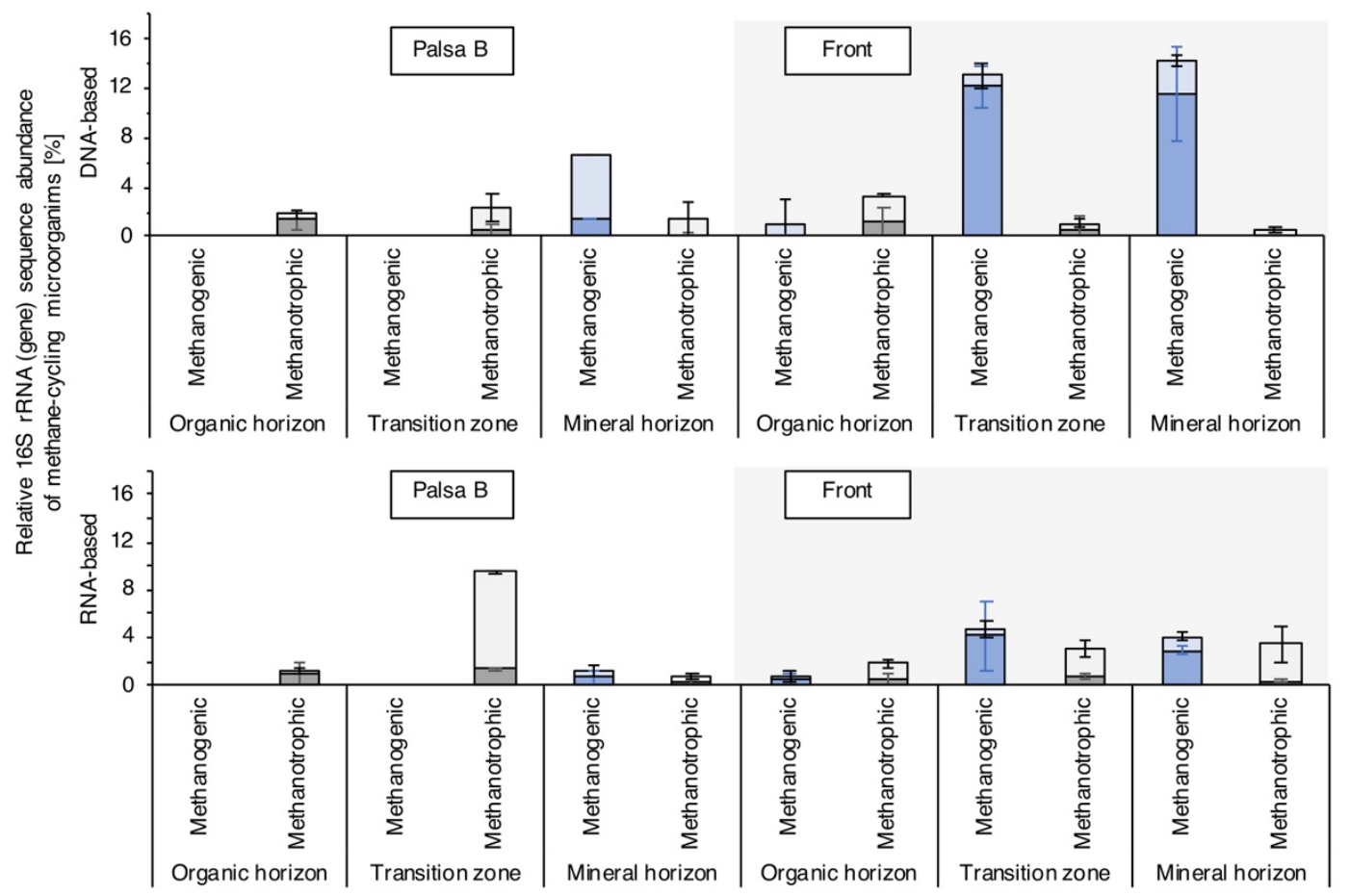

1060 Figure S11. Relative abundance of 16S rRNA (gene) sequence of a, iron- and b, methane

1061 cycling microorganisms (DNA- and RNA-based) in replicate cores (Palsa B and Front)

1062 along the palsa hillslope (transect 3, Figure 1). All iron- and methane-cycling taxa below

$10630.1 \%$ relative 16S rRNA gene sequencing abundance are not illustrated in this figure. For 
1064 absolute abundance of bacteria and archaea based on qPCR analysis, specific for 16S rRNA 1065 gene (based on DNA) and Fe- and methane-cycling microorganisms, analyzed in these study 1066 (adapted from Otte et $a l .{ }^{4}$ and Weber et $a l .{ }^{5}$ ), see also Figure S8. Reported values and error bars 1067 represent the average and standard deviation of triplicate analysis of each soil horizon (organic 1068 horizon, transition zone and mineral horizon) along the palsa hillslope.

1069 


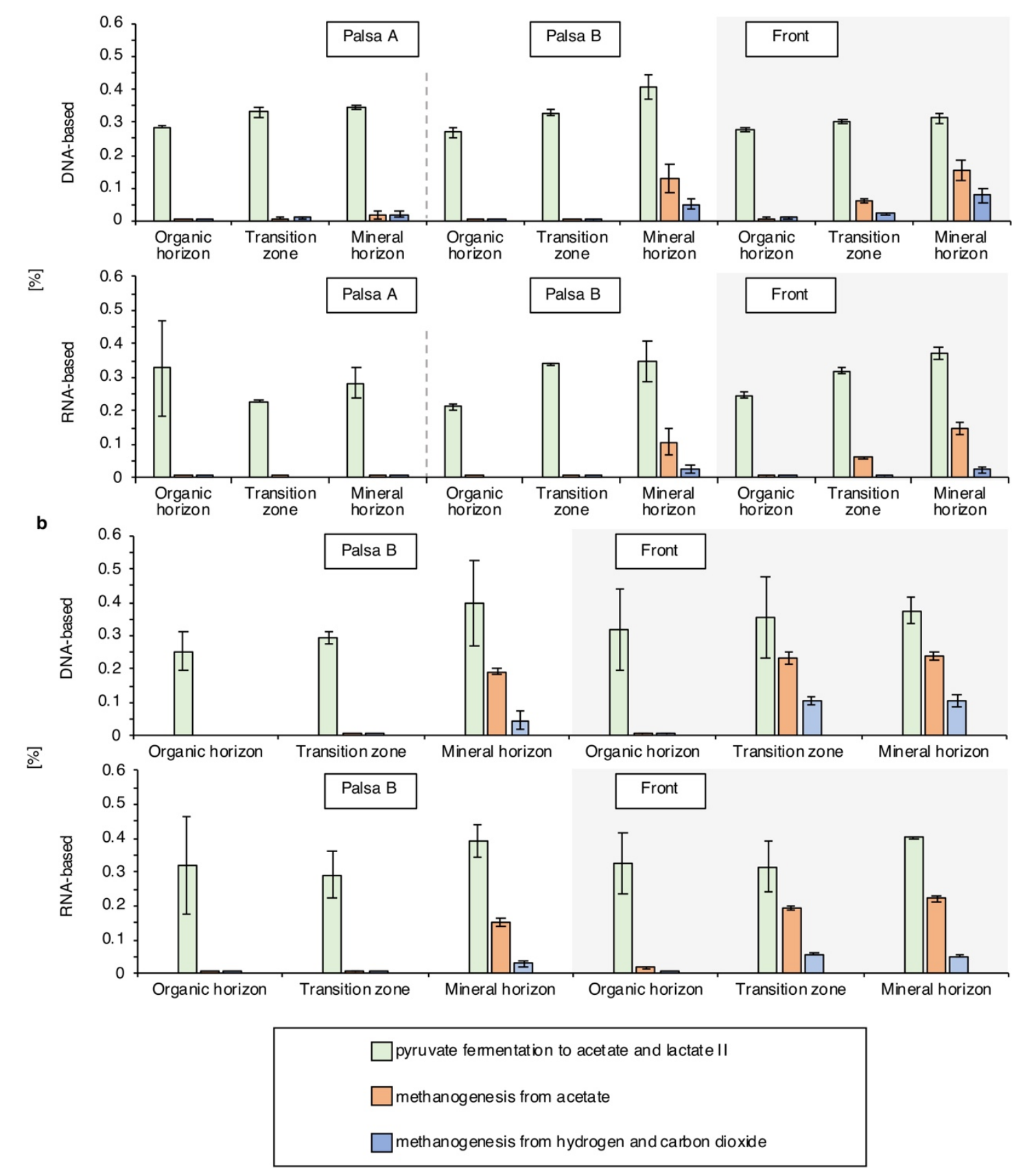

1070

1071

1072 Figure S12. Predicted metabolic pathways of the present (DNA-based) and potentially 1073 active (RNA-based) microbial communities along the palsa hillslope in a, cores presented

1074 in the main text (transect 3, Figure S1) and b, replicate cores. Analyses were performed

1075 with MetaCyc Metabolic Pathway Database. Reported values and error bars represent the 1076 average and standard deviation of triplicate analysis of each soil horizon (organic horizon,

1077 transition zone and mineral horizon) along the palsa hillslope. 
1079 Table S5. Elemental composition percentage and number of FT-ICR-MS assigned

1080 formula. Values are derived from total assigned formula tables. Not available (N/A) values for

1081 CHNOS formula in porewater samples and salt control extractions are due to lack of reliable

1082 formula series detected in those samples. A comparison of the soil extractions using salt or

1083 dithionite solutions indicates that the extracts are not identical, but provides little to no evidence

1084 of CHOS molecular artifacts formed through reactions with dithionite, as reported by Lv et 1085 al. ${ }^{15}$.

1086

1087

\begin{tabular}{|c|c|c|c|c|c|c|}
\hline Sample Type & Sample & Extraction & $\mathrm{CHO}$ & CHNO & $\begin{array}{c}\text { CHOS } \\
\text { (\% abundanc }\end{array}$ & (\% abundance / \# formula) \\
\hline \multirow{4}{*}{ 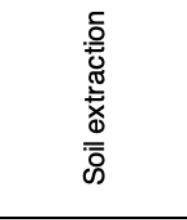 } & Palsa A, Transition zone & Dithionite & $74.19 \% / 7486$ & $11.21 \% / 2887$ & $13.76 \% / 2018$ & $0.84 \% / 319$ \\
\hline & & Salt control & $58.67 \% / 4952$ & $7.08 \% / 1716$ & $34.25 \% / 6609$ & $\mathrm{~N} / \mathrm{A}$ \\
\hline & Front Transition zone & Dithionite & $76.12 \% / 7466$ & $9.25 \% / 2668$ & $14.42 \% / 2881$ & $0.21 \% / 98$ \\
\hline & & Salt control & $76.22 \% / 6536$ & $7.08 \% / 1716$ & $13.79 \% / 2249$ & $\mathrm{~N} / \mathrm{A}$ \\
\hline \multirow{2}{*}{ 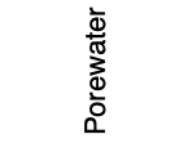 } & Palsa A & $\mathrm{N} / \mathrm{A}$ & $89.79 \% / 9009$ & $7.81 \% / 3374$ & $2.40 \% / 991$ & N/A \\
\hline & Front & $N / A$ & $87.41 \% / 9072$ & $10.80 \% / 4172$ & $1.79 \% / 984$ & $\mathrm{~N} / \mathrm{A}$ \\
\hline
\end{tabular}

1088 
1089 Table S6. Absolute values of iron and carbon in locations Palsa A, Palsa B and Front of

1090 the cores reported in the main text. Errors of the dithionite/citrate extractable a, iron (reactive

$1091 \mathrm{Fe}$, control corrected) and b, carbon (carbon bound to reactive iron, control corrected) represent

1092 a combined standard deviation of sodium chloride bicarbonate extractable $\mathrm{a}$, iron and $\mathrm{b}$, carbon,

$1093 \mathrm{~b}$, citrate blank and dithionite/citrate extractable a, iron and b, carbon (not control corrected).

1094

\begin{tabular}{|l|cccc|ccc|}
\hline & \multicolumn{9}{|c|}{ Palsa A } & \multicolumn{3}{c|}{ Palsa A } \\
\hline & Reactive Fe [mg/g soil] & Error bars & Associated OC [mg/g soil] & Error bars & Leachable Fe [mg/g soil] & Error bars & Leachable OC [mg/g soil] Error bars \\
\hline Organic horizon & 0.20 & 0.12 & 1.42 & 1.42 & 0.05 & 0.07 & 2.26 \\
Transition zone & 10.04 & 0.07 & 83.69 & 10.04 & 0.09 & 0.07 & 0.45 \\
Mineral horizon & 3.76 & 0.48 & 47.21 & 14.30 & 0.05 & 0.03 & 0.00 \\
\hline & \multicolumn{7}{|c|}{ Palsa B } \\
\hline
\end{tabular}

1095 
a
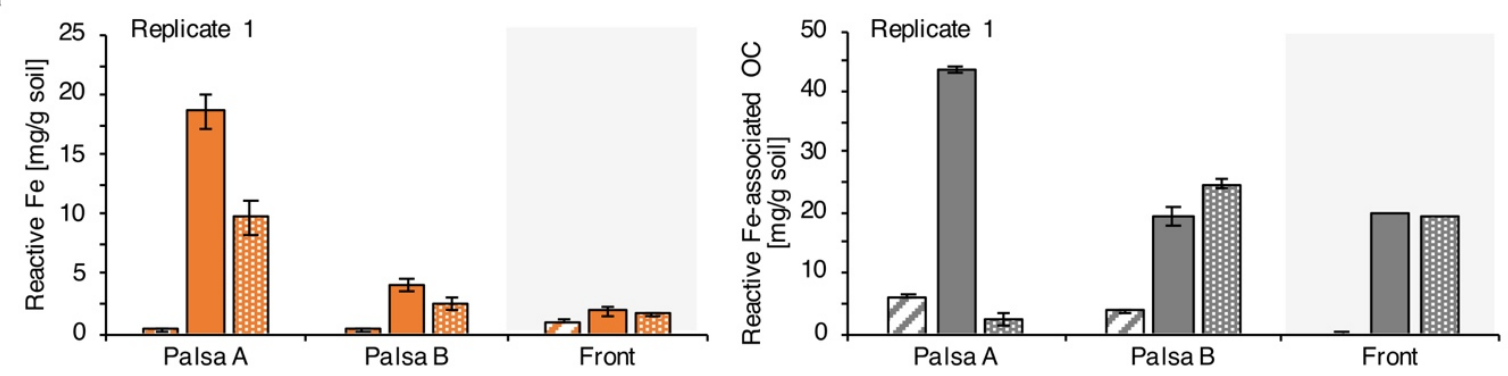

ZOrganic horizon $\square$ Transition zone 闻Mineral horizon

ZOrganic horizon $\square$ Transition zone 聞Mineral horizon

b
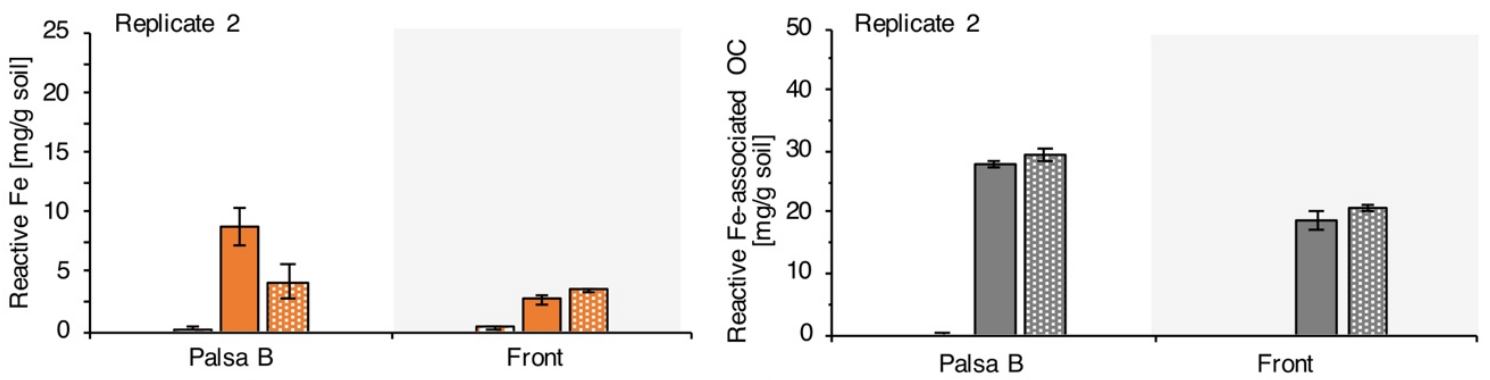

Organic horizon $\square$ Transition zone

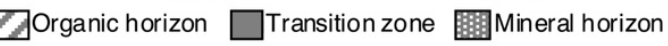

c
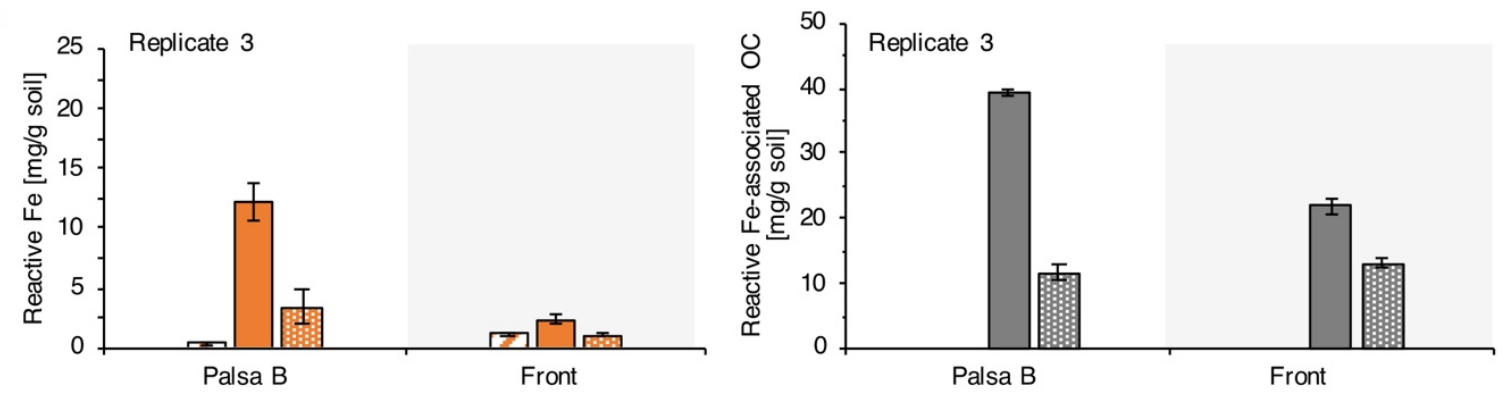

Organic horizon $\square$ Transition zone

ZOrganic horizon $\square$ Transition zone 闻聞Mineral horizon

1097

1098 Figure S13. Organic carbon (OC, grey) associated with reactive iron (Fe, orange) along 1099 three replicate palsa hillslopes: a, replicate 1 (transect 3), b, replicate 2 (transect 3) and c,

1100 replicate 3 (transect 2). Reactive Fe and associated organic carbon along the palsa hillslope

1101 (Palsa A, Palsa B and Front) per each soil horizon (organic horizon, transition zone and mineral

1102 horizon) $[\mathrm{mg} / \mathrm{g}]$ decreases towards the collapsing front. Palsa A shows the highest reactive Fe

1103 and associated organic carbon in intact permafrost soils. Along the palsa hillslope towards the

1104 collapsing front, reactive Fe and associated OC are lost in the solid phase. Reactive Fe reported

1105 values are the average of sodium dithionite citrate duplicate extractions of each soil horizon,

1106 control corrected by a sodium chloride bicarbonate extractable Fe (leachable Fe). Associated

1107 OC reported values are the average of sodium dithionite citrate extractions of each soil horizon,

1108 control corrected by the citrate background and the sodium chloride bicarbonate extractable OC

1109 (leachable OC) (see also Material and Methods). Cores were taken in July 2019 (see Figure 
1110 S1). Error bars of the reactive Fe represent a combined standard deviation of sodium chloride

1111 bicarbonate extractable iron and dithionite/citrate extractable Fe. Errors of the associated carbon

1112 represent a combined standard deviation of citrate blank, sodium chloride bicarbonate 1113 extractable OC and dithionite/citrate extractable OC.

1114 

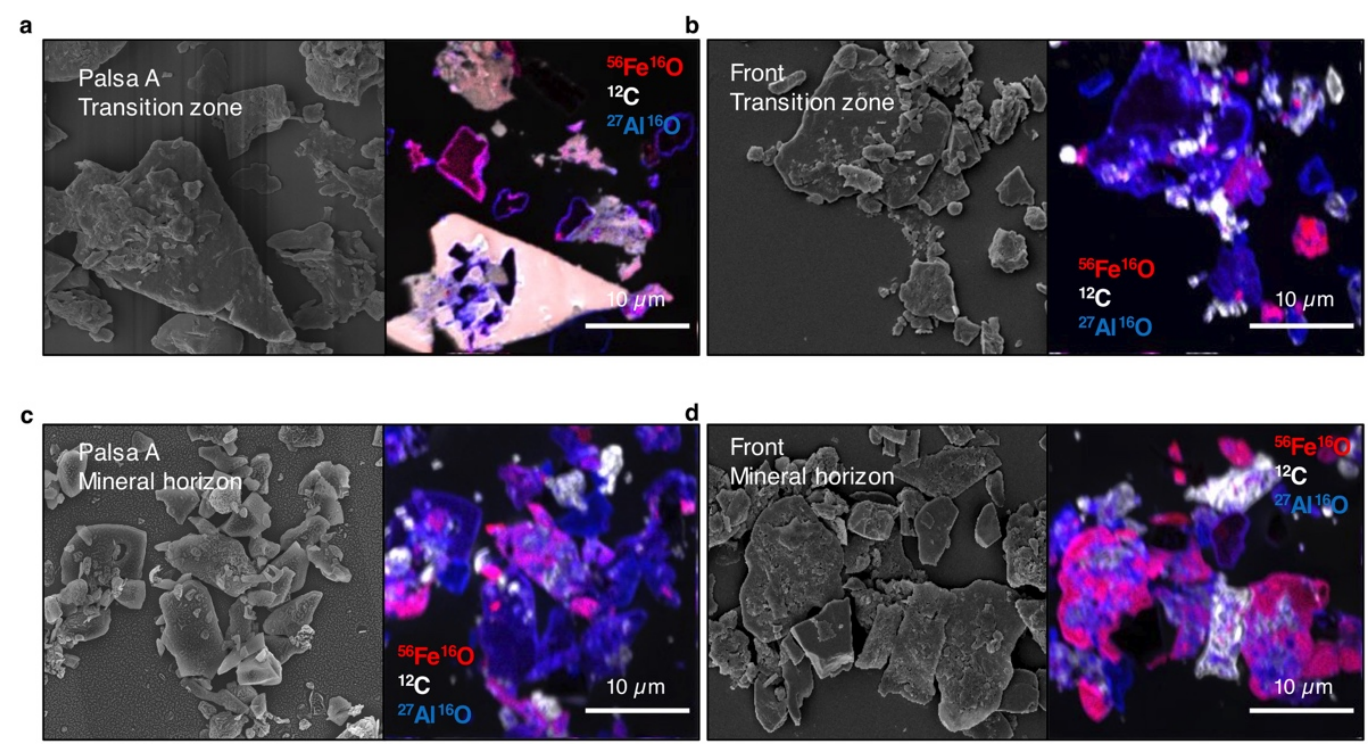

1116

1117 Figure S14. Correlative scanning electron microscopy and nanoscale secondary ion mass

1118 spectrometry (nanoSIMS) of fine fraction of palsa soil horizons along the palsa hillslope.

1119 Fine particle analysis of a, Palsa A transition zone; b, Front transition zone; c, Palsa A mineral

1120 horizon and d, Front mineral horizon (transect 1, Figure S1). Seven detectors were used during

1121 nanoSIMS measurements for ${ }^{12} \mathrm{C}^{-},{ }^{16} \mathrm{O}^{-},{ }^{12} \mathrm{C}^{14} \mathrm{~N}^{-},{ }^{31} \mathrm{P}^{-},{ }^{32} \mathrm{~S}^{-},{ }^{27} \mathrm{Al}^{16} \mathrm{O}^{-}$and ${ }^{56} \mathrm{Fe}^{16} \mathrm{O}^{-}$and ${ }^{27} \mathrm{Al}^{16} \mathrm{O}$. Here,

$1122{ }^{12} \mathrm{C}^{-}$(white), ${ }^{56} \mathrm{Fe}^{16} \mathrm{O}^{-}$(red) and ${ }^{27} \mathrm{Al}^{16} \mathrm{O}^{-}$(blue) are overlaid in a single composite image.

1123 

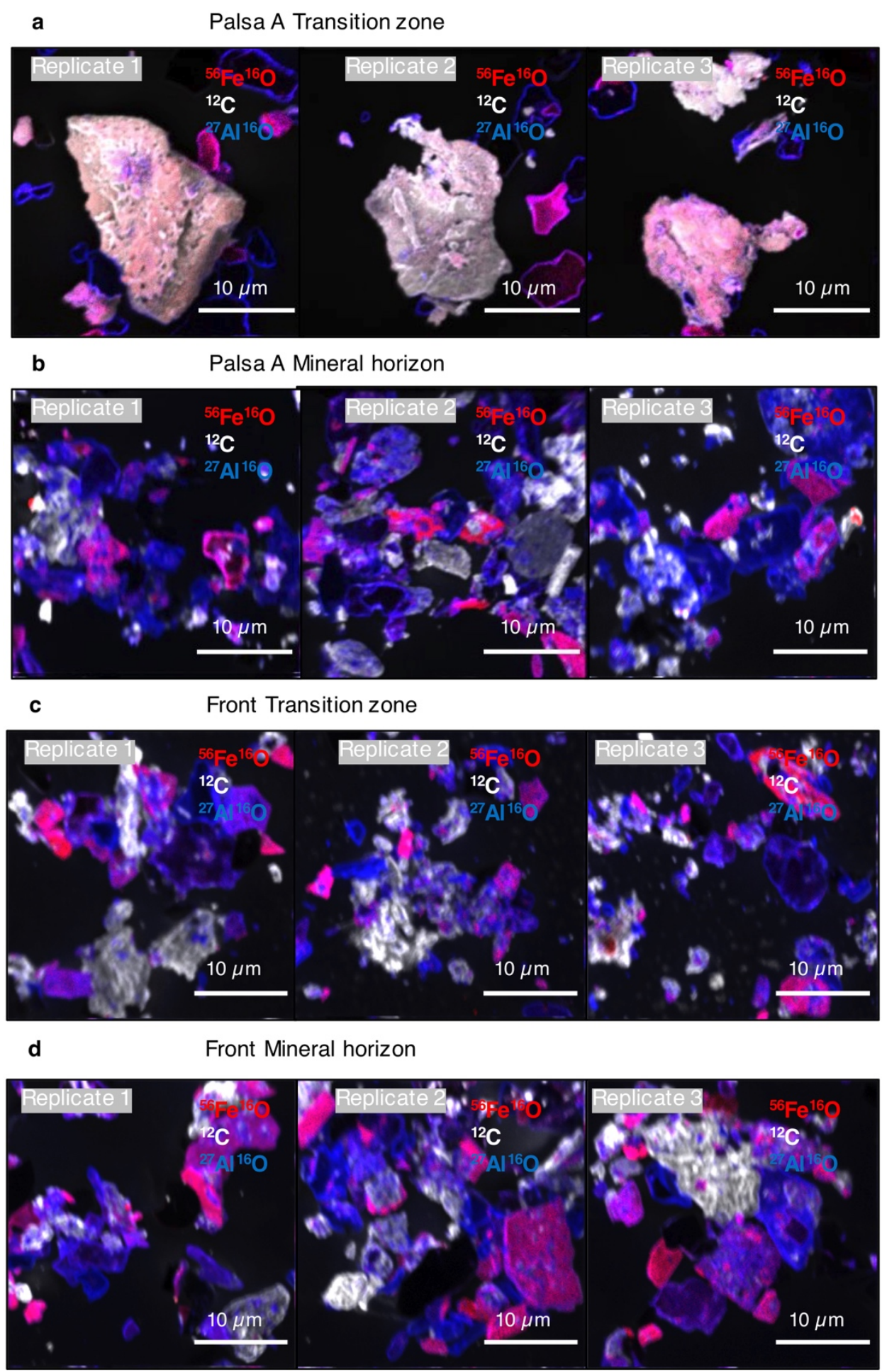

1126 Figure S15. Replicate analysis of nanoscale secondary ion mass spectrometry (nanoSIMS)

1127 of fine fraction: a, Palsa A transition zone; $b$, Palsa A mineral horizon; c, Front transition zone

1128 and d, Front mineral horizon (transect 1, Figure S1). Seven detectors were used during

1129 nanoSIMS measurements for for ${ }^{12} \mathrm{C}^{-},{ }^{16} \mathrm{O}^{-},{ }^{12} \mathrm{C}^{14} \mathrm{~N}^{-},{ }^{31} \mathrm{P}^{-},{ }^{32} \mathrm{~S}^{-},{ }^{27} \mathrm{Al}^{16} \mathrm{O}^{-}$and ${ }^{56} \mathrm{Fe}^{16} \mathrm{O}^{-}$and ${ }^{27} \mathrm{Al}^{16} \mathrm{O}$. 
1130 Here, ${ }^{12} \mathrm{C}^{-}$(white), ${ }^{56} \mathrm{Fe}^{16} \mathrm{O}^{-}$(red) and ${ }^{27} \mathrm{Al}^{16} \mathrm{O}^{-}$(blue) are overlaid in a single image. In total, 1131 four representative fine particles were analyzed with nanoSIMS.

1132 

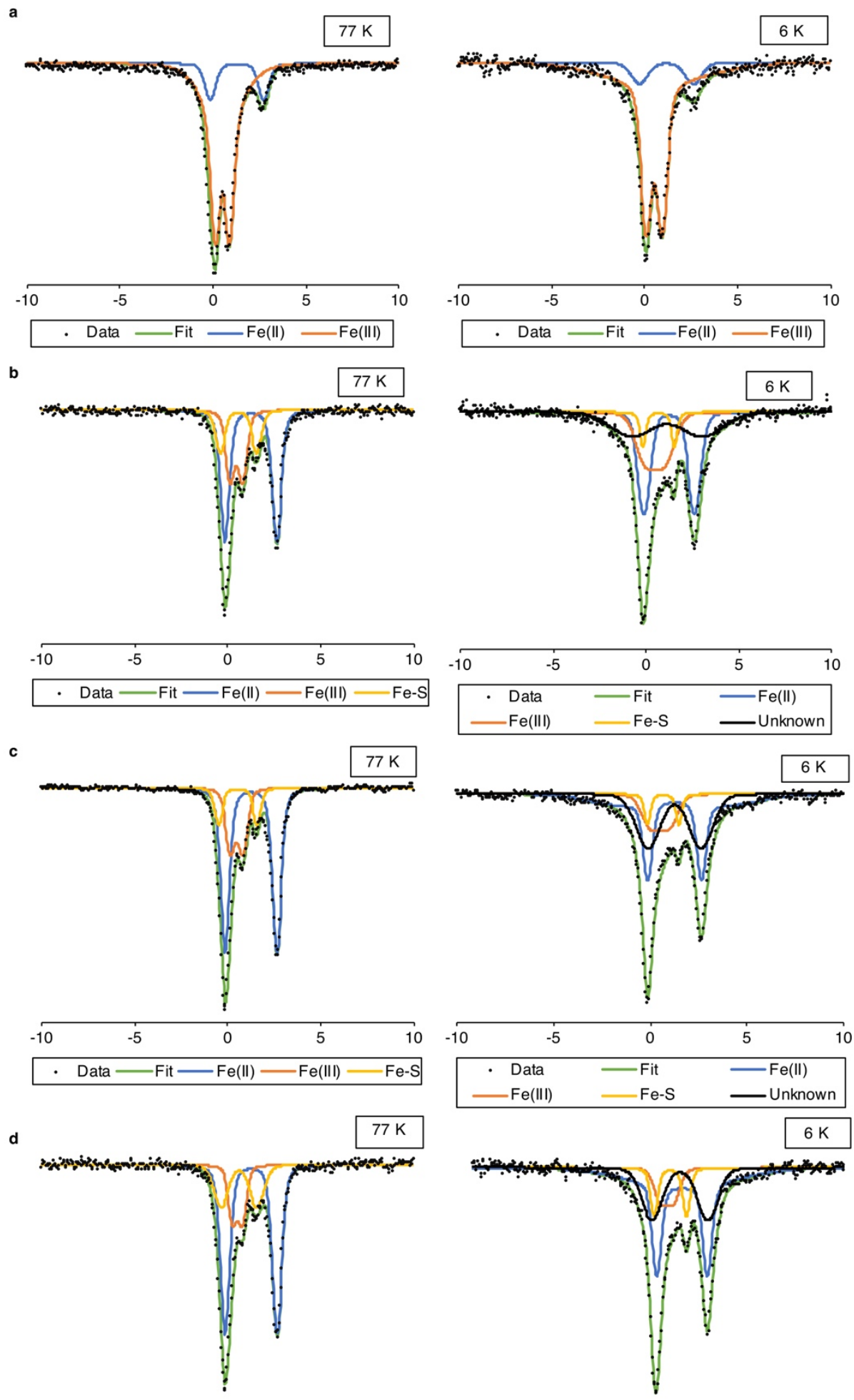

1133
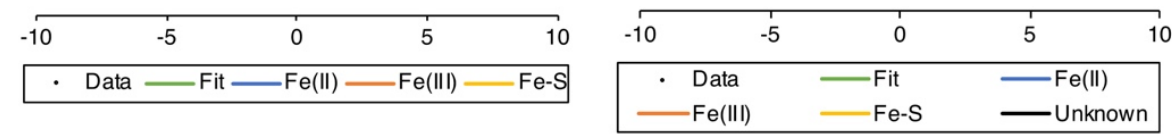

1134 
1135 Figure S16. Mössbauer spectroscopy analysis at $77 \mathrm{~K}$ and $6 \mathrm{~K}$ of the present Fe minerals

1136 along the thaw gradient: a, Palsa A transition zone; b, Palsa A mineral horizon; c, Bog (Bog

$1137 \mathrm{C}^{3}$ ) mineral horizon; d, Fen (Fen $\left.\mathrm{E}^{3}\right)$ mineral horizon. 
1138 Table S7. Mössbauer spectroscopy parameters (measured at 77 and 6 K) derived from

1139 fitting spectra obtained for Palsa A transition zone and mineral horizon, Bog $\left(\operatorname{Bog} \mathrm{C}^{3}\right)$ and Fen

$1140 \quad\left(\right.$ Fen $\left.^{3}\right)$ mineral horizon.

1141

\begin{tabular}{|c|c|c|c|c|c|c|c|c|}
\hline Sample & Components & $\begin{array}{l}\mathrm{CS}_{\mathrm{a}} \\
(\mathrm{mm} / \mathrm{s})\end{array}$ & $\begin{array}{l}\Delta E_{Q b} \\
(\mathrm{~mm} / \mathrm{s})\end{array}$ & $\begin{array}{l}\sigma(\Delta)_{\mathrm{c}} \\
(\mathrm{mm} / \mathrm{s})\end{array}$ & $\begin{array}{l}\text { Bufd } \\
\text { (T) }\end{array}$ & $\begin{array}{l}\text { RAe } \\
(\%)\end{array}$ & $\begin{array}{l} \pm \\
(\%)\end{array}$ & $\chi 2 \mathrm{f}$ \\
\hline \multicolumn{9}{|l|}{$77 \mathrm{~K}$} \\
\hline \multicolumn{9}{|l|}{ Palsa A } \\
\hline \multirow[t]{2}{*}{ Transition zone } & $\mathrm{Fe}(\mathrm{II})$ & 1.28 & 2.87 & 0.45 & 0.00 & 15.30 & 0.10 & 1.77 \\
\hline & $\mathrm{Fe}(\mathrm{III})$ & 0.50 & 1.18 & 1.01 & 2.06 & 84.70 & 0.10 & \\
\hline \multicolumn{9}{|l|}{ Palsa A } \\
\hline \multirow[t]{3}{*}{ Mineral horizon } & $\mathrm{Fe}(\mathrm{II})$ & 1.24 & 2.79 & 0.39 & 0.00 & 54.46 & 0.97 & 0.88 \\
\hline & $\mathrm{Fe}(\mathrm{III})$ & 0.46 & 0.67 & 0.35 & 0.26 & 27.45 & 0.91 & \\
\hline & $\mathrm{Fe}-\mathrm{S}$ & 0.58 & 1.96 & 0.40 & 0.00 & 18.09 & 0.93 & \\
\hline \multicolumn{9}{|c|}{ Bog (Bog C, see Patzner et al., 2020) } \\
\hline \multirow[t]{3}{*}{ Mineral horizon } & $\mathrm{Fe}(\mathrm{II})$ & 1.25 & 2.78 & 0.37 & 0.00 & 62.87 & 0.38 & 3.47 \\
\hline & $\mathrm{Fe}(\mathrm{III})$ & 0.47 & 0.68 & 0.37 & 0.31 & 24.73 & 0.34 & \\
\hline & $\mathrm{Fe}-\mathrm{S}$ & 0.54 & 2.07 & 0.30 & 0.00 & 12.40 & 0.34 & \\
\hline \multicolumn{9}{|c|}{ Fen (Fen E, see Patzner et al., 2020) } \\
\hline \multirow[t]{3}{*}{ Mineral horizon } & $\mathrm{Fe}(\mathrm{II})$ & 1.25 & 2.79 & 0.44 & 0.00 & 61.30 & 0.21 & 0.61 \\
\hline & $\mathrm{Fe}(\mathrm{III})$ & 0.52 & 0.54 & 0.31 & 0.41 & 17.30 & 0.18 & \\
\hline & $\mathrm{Fe}-\mathrm{S}$ & 0.61 & 1.93 & 0.67 & 0.03 & 21.40 & 0.22 & \\
\hline \multicolumn{9}{|l|}{$6 \mathrm{~K}$} \\
\hline \multicolumn{9}{|l|}{ Palsa A } \\
\hline \multirow[t]{2}{*}{ Transition zone } & $\mathrm{Fe}(\mathrm{II})$ & 1.17 & 2.90 & 0.80 & 0.00 & 12.30 & 0.16 & 0.85 \\
\hline & $\mathrm{Fe}(\mathrm{III})$ & 0.52 & 2.17 & 2.65 & 2.26 & 87.70 & 0.16 & \\
\hline \multicolumn{9}{|l|}{ Palsa A } \\
\hline \multirow[t]{4}{*}{ Mineral horizon } & $\mathrm{Fe}(I I)$ & 1.25 & 2.73 & 0.58 & 0.00 & 38.10 & 0.25 & 0.81 \\
\hline & $\mathrm{Fe}-\mathrm{S}$ & 0.68 & 1.68 & 0.19 & 0.00 & 6.50 & 0.16 & \\
\hline & $\mathrm{Fe}(\mathrm{III})$ & 0.49 & 1.19 & 0.79 & 0.64 & 26.90 & 0.27 & \\
\hline & Unknown & 1.13 & 3.87 & 2.06 & 0.29 & 28.50 & 0.30 & \\
\hline \multicolumn{9}{|c|}{ Bog (Bog C, see Patzner et al., 2020) } \\
\hline \multirow[t]{4}{*}{ Mineral horizon } & $\mathrm{Fe}(I I)$ & 1.26 & 4.07 & 2.55 & 1.50 & 42.10 & 0.77 & 0.75 \\
\hline & $\mathrm{Fe}-\mathrm{S}$ & 0.66 & 1.64 & 0.22 & 0.00 & 6.00 & 0.18 & \\
\hline & $\mathrm{Fe}(\mathrm{III})$ & 0.48 & 1.07 & 0.70 & 0.60 & 15.90 & 0.34 & \\
\hline & Unknown & 1.26 & 2.77 & 1.13 & 0.08 & 36.00 & 0.76 & \\
\hline \multicolumn{9}{|c|}{ Fen (Fen E, see Patzner et al., 2020) } \\
\hline \multirow[t]{4}{*}{ Mineral horizon } & $\mathrm{Fe}(\mathrm{II})$ & 1.28 & 3.65 & 2.62 & 2.03 & 49.20 & 0.54 & 0.54 \\
\hline & $\mathrm{Fe}-\mathrm{S}$ & 0.64 & 1.74 & 0.27 & 0.00 & 10.70 & 0.27 & \\
\hline & $\mathrm{Fe}(\mathrm{III})$ & 0.47 & 0.76 & 0.48 & 0.55 & 11.50 & 0.27 & \\
\hline & Unknown & 1.16 & 3.02 & 0.98 & 0.02 & 28.50 & 0.58 & \\
\hline
\end{tabular}

a CS $=$ center shift

b $\triangle \mathrm{EQ}=$ quadrupole splitting;

c $\sigma(\Delta)=$ standard deviation of quadrupole splitting component $\mathrm{d} B \mathrm{Bh}=$ hyperfine magnetic field

e RA = Relative abundance

$f \times 2=$ goodness of fit

1142

1143 

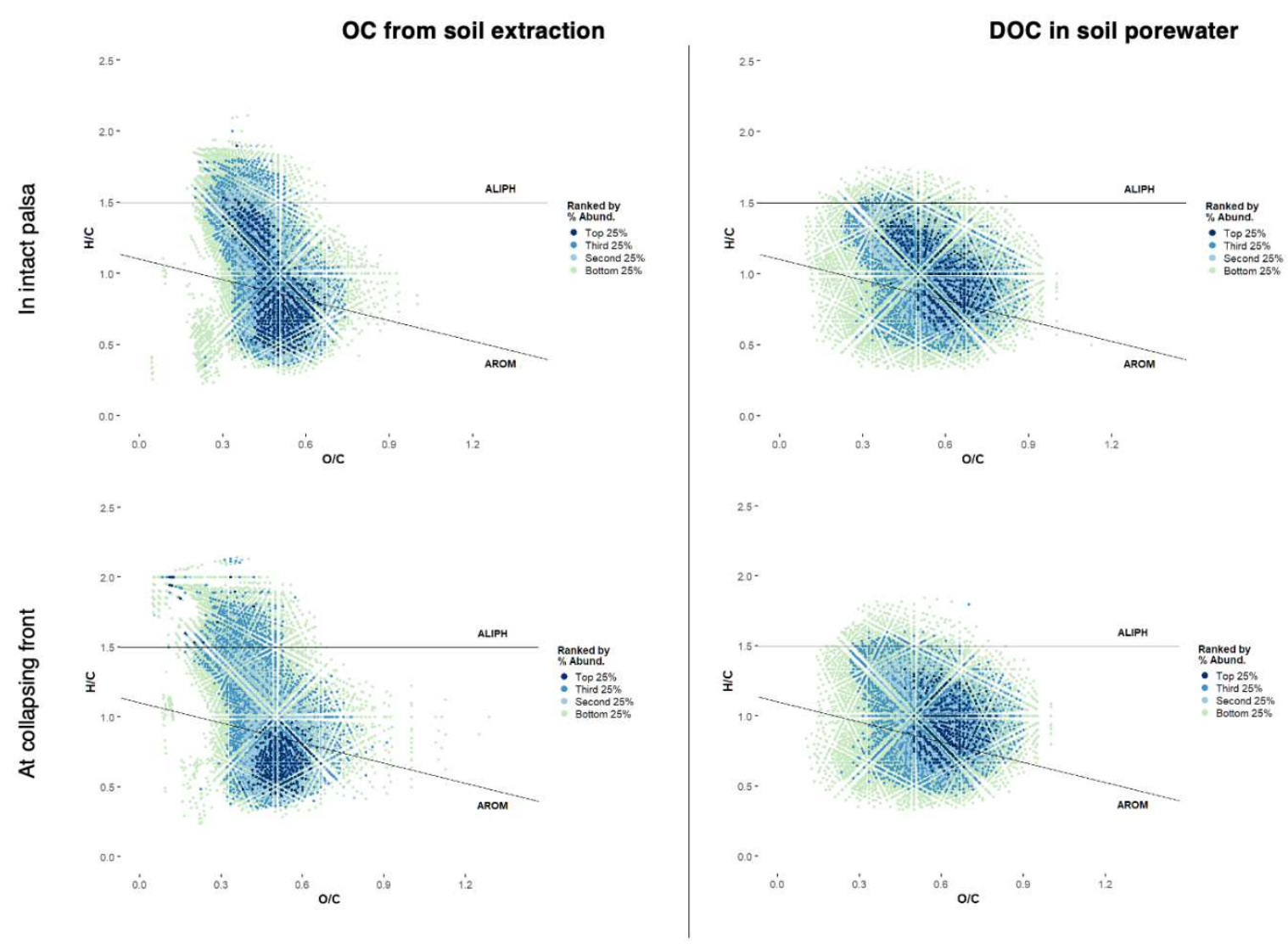

1144

1145

1146 Figure S17. Van Krevelen diagrams for individual samples for solid phase extracted OC

1147 (dithionite extractable) from the transition zone of the intact palsa and of the collapsing

1148 front (transect 1, Figure S1) and DOC, extracted from $30 \mathrm{~cm}$ depth, in intact palsa and at 1149 the collapsing front.

1150 

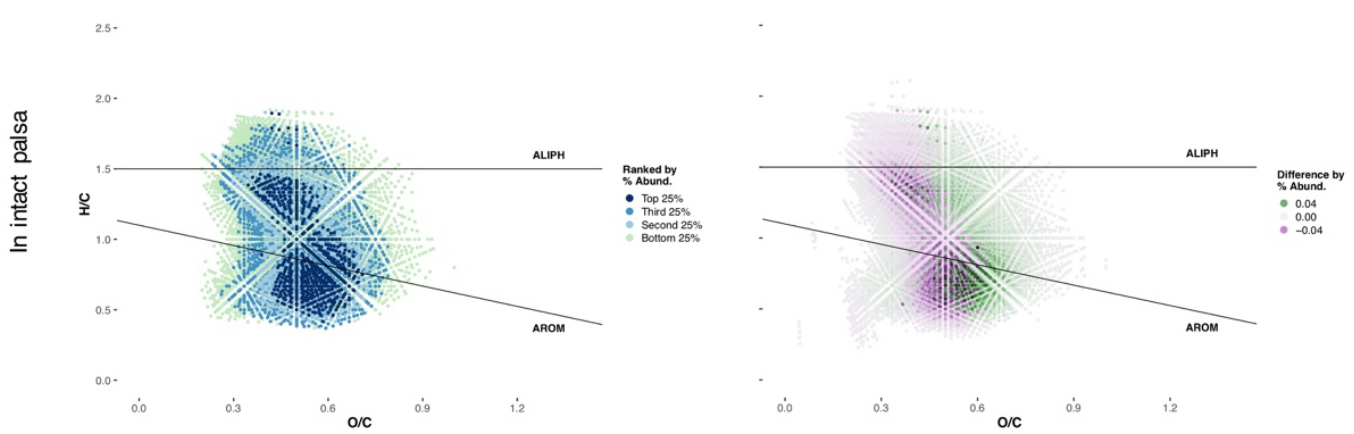

More abundant in control More abundant in dithionite extraction
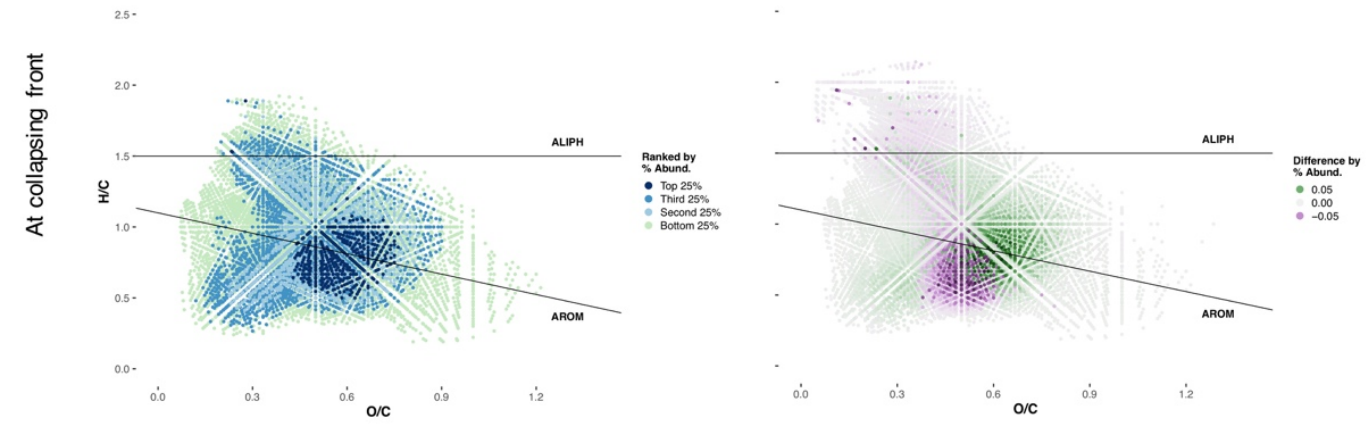

More abundant in control

More abundant in dithionite extraction

1153 Figure S18. Van Krevelen diagrams of control extractions (sodium chloride bicarbonate

1154 with the same ionic strength and $\mathbf{p H}$ as the sodium dithionite extraction): left, each

1155 individual van Krevelen diagram and right, in direct comparison with the sodium dithionite

1156 citrate extractable CHO. Organic carbon (OC) which is more abundant in control (green)

1157 represents $\mathrm{OC}$ which is leachable of the soil by the same ionic strength and $\mathrm{pH}$ as the sodium 1158 dithionite extraction. OC which is more abundant in the sodium dithionite extraction (purple) 1159 is only dissolved by reductive dissolution. 
DOC in soil porewater (along replicate palsa hillslope)
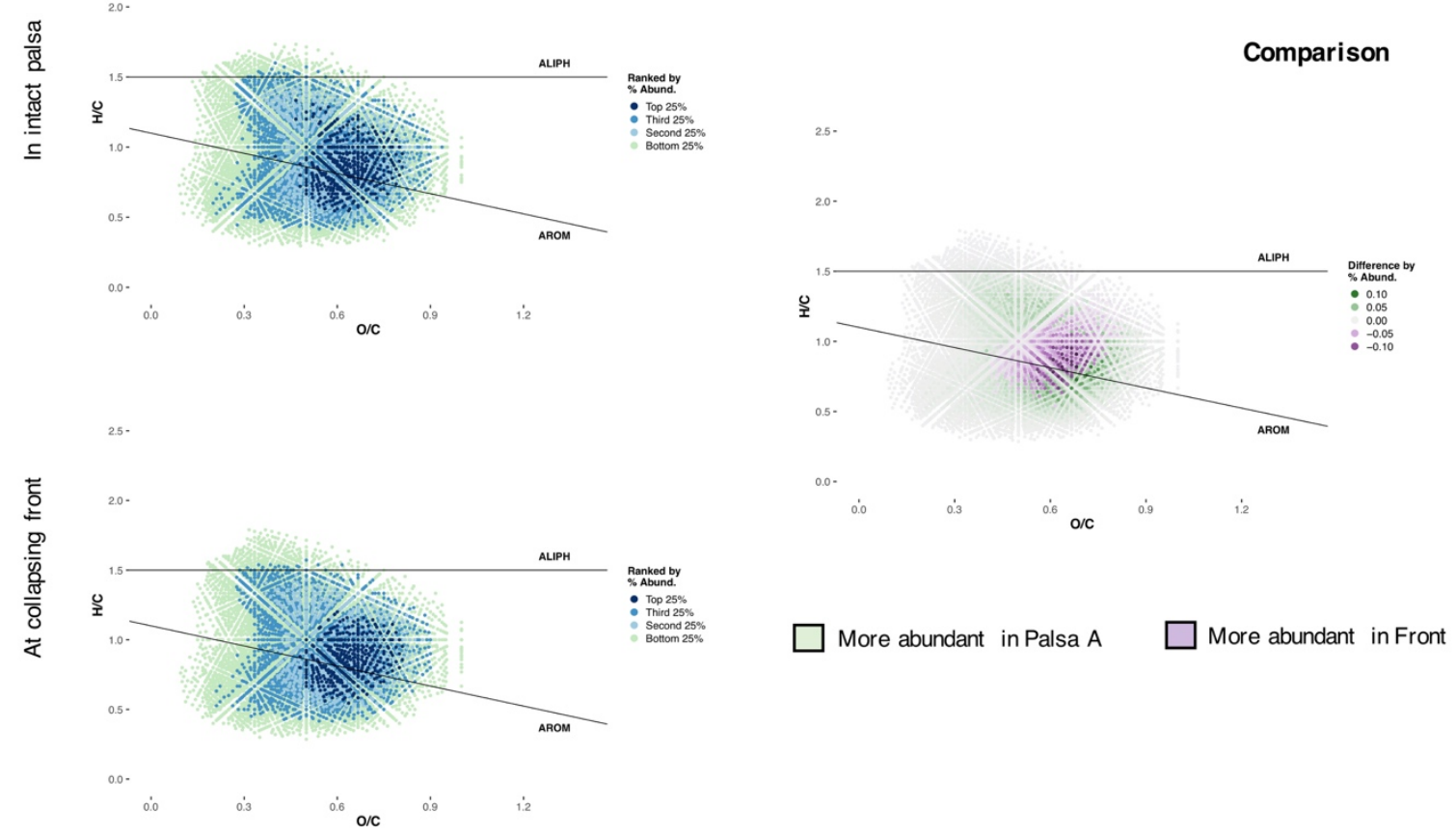

1163

1164 Figure S19. Van Krevelen diagrams for replicate porewater samples (30 cm depth) (left)

1165 and in direct comparison to each other (right). Dissolved OC, which is only found in Palsa

1166 A, is enriched in more aliphatic compounds (green). Towards Front and Bog, only more 1167 aromatic molecules (purple) remain.

1168 


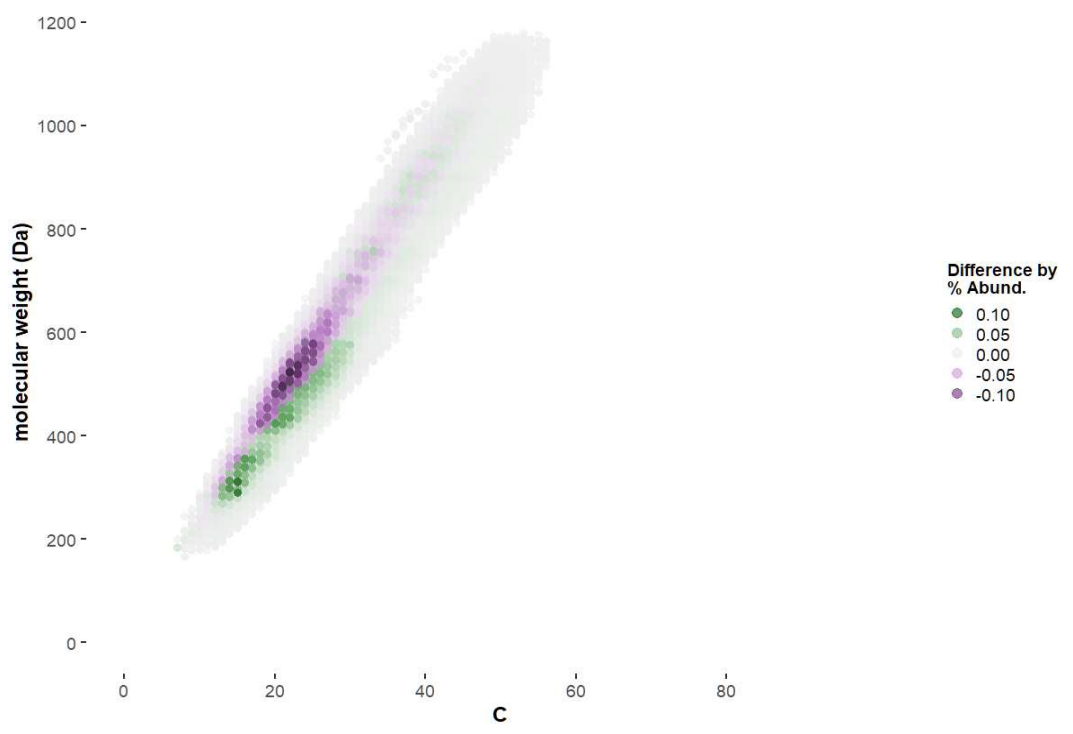

1170 Figure S20. Molecular weight (MW) of dissolved organic carbon compounds in intact

1171 palsa versus at the collapsing front. Lower MW compounds have higher relative abundance

1172 in porewater samples from intact palsa at a lower molecular weight for a given carbon number

1173 (colored in green). Higher MW compounds have higher relative abundance for a given carbon

1174 number at the collapsing front (colored in purple).

1175 
11781 Rinne, J., ICOS Sweden Ecosystem eco time series (ICOS Sweden), Abisko-Stordalen Palsa Bog, 2018-12-31-2019-12-31, https://hdl.handle.net/11676/s5oBzukX_FaXpHU 86QasO) (2021).

11812 Hodgkins, S. B. et al. Changes in peat chemistry associated with permafrost thaw increase greenhouse gas production. Proc. Natl. Acad. Sci. USA 111, 5819-5824, 1183 (2014).

11843 Patzner, M. S. et al. Iron mineral dissolution releases iron and associated organic 1185 carbon during permafrost thaw. Nat Commun 11, 6329 (2020).

11864 Otte, J. M. et al. The distribution of active iron-cycling bacteria in marine and freshwater sediments is decoupled from geochemical gradients. Method Enzymol 20, 2483-2499 (2018).

11895 Weber, K. A., Achenbach, L.A., Coates, J.D. Microorganisms pumping iron: anaerobic microbial iron oxidation and reduction. Nat. Rev. Microbiol. 4, 752-764 (2006).

11926 Dinh, H. T., Kuever, J., MussBmann, M., Hassel, A.W. Iron corrosion by novel 1193 anaerobic microorganisms. Nature 427, 829 (2004).

11947 Berg, J. S., Michellod, D., Pjevac, P., Martinez-Perez, C., Buckner, C.R., Hach, P.F. 1195 Instensive cryptic microbial iron cycling in the low iron water column of the 1196 meromictic Lake Cadagno. Method Enzymol 18, 5288-5302 (2016).

11978 Li, X., Zhang, W., Liu, T., Chen, L., Chen, P., Li, F. Changes in the composition and 1198 diversity of microbial communities during anaerobic nitate reduction and $\mathrm{Fe}(\mathrm{II})$ 1199 oxidation at circumneutral pH in paddy soil. Soil Biol Biochem 94, 70-79 (2016).

12009 Holmes, D., Bond, D., O’neil, R., Reimers, C., Tender, L., Lovely, D. Microbial 1201 communities associated with electrodes harvesting electricity from a variety of aquatic sediments Microb Ecol 48, 178-190 (2004). 
120310 Finneran, K. T., Johnsen, C.V., Lovely, D.R. Rhodoferax ferrireducens sp. nov., a 1204 psychotolerant, facultatively anaerobic bacterium that oxidizes acetate with the 1205 reduction of Fe(III). Inst J Syst Evol Microbiol 53, 669-673 (2003).

120611 Kim, W., Whitman, W.B. Methanogens. Encyclopedia of Food Microbiology (Second 1207 Edition), Academic Press, ISBN 9780123847331, 602-606 (2014).

120812 Mondav, R. et al. Discovery of a novel methanogen prevalent in thawing permafrost. $1209 \quad$ Nat Commun 5, 3212 (2014).

121013 Jiang, H., Chen, J.C., Murrell, P., Jiang, C., Zhang, C., Xing, X.-H., Smith, T.J. .

1211 Methanotrophs: Multifunctional bacteria with promising applications in environmental 1212 bioengineering. Comprehensive Biotechnology (Second Edition), Academic Press, 1213 ISBN 9780080885049, 249-262 (2011).

121414 Singelton, C. M. et al. Methanotrophy across a natural permafrost thaw environment 1215 The ISME Journal 12, 2544-2558 (2018).

121615 Lv, J., Huang, Z., Christie, P., Zhang, S. Reducing reagents induce molecular artifacts 1217 in the extraction of soil organic matter. ACS Earth and Space Chem 4 (11), 1913-1919 $1218 \quad$ (2020). 